-
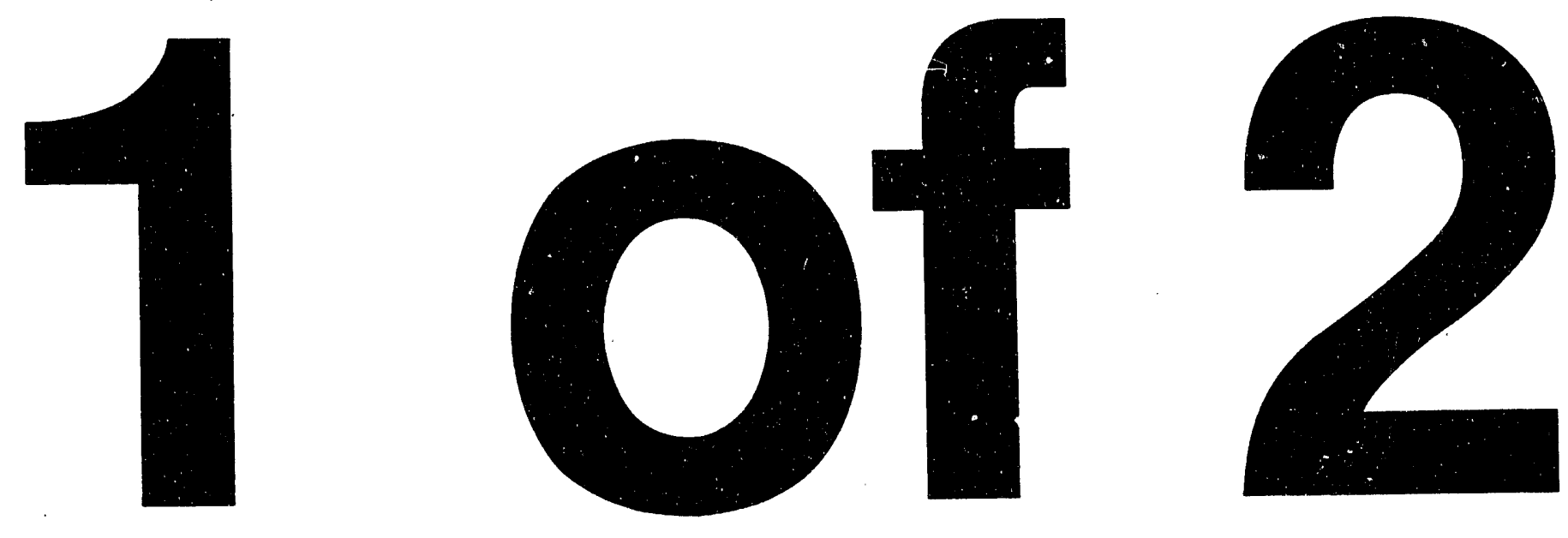


\title{
AISI DIRECT STEELMAKING PROGRAM
}

\author{
Final Technical Report
}

By Egil Aukrust

August 1994

Work Performed Under Contract No. DE-FC07-89ID12847

Prepared for the

U.S. Department of Energy

Under DOE Idaho Operations Office

Sponsored by the Office of the Assistant Secretary

for Energy Efficiency and Renewable Energy

Office of Industriai Technologies

Washington, D.C. 
Page

1. Executive Summary and Abstract 1

2. Introduction, Background, and objectives 7

3. Laboratory Research Programs 9

4. Large-scale Heat Transfer studies 20

5. Hylsa Prereduction studies $\quad 24$

6. Design, Construction, and operation of the First 27 (Vertical BOF-shaped) Vessel

7. Two-Zone Smelting Reactor: Concept and Results of 50 Physical Modeling

8. Construction and operation of the Horizontal Vessel 53

9. Evaluation of steelmaking Processes 62

10. Construction and operation of Pressurized Vertical 64 Vessel and offgas system

11. Mannesmann Demag Basic Study of AISI Direct 77 Ironmaking Process

12. Mannesmann Demag Pre-engineering study for a 81 350,000 tpy Demonstration Plant

13. Technical Analysis of Pilot Plant Trials 91

14. Economic Analysis 139

15. Commercialization 141

16. References 143

17. List of Published Reports, Talks, and 145 Technical Papers 


\section{EXECUTIVE SULALRY AND ABSTRACT}

\section{Executive Summary}

This final report on the joint AISI-DOE Direct steelmaking Program deals with the results of a five-year project for development of a new, more energy efficient, environmentally friendly, and less costly process for prisduction of hot metal than the current technology of coke ovens and blast furnaces. DOE provided $\$ 46.4$ million, or $77 \%$, of the $\$ 60.3$ million cost of the program; AISI provided the remaining $\$ 13.9$ million.

The pilot plant program, supported by extensive research at leading universities and industrial laboratories, indicates that the process fundamentals, on the basis of which the Direct steelmaking Program was initiated, are valid. While the Direct steelmaking program ended without solving all of the problems associated with high volatile coals, the shortfalls have been attributed to the engineering design of the charging system at the pilot plant in combination with relatively low pressure operation. This analysis has been verified through technical exchanges with other smelting programs worldwide, and these design deficiencies can be corrected during scale-up. Several steel companies view the results of this development to be sufficiently encouraging to consider building a demonstration plant.

Based on the program's findings, AISI and DOE have launched another cooperative program, the steel plant waste oxide Recycling and Resource Recovery by Smelting Program, to determine the feasibility of converting steel plant waste to pig iron. Currently, most such wastes are disposed of in landfills. This follow-on program is broadening and further enhancing the basic smelting technology.

AISI will make every effort to commercialize the process and has established the steel Technology corporation to license AISI technology and to promote commercialization. 


\section{Abstract}

\section{Background}

The American Iron and Steel Institute (AISI) assembled a task force in August, 1987 , to select the process most likely to improve $U$. $S$. steel industry competitiveness and to outline a program of research and development to facilitate rapid implementation of the technology. After extensive domestic and overseas technology assessment, the task force concluded that future steelmaking should be based on a coke-free, coal-based bath smelting process for the production of the hot metal that is subsequently refined to steel. This task group issued an internal report entitled Direct Steelmaking, A Plan for the American Steel Industry in March, 1988, and recommended that AISI propose a research and development program for joint funding by the industry and the Department of Energy (DOE) under the 1986 congressionally- mandated steel Initiative.

AISI submitted a proposal to the DOE on July 29, 1988, for a threeyear, direct steelmaking research program involving research at university and industrial research laboratories, a pilot plant program for smelting and refining domestic pelletized ore, and steel-plant-scale trials to study the postcombustion and heat transfer required to make maximum use of the energy available from the direct use of coal in the process. The program began on November 28, 1988, under Cooperative Agreement No. DE-FC0789ID12847. The DOE cost share funding was about $77 \%$, and the AISI cost share was about $23 \%$. Subsequent amendments extended the program to March 31, 1994, a total of 5-1/2 years, with a total program cost of about $\$ 60.3$ million.

\section{Process Description}

The ironmaking process that was to be developed entails the smelting of iron ore pellets in a foamy slag created by the reaction of char from the coal with the molten slag to produce carbon monoxide (CO). The $\mathrm{CO}$ evolved is further reacted (postcombusted) with oxygen, which also reacts with coal volatile matter, to produce the heat necessary to sustain the endothermic reduction reaction. The gas generated in the reactions causes the slag to foam. The uncombusted $\mathrm{CO}$ and hydrogen $\left(\mathrm{H}_{2}\right)$ from the coal are used to preheat and prereduce hematite pellets $\left(\mathrm{Fe}_{2} \mathrm{O}_{3}-\right.$ an abundant domestic commodity) to wustite pellets (FeO) to make as efficient use of the energy in the coal as possible.

\section{Laboratory Programs}

Laboratory research programs confirmed that the postulated process steps worked, that the prereduced pellets dissolved rapidiy, and that the overall reduction rate should be directly proportional to the Feo content of the slag. Laboratory studies also provided 
valuable insight into fluid flows, heat transfer, lance design and positioning, coal devolatilization, and reaction rates. The process control models were based on laboratory research.

Plant Trials

The plant-scale postcombustion and heat transfer studies confirmed that combustion could take place in the foamy slag and that much of the heat from postcombustion could be transferred to the process.

Prereduction

Studies were conducted by Hylsa in Monterrey, Mexico, on preheating and prereducing commercial hematite pellets. They established that a moving-bed shaft furnace could provide the requisite feed for the smelter using smelter offgas as the reductant. Hylsa established designs for a pilot-scale and a demonstration-scale shaft furnace and for a pneumatic transport system to convey the prereduced pellets to a pressurizea smelter. They also established that, by adding dolomite to the shaft furnace, most of the sulfur from the coal would be returned to the smelter.

\section{Pilot Plant Trials - First Vessel}

Pilot plant trials with the first vessel, a basic-oxygen-furnace(BOF)-shaped vessel operating at atmospheric pressure, were initiated in June, 1990, at Universal, Pennsylvania, and continued for 49 trials through August, 1991. Various coals, ores, and fluxes were studied, and production rates of $4-5$ tonnes of hot metal per hour ( $t \mathrm{ph}$ ) were achieved. Extrapolations to operating conditions for a 350,000 tonne-per-year plant with preheated and prereduced pellets and with full dust recycling were favorable.

\section{Two-Zone and Horizontal Vessel Trials}

Program personnel developed a two-zone vessel concept wherein most of the smelting reduction would take place in one zone and refining (decarbonization) in a second zone. The slag would flow countercurrent to the hot metal and would be high in Feo in the refining zone and low in the reducing zone. Expectations were that the production rate would be approximately double that of a similar sized single-zone vessel. Water modeling established that the concept had promise, that a barrier would be essential, and that back-mixing between the two turbulent zones could present real problems.

The second vessel for pilot plant trials was a horizontal vessel with a water-cooled top that could operate either as a single-zone smelter or a two-zone smelter with a barrier. sixteen single-zone and five two-zone trials were conducted between December, 1991, and September, 1992, when installation of the third, pressurized vessel was begun. Production rates in excess of $7 \mathrm{tph}$ and postcombustion 
rates of $30 \%$ and $40 \%$ were achieved in the vessel acting as a single zone. Production rates were limited by the offgas system capacity for two-zone operation, and decarbonizing in the refining zone was limited to a carbon content of about $1 \%$

\section{Evaluation of steelmaking Processes}

A task force to evaluate steelmaking processes studied trough processes, posthearth refining, electric arc furnace processes, energy-optimizing furnace processes, and the IRSID process as alternatives to basic oxygen steelmaking. of the continuous processes, trough, and IRSID, IRSID was the most promising. In this process, as the hot metal enters the reactor, it is hit with an oxygen jet, causing the metal to be emulsified. The lighter emulsion flows over a barrier into a decanter. Carbon in the metal droplets in the emulsion reacts with the oxygen to decarbonize the droplets. The average residence time of the droplets in the emulsion determines tile degree of decarbonization. Potential advantages are low-capital cost and continuous processing.

The task force concluded that there is insufficient technical or economic incentive to replace a working basic oxygen furnace with any of the processes evaluated. However, for new or incremental steelmaking, the IRSID process or the energy-optimizing furnace process should be considered in competition with the basic oxygen or electric arc furnace processes.

\section{Third Vessel Trials}

A third, pressurized vessel was designed to operate at 1.7 atmospheres absolute, along with an offgas cleaning and tempering loop. This offgas system was designed with a cyclone to capture and recycle the dust and a scrubber system to further clean and temper the offgas so that recycled offgas could be used to control the cyclone temperature and to produce a final process gas suitable for operation of the moving-bed shaft furnace.

Nineteen trials were conducted with the third smelter during the period from July, 1993, through March, 1994, at which time the Waste oxide Recycling Program began. Early operation identified many seal problems in the vessel, feed problems with the lockhopper systems, rupture disk problems in the offgas system, plugging in the dust recycle system, and problems with maintaining a fluid slag during tapping. As problems were remedied, operation became more stable, and both medium volatile and high volatile coals were studied. Recoveries from planned and unplanned (plant power outage) shutdowns were straightforward, and stable operations could be quickly achieved. However, the goal of $40 \%$ postcombustion with high volatile coal could not be achieved within the constraints of the raw material feeding systems and the operating pressure limits. 


\section{Mannesmann Demag Basic study}

The early success with the first vessel prompted a request for an independent assessment by a steel plant engineering company. Mannesmann Demag (MD) was requested to perform a basic study of the ironmaking process and examine scale-up to a commercial-size plant. MD confirmed the analyses of the AISI staff, expressed confidence in the ability to scale up the process, determined that the operating costs for a scaled-up plant would be competitive with the coke oven, blast furnace process, or alternative ironmaking processes, and recommended a pre-engineering study to examine a commercial-scale plant in more detail and to provide a capital cost estimate.

\section{Mannesmann Demag Pre-engineering study}

The MD pre-engineering study continued to confirm the technical and economic feasibility of a commercial-scale plant and arrived at a capital cost for a plant of about $\$ 94.4$ million for production of 350,000 tonnes per year of hot metal at a steel plant host company with infrastructure in place. This was considered to be attractive and provided impetus for the third vessel program.

\section{Technical Analysis of Pilot Plant Trials}

Trials confirmed that the rate of reduction is proportional to the amount of Feo present. However, the amount of Feo present is not directly controlled but rather responds to other process variables such as ore, coal, and oxygen feed rates. The amount of char required to control slag foaming is about $20 \%$. The amount present can be calculated from the process variables and controlled by control of the coal, ore, and oxygen feed rates.

Sulfur in the hot metal in steady-state operation ranges from 0.05 to $0.250 \%$, depending on the sulfur content of the coal, slag basicity and Feo content, and operating temperature. Ninety to ninety-five percent of the sulfur is captured in the hot metal and slag, depending on the amount of dolomite added to the prereducing shaft furnace (dolomite captures about half of the sulfur in the offgas and returns it to the smelter). The lower the Feo in the slag, the more sulfur is captured in the slag. The phosphorus in the hot metal also depends on the Feo content and the basicity of the slag. In general, the phosphorus in the smelter hot metal is 10 to $20 \%$ less than in blast furnace hot metal for the same ore.

Dust formation is significant and increases with increasing coal volatile matter content and offgas flow rate and decreases with increasing vessel pressure. For efficient operation, it must be captured and recycled, both because of its process material content and to prevent clogging of the shaft furnace. 
Energy consumption is dependent largely on the degree of postcombustion and the heat-transfer efficiency of the postcombustion energy to the slag. Postcombustion degrees in the trials ranged from a low of about $10 \%$ to a high of about $50 \%$, and heat transfer efficiency ranged from a low of about $75 \%$ to a high of about $98 \%$.

Smelting intensity in the third vessel reached highs of 8.5 and $9.7 \mathrm{t} / \mathrm{m}^{3} \mathrm{~d}$ with hematite at pressures of $1.5 \mathrm{~atm}$. These are projected to be about $14 t / \mathrm{m}^{3} \mathrm{~d}$ for wustite as the feed at a pressure of $3 \mathrm{~atm}$. absolute as planned for the demonstration plant.

\section{Economic Analysis}

Economic analyses for a 1,000,000 tpy plant showed promise, both in capital and in operating costs, and compared favorably with the costs for rebuilding and operating a large blast furnace and its required coke plant.

\section{Steps to Commercialization}

AISI is making every effort to commercialize the process and has established the steel Technology corporation to license the AISI technology and to promote commercialization. 


\section{INTRODUCTION, BACKGROUND, AND OBJECTIVES}

During 1993, more than 90 million metric tons of liquid steel were produced in the United states to support steel product sales approaching $\$ 41$ billion dollars. About $60 \%$ of the steel came from iron ore and coal through the coke plant, blast furnace, and basic oxygen furnace system, and recycled scrap provided $40 \%$ through the electric furnace.

The blast furnace that produces a "hot metal" containing about $4 \%$ carbon is dependent on coke ovens which are becoming increasingly expensive to operate because of ever stricter environmental control requirements. Blast furnaces have been producing hot metal for about 150 years. A large, modern blast furnace now can produce as much as 3.5 million metric tons of hot metal per year. The next manufacturing step, the basic oxygen furnace that refines the high-carbon hot metal to a low-carbon steel, has become the predominant steelmaking process in the United states since its introduction in 1956.

By 1988, the member companies of the AISI became convinced that the time had come to develop a new process and that, to remain competitive, the domestic industry must take the lead in developing a more efficient process. The objectives of this process development were:

- A lower cost method to smelt iron directly from domestic coal, limestone, and iron ore pellets, without coke.

- A closed, continuous, energy efficient, environmentally acceptable smelting process that would provide the base for a competitive industry.

- A smelting process that could be further developed to provide continuous steel production when this is required to match future downstream developments for further continuous processing.

- A smelting process that could be adapted to the needs of the electric furnace producer whose future strategy is constrained by an increasing shortage of high-quality scrap and the very high cost of alternative charge materials.

This project, proposed by AISI, has been funded by DOE since 1989 under the terms of the steel initiative established by congress in 1986. Through plant trials, university research, and a series of pilot plant programs, the technology has been developed and defined for a process which readily meets all of the above requirements. The $\$ 60$ million, 5-1/2 year research and development program was concluded in March, 1994. The DOE funded $77 \%$, about $\$ 46$ million, 
and the AISI funded the balance, about $\$ 14$ million. The results of the program have led to the recommendation that the next step be a 350,000 metric-ton-per-year demonstration plant at the site of a steel industry host company.

There are two advantages for placing a demonstration plant at a host company site:

1. The site would have available the necessary supporting facilities, such as rail service, cranes, installed utilities, and other equipment and services, which would substantially reduce construction and operating costs.

2. A realistic evaluation of operating costs requires that there be a "market" for the molten iron and excess fuel gas produced by the smelter. The host company would buy the iron for use in its own steelmaking furnaces and the fuel gas for heating in various plant processes.

Strong continuing Federal support, through DOE, is justified because savings in the capital and operating costs of ironmaking are projected to be in excess of 10 percent. The savings in energy use is projected at 27 percent, which is equivalent to 0.27 quadrillion BTU per year, or 9 percent of the total energy used by the nation's primary metals industries. Elimination of the requirements for coke ovens will substantially reduce emissions of polycyclic aromatic hydrocarbons, sulfur dioxide, and other toxic and noxious compounds.

- This technology would improve the industry's profitability and its position in international competition.

- Early implementation of the process by the industry is essential to obtain the benefits in terms of energy savings, environmental improvements, and improved competitiveness, objectives toward which the AISI and DOE have already spent in excess of $\$ 60$ million.

The pilot plant is currently being used to study steel plant waste oxide recycling and resource recovery under an AISI program sponsored by 13 member companies, funded $70 \%$ by the DOE under the Metals Initiative and directed by the team that directed the Direct steelmaking Program.

The pilot plant could be made available for special studies that might be required in support of the demonstration plant program. 


\section{LABORATORY RESEARCH PROGRAMS}

\section{Introduction}

The AISI Direct steelmaking process has been researched in the pilot plant and at various laboratories for about five years. As a result, we have learned a great deal concerning the process fundamentals and how the process works in practice. At the beginning of the project, there were a large number of issues regarding the process which were not understood. For example, the dissolution of materials, reduction mechanisms and rates, slag foaming and control, the behavior of sulfur, dust generation, and the entire question of energy efficiency, including postcombustion and the role of coal volatile matter, were not understood. As the result of both laboratory and pilot programs, we now know the process fundamentals and how to optimize the process with regard to many of these issues; some will require more research in order to better optimize the process.

A process description is provided here as background for the various laboratory research programs. Partially reduced iron oxide pellets are top fed into the smelter and dissolved into the slag. The Feo in the slag is reduced by coal char or by carbon in iron drops ejected into the slag from the metal bath. Coal is either top fed or injected in the slag and devolatilizes rapidly. Oxygen is top blown with a step lance (primary and secondary), or it can be blown in by side tuyeres. The oxygen combusts fixed carbon (char) and postcombusts $\mathrm{H}_{2}$ and $\mathrm{CO}$ from the process. For $40 \%$ postcombustion, over $50 \%$ of the energy is supplied by postcombustion (\% postcombustion $=100 \times\left[\mathrm{CO}_{2}+\mathrm{H}_{2} \mathrm{O}\right] /\left[\mathrm{CO}+\mathrm{CO}_{2}+\mathrm{H}_{2}\right.$ $\left.+\mathrm{H}_{2} \mathrm{O}\right]$ ).

The slag is critical, since it is the reduction medium and insulates the metal bath chemically from the postcombusted gas. Due to the high volume of gas generated, the slag foams considerably; the slag expands to over twice its normal volume. Foaming is controlled by having a critical amount of char in the slag.

Since the process is more oxidizing than a blast furnace, and coal is used directly, the sulfur content of the metal is higher than in blast furnace hot metal. Due to the high superficial gas velocities and the use of coal directly, a substantial amount of dust is formed that must be reinjected into the smelter for economical operation. 


\section{Dissolution of Materials}

\section{Iron oxide pellets}

When the process flowsheet was initially being developed, there was major concern as to whether the large amount of wustite or hematite pellets would dissolve into the slag at a sufficient rate. There were concerns that possibly large agglomerates of pellets would form like "icebergs." There was particular concern with the use of hematite pellets because of hematite's high melting point.

Prior to the startup of the pilot plant, a research program was conducted at $\mathrm{CMU}^{1}$ to determine the rate of dissolution of $\mathrm{Fe}_{2} \mathrm{O}_{3}$ and Feo pellets and the release of oxygen for

$$
3 \mathrm{Fe}_{2} \mathrm{O}_{3}=2 \mathrm{Fe}_{3} \mathrm{O}_{4}+1 / 2 \mathrm{O}_{2} \quad(\mathrm{II}-1)
$$

The rate of dissolution was measured using $x$-ray video and a computer software program for image analysis, while the oxygen evolution was measured using a constant volume-pressurs increase technique. It was found that the pellets dissolved very quickly and that dissolution of $\mathrm{Fe}_{2} \mathrm{O}_{3}$ and $\mathrm{FeO}$ is enhanced by the stirring provided by the release of oxygen. Typical results are shown in Figure 3.1, with and without stirring.

A simple heat transfer model was developed to determine the rate for bath smelting conditions. For a preheated pellet, the dissolution time is less than 5 seconds. The amount of undissolved pellets in the slag, at any time, is estimated to be less than $1 \%$. These results have been confirmed in the pilot plant, in that undissolved pellets have never been found in siag samples.

Coal char

The coal char has four functions: its oxidation supplies much of the energy, it controls foaming, it reduces Feo in the slag, and it carburizes the metal. The carbon in the metal is then partially used for reduction and may be oxidized by the oxygen jet or the postcombusted gases. Therefore, it is necessary to dissolve char at a reasonable rate to maintain a reasonable carbon content.

Work was conducted at MIT on the rate of solution of char into iron. It was found that the rate was retarded by sulfur in the metal as shown in Figure 3.2 and by the ash in the char. ${ }^{2}$ The effect of sulfur on the solution rate is not clearly understood, but it is currently believed that sulfur reduces the rate of solution by changing the wettability of the char by the metal. 


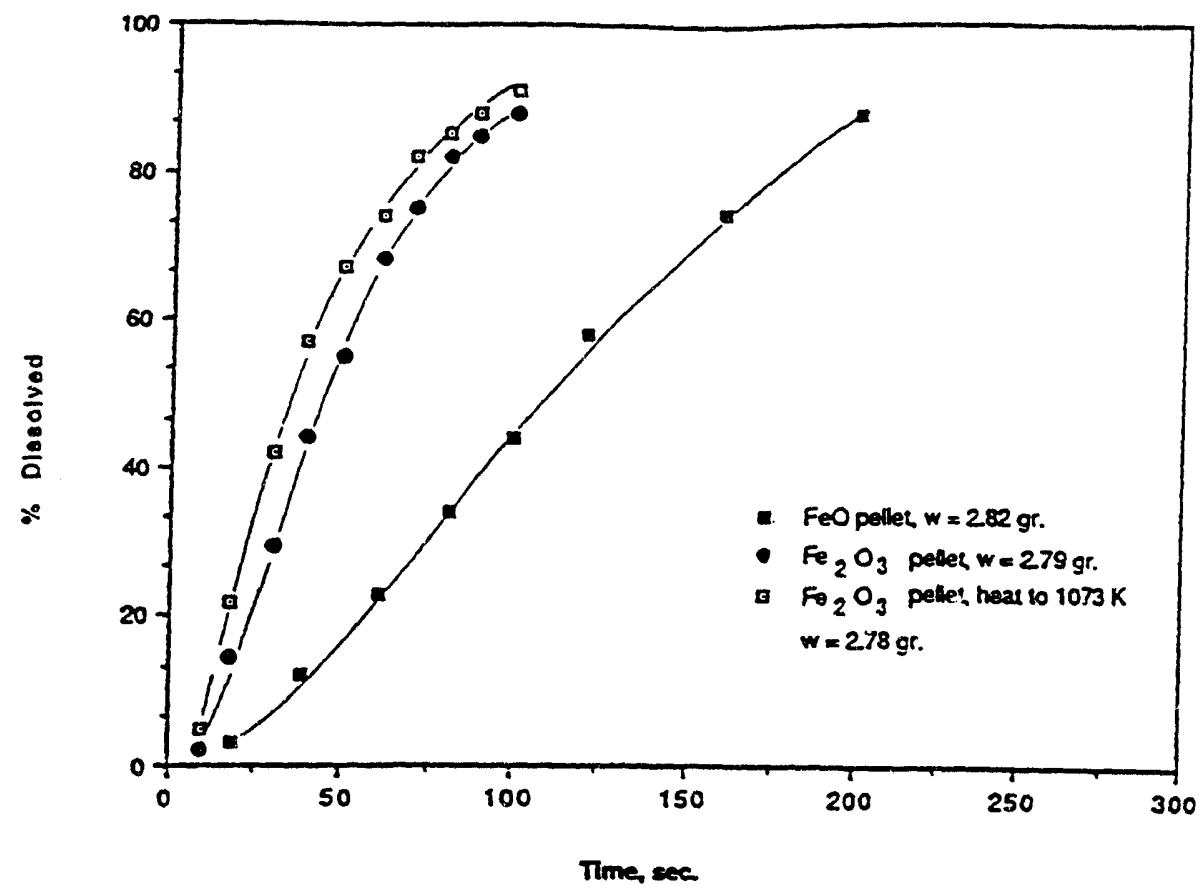

Rate of dissolution of a wustite, a hematite and a hemitate pellet heated to $1073 \mathrm{~K}$ in $40 \% \mathrm{CaO}-40 \% \mathrm{SIO}_{2}-20 \% \mathrm{Al}_{2} \mathrm{O}_{3}$ slat at $1723 \mathrm{~K}$.

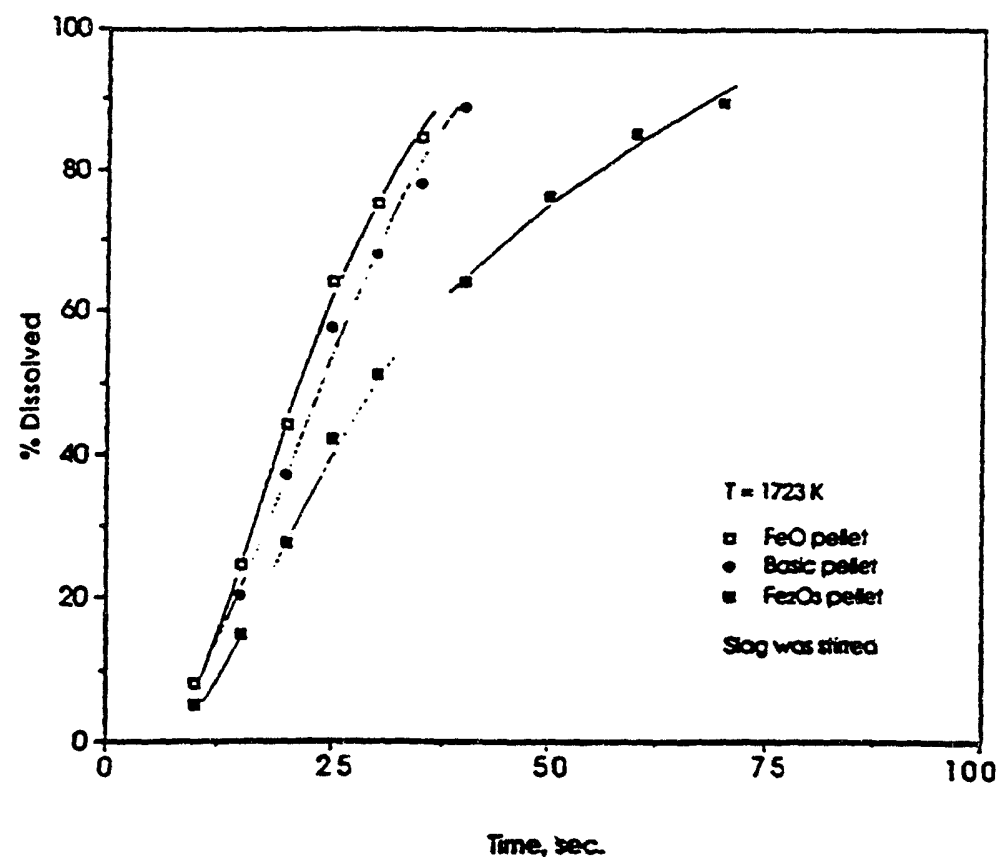

Rate of dissolution of a wustite, a hematite and basic pellet in $40 \% \mathrm{CaO}-40 \% \mathrm{SIO}_{2}-20 \% \mathrm{Al}_{2} \mathrm{O}_{3}$ slag at $1723 \mathrm{~K}$. 
FICURE 3.2

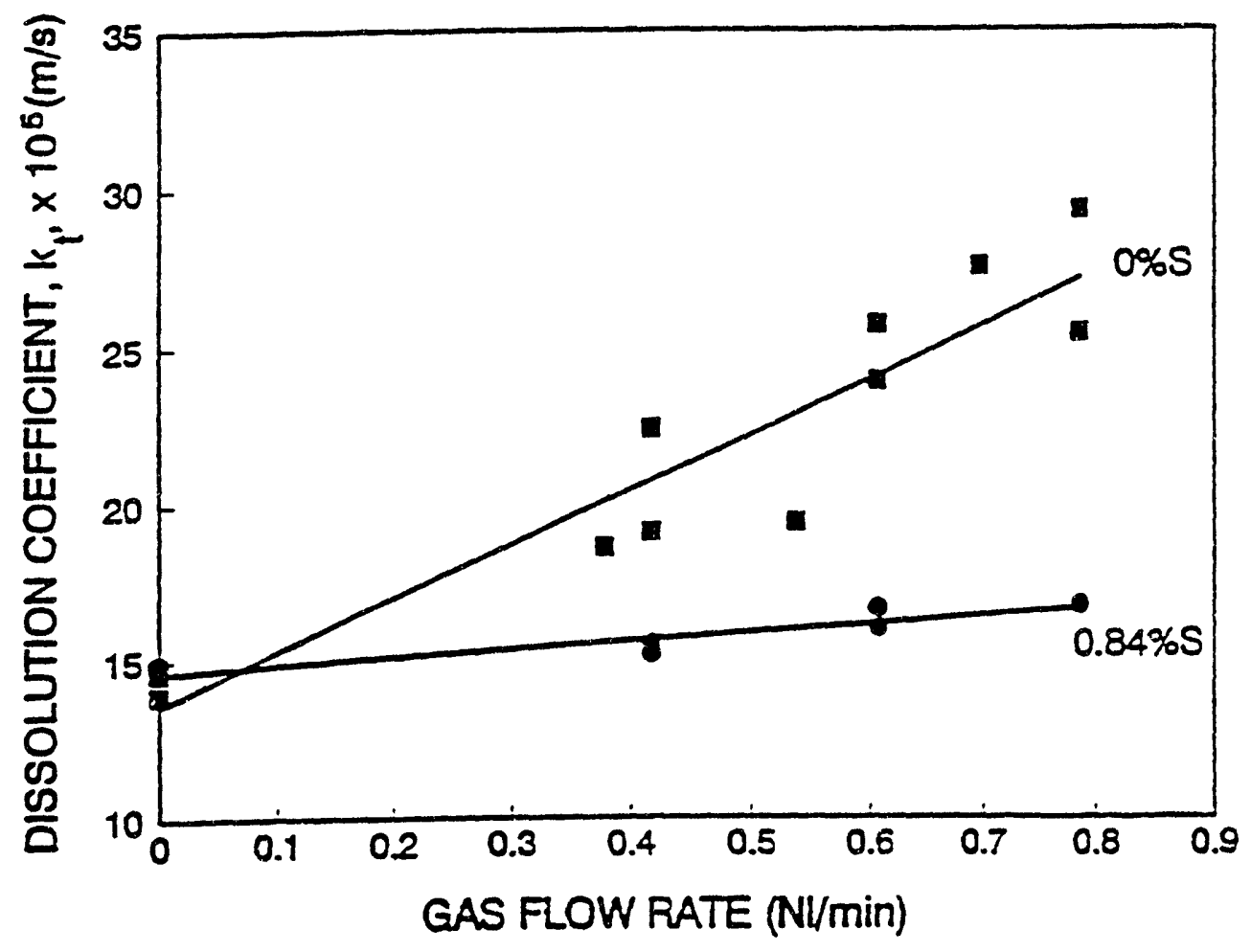

The effect of sulfur on the rate of dissolution of carbon. 
Rate of Reduction

\section{Mechanisms}

The iron ore pellets and the iron oxide in the recycled dust dissolve into the slag primarily as $\mathrm{Fe}^{+2}$ and $\mathrm{O}^{-2}$ irons. The dissolved iron oxide is reduced by carbon dissolved in the metal drops in the slag (III-1) or by the char (IIT-2):

$$
\begin{array}{ll}
\underline{C}+(\mathrm{FeO})=\mathrm{Fe}+\mathrm{CO} & (\text { III-1) } \\
\mathrm{C}+\mathrm{FeO}=\mathrm{Fe}+\mathrm{CO} & (\text { III-2) }
\end{array}
$$

Reaction (1) was extensively studied by Min and Fruehan ${ }^{3}$ in laboratory experiments. When an iron-carbon drop enters the slag, a gas halo surrounds the drop, and the reaction proceeds by the intermediate gas-slag and gas-metal reactions:

$$
\begin{array}{ll}
\mathrm{CO}+(\mathrm{FeO})=\mathrm{CO}_{2}+\mathrm{Fe} & (\mathrm{III}-3) \\
\mathrm{CO}_{2}+\underline{\mathrm{C}}=2 \mathrm{CO} & (\mathrm{III}-4)
\end{array}
$$

The rate is controlled primarily by reaction III-4. The rate is proportional to the FeO content, because reaction III-3 is fast and is at equilibrium; consequently, the $\mathrm{CO}_{2}$ pressure for reaction III-3 is proportional to the FeO in the slag. The rate is shown in Figure 3.3 as a function of sulfur content. It depends on the sulfur, since sulfur is surface active and retards the rate of reaction (III-4). However, at the high sulfur contents in the metal for smelting, the rate is independent of sulfur due to the residual rate for (III-4) at high sulfur. That is, at high sulfur contents, the rate of reaction III-4 is independent of sulfur. ${ }^{4}$

Reaction (III-2) was studied by Sarma, Cramb, and Fruehan ${ }^{5}$ for various forms of carbon, such as rotating cylinders, disks, and spheres. As shown in Figure 3.4, the rate is approximately proportional to the Feo. The reaction proceeds via the gas reactions similar to (III-3) and (III-4). However, since the gascarbon reaction is relatively fast, the overall rate of reduction is primarily controlled by mass transfer of Feo in the slag. Therefore, the rate is proportional to the Feo content of the slag.

\section{Rate Equations for Smelting}

Both reactions III-1 and III-2 are proportional to the Feo content and the surface areas of the iron drops $\left(A_{d}\right)$ and char $\left(A_{c}\right)$ respectively in the slag. It follows that

$$
R=\left(k_{d} A_{d}+k_{c} A_{c}\right)(\% \mathrm{FeO})
$$

$k_{d}$ and $k_{c}$ are the rate constants for reactions III- 1 and III-2.5,6 Using Nippon steel Corporation data ${ }^{7}$, on amounts of char and iron 
FIGURE 3.3

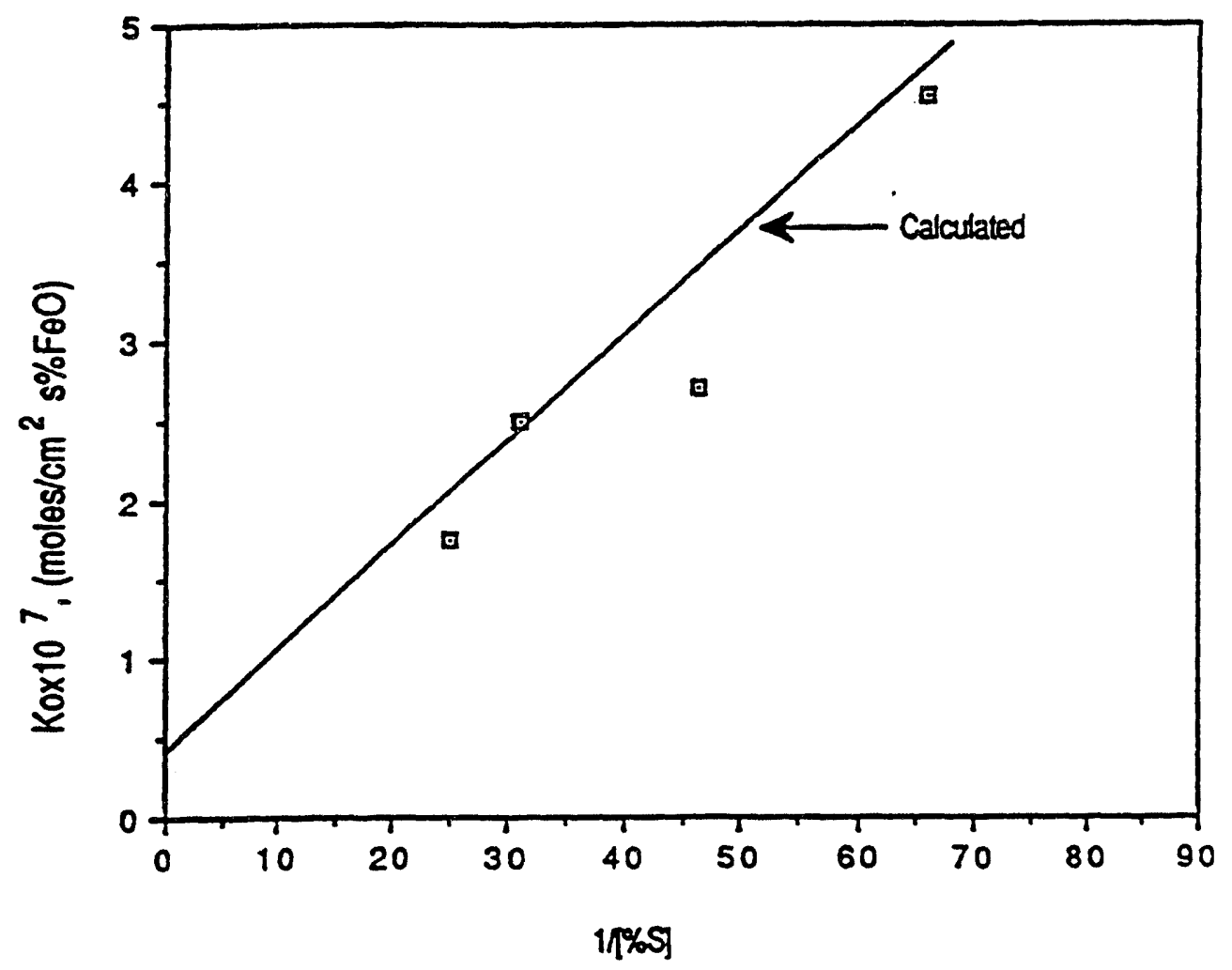

Rate of reduction of FeO in slag by Fe-C drops as a function of sulfur content. 
FTGURE 3.4

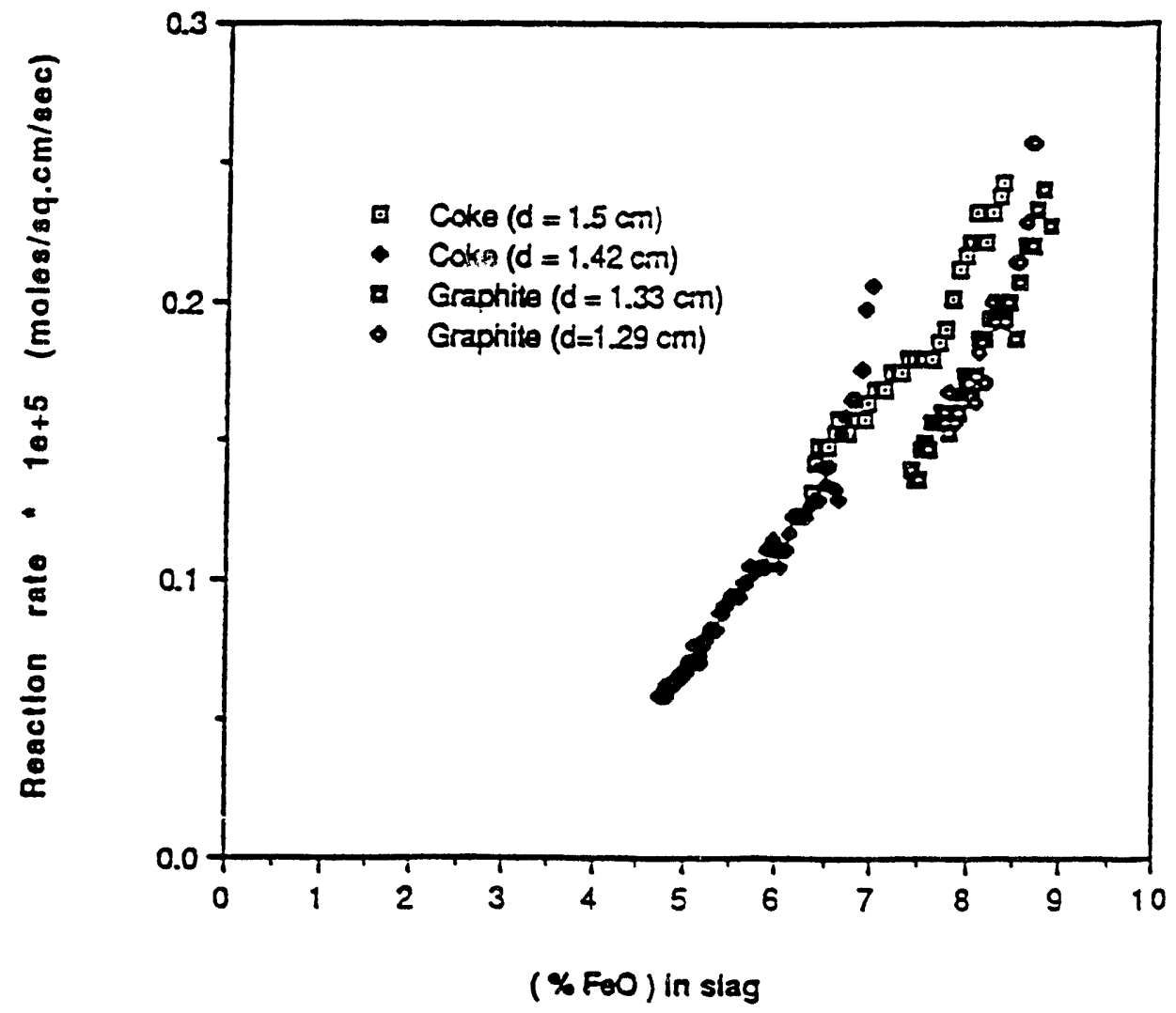

Reaction rate vs FeO content of slag for spheres of graphite and coke. 
drops and their size in the slag, sarma et $a 1^{8}$ were able to confirm equation (III-5) by comparing the calculated rate of smelting using the measured laboratory rate constants and the computed surface areas to that observed by NSC.

In general, $A_{d}$ and $A_{c}$ are not known; it is assumed that they are proportional to the respective amounts in the slag. It is rurther assumed that the amounts are proportional to the slag weight. However, $A_{d}$ can be increased by kottom stirring and $A_{c}$ by increasing the char in the slag. The simplified form of the reduction rate equation is therefore given by

$$
\mathrm{R}=\mathrm{W}_{\mathrm{s}} \mathrm{k}(\text { \& } \mathrm{FeO})
$$

where $W_{s}$ is the weight of slag and $k$ is the observed rate constant. This rate equation has been well confirmed by data from subsequent pilot plant operation.

\section{Slag Foaming}

\section{Fundamentals}

slag foaming is an important factor in the smelting process. The foam insulates the metal from the postcombustion gases; however, if foaming is excessive, it will limit the production rate. Foaming differs from slopping in a BOF, even though they appear similar. In slopping in a BOF, there is a sudden release of gas ejecting slag and metal. Foaming occurs from the continuous high rate of gas evolution and would be similar to blowing through a straw into a glass of beer with the foam overflowing.

slag foaming has been extensively studied by Ito and Fruehan and Zhang and Fruehan ${ }^{10}$ in laboratory experiments. They showed that the volume of foam $\left(V_{f}\right)$ was proportional to the volumetric gas flow rate (Q)

$$
V_{f}=\Sigma Q
$$

where $\Sigma$ is the foam index in seconds. Over 50 slag compositions were studied, as well as different bubble sizes, and it was found that

$$
\Sigma=1.83 \frac{\mu^{1.2}}{\sigma^{0.2} \rho \mathrm{D}_{b}^{0.9}}
$$

where, $\mu$ is the viscosity

$\sigma$ is the surface tension

$\rho$ is the density

$D_{b}$ is the bubble diameter. 
The correlation is shown in Figure 3.5., where

$$
N_{\Sigma}=\frac{\Sigma \mu g}{\sigma}
$$

and

$$
\text { Mo }=\frac{\mu^{4} g}{\sigma^{3} \rho}
$$

is the dimensionless Morton Number and

$$
A r=\frac{\rho^{2} D_{b}^{3} g}{\mu^{2}}
$$

is the dimensionless Archimedes Number. It was further shown that carbonaceous materials, such as coal char or coke, reduced foaming. It was found that, when about $20 \%$ of the slag by weight was char or coke, the foaming index was reduced by about a factor of three. $x$-ray video observation of he foaming indicated that the effect of char and coke was related to the wettability by the slag. It was also demonstrated that the foam height or volume decreases with increasing pressure simply because the volumetric flow rate of the gas is less at higher pressure (Figure 3.6). Other materials such as alumina or iron pellets did not reduce foaming. The effect of char on slag foaming was also reported by $\mathrm{NSC}^{7}$.

\section{sulfur}

Ozturk and Fruehan ${ }^{11}$ investigated the rate of sulfur removal from bath smelting slags by gas mixtures representing those in bath smelting. Both gas injection onto a slag surface and into the slag, forming a foam, were studied. Whereas the rate of sulfur removal in the foamed slag was faster, the rate in either case was relatively slow. It was concluded that, during smelting, the formation of $\mathrm{H}_{2} \mathrm{~S}$ from the slag is considerably slower than the rate of feeding sulfur. The transfer of sulfur from coal during combustion was also studied.12 It was found that the volatile (organic) sulfur came off quickly, and most of the mineral (inorganic) sulfur was transferred to the gas phase as the coal was combusted. 
FIGURE 3.5

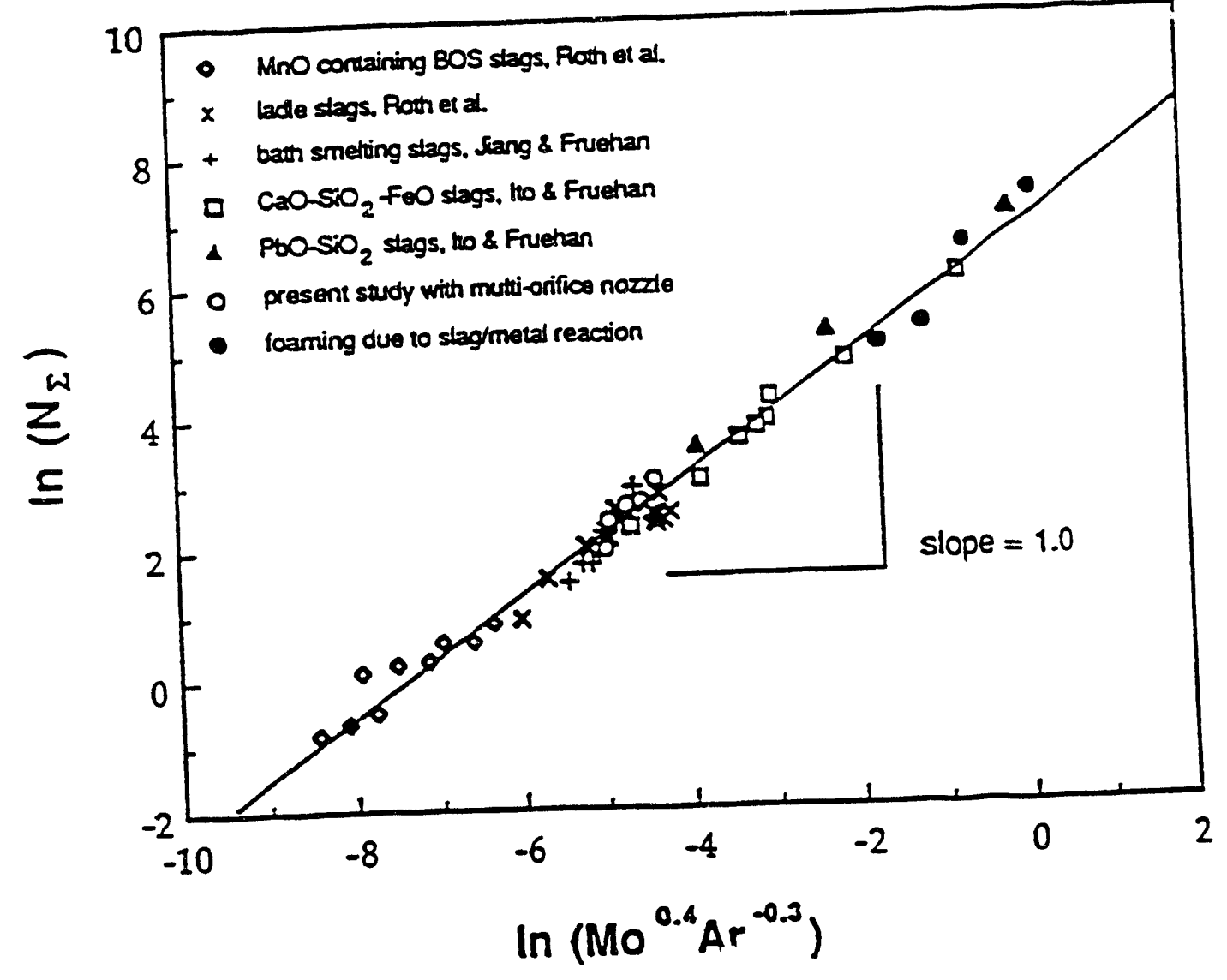

The result of the dimensional analysis considering the effect of the bubble size. 
FIGURE 3.6

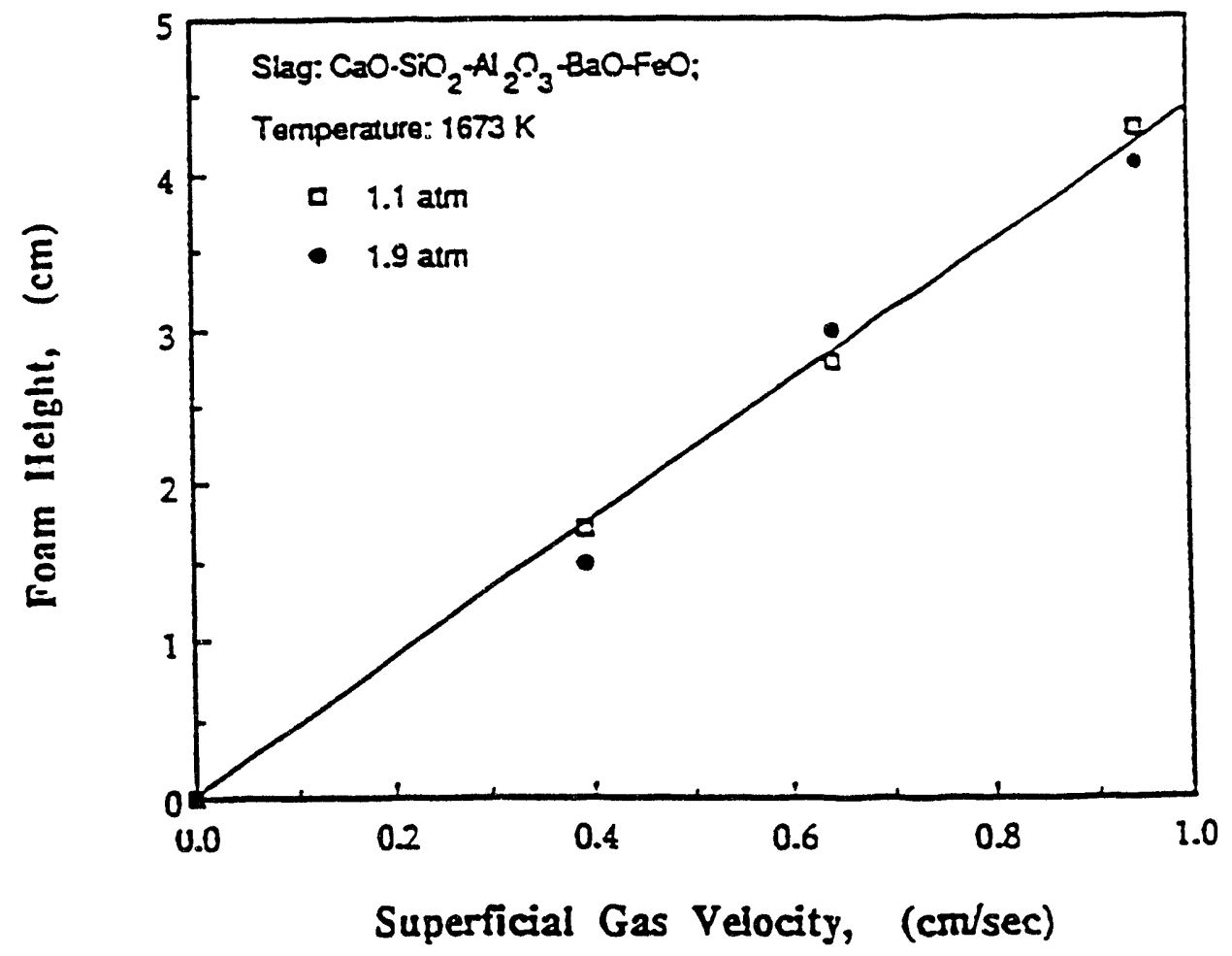

The effect of pressure on slag foaming. 


\section{LARGE-SCALE HEAT TRANSFER STUDIES}

A large-scale heat transfer measurement program was carried out at DOFASCO steel. Initiated in 1989, the program had three objectives:

1. To develop techniques to measure postcombustion and heat transfer efficiency in a full-scale operating vessel.

2. To obtain data for modeling of the postcombustion and smelter process.

3. To obtain spinoff to conventional BOF operations, such as improved scrap melting from enhanced postcombustion.

The year-long intense effort started with installation of a gas sampling and analysis system. Computer programs developed in conjunction with the AISI team at the pilot plant and the modeling effort at McMaster University were used to interpret the results of modifications of slagmaking and blowing practices.

The trials were carried out using the combined blowing K-OBM vessel at DOFASCO's No. 2 melt shop. The K-OBM process is a combined top and bottom oxygen blown process equipped with bottom oxygen and lime injection and a top lance designed for increased postcombustion. One advantage of this process is that special manipulation of the top lance to control slag development (as in the BOF) is not necessary. As a result, a constant top lance postcombustion practice can be followed throughout a heat.

The degree of postcombustion (PCD) is measured directly by the offgas analysis equipment. Figure 4.1 illustrates the layout of the shop and the location of the gas sampling equipment. Figure 4.2 is a typical test heat output graph.

The heat transfer efficiency (HTE) from gas to metal and slag is calculated using the offgas volume and temperature. The HTE is defined as being $100 \%$ if the temperature of the offgas leaving the vessel is the same as the temperature of the steel bath at that time. An increase in offgas temperature above the steel bath temperature indicates an additional loss of energy and, therefore, an HTE of less than $100 \%$. The reference bath temperature used in the calculations was based on previously measured values from DOFASCO's operation. During the trials, the main variables used to influence $P C D$ and $H T E$ were slag basicity (B/A $0.8-2.5$ ), lance height ( 3 to 5 meters above the metal), and additions to the system, such as ore pellets.

Full-scale PCD and HTE data useful in the verification of smelter modeling work were obtained for the following conditions: 


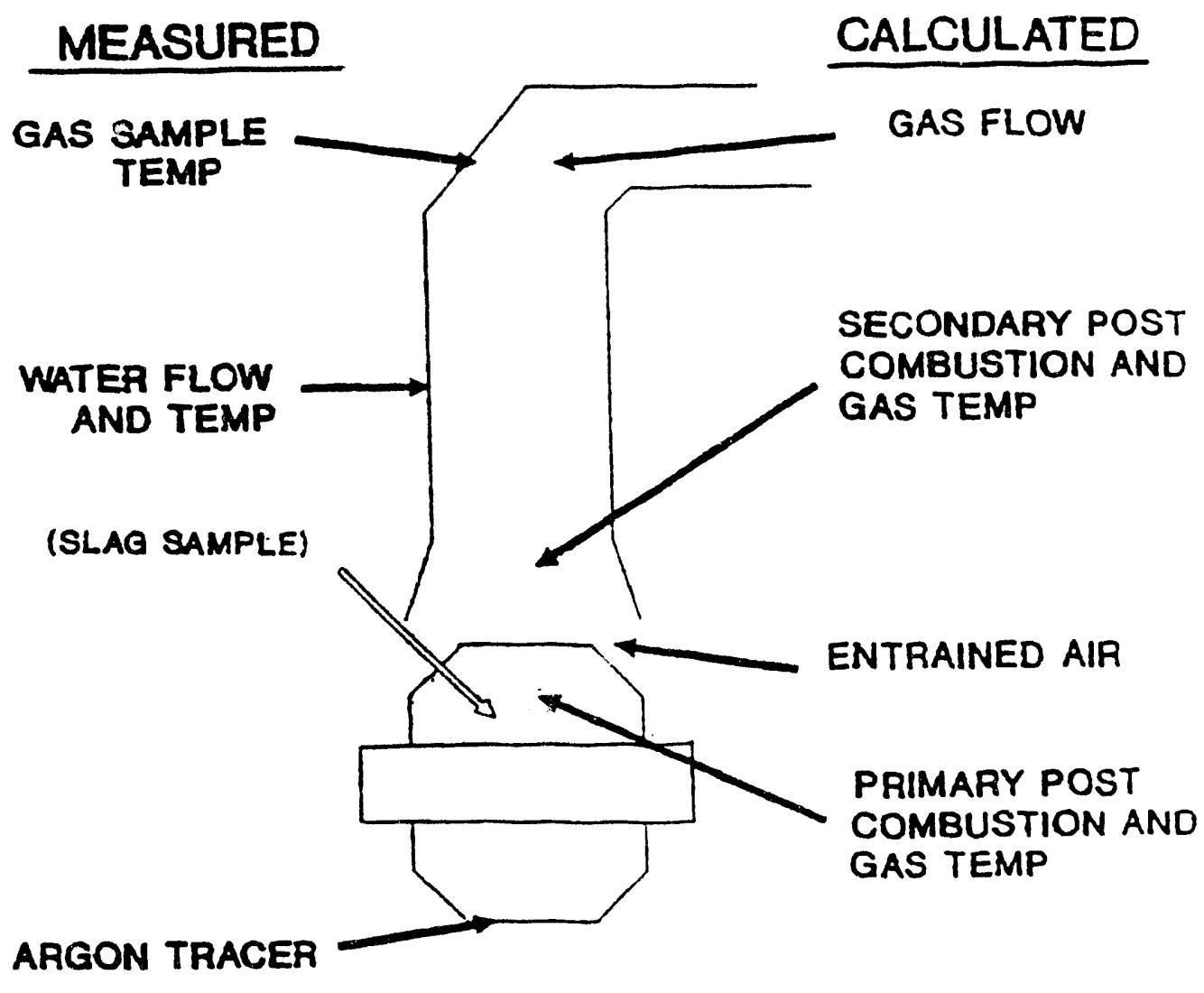

Schematic of Method to Determine PCR and HTE at DOFASCO's $\mathrm{K}-O \mathrm{BM}$ 
FIGURE 4.2
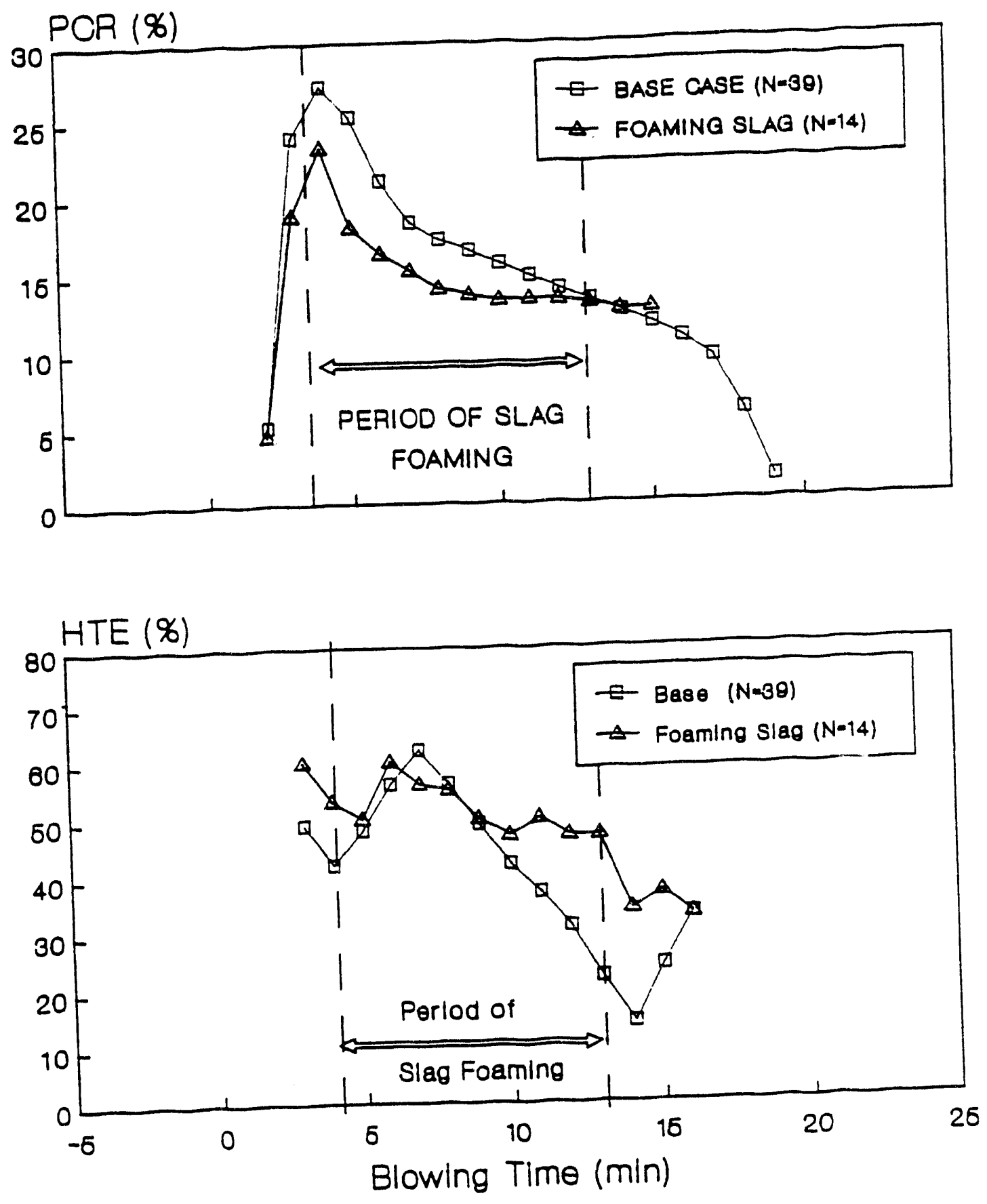

Effect of Foaming Slag on Post Combustion and Heat Transfer in a 300-Ton K-OBM. 
1. Standard postcombustion operation

2. With increasing furnace volume (more headspace for the same charge as lining wears)

3. With foaming slag

4. With foaming slag and ore pellet additions

slags foamed by delaying part of the flux addition (Base/Acid = 1.4) were found to intensify heat transfer from the postcombustion flame. Total heat available from enhancement of the postcombustion reaction could not be harnessed because the foaming slag diminished the extent of postcombustion. The net effect was a minor increase in energy input to the furnace. This may be the consequence of the lance design (meant for BOF normally non-foaming slags) and may be correctible for a smelter designed to operate with a foaming slag always covering the vessel walls and the lance ports.

The key results are:

1. Control of the foaming slag is very sensitive to the $\mathrm{CaO} / \mathrm{SiO}_{2}$ ratio (stable only in the range of $\mathrm{CaO} / \mathrm{SiO}_{2}$ from 1.2 to 1.5 ).

2. Additions of ore pellets to a foaming slag (equal to $20 \%$ slag FeO) did not change either the PCD or the HTE. pellets dissolved and were reduced at a rate of 500 to $700 \mathrm{~kg} / \mathrm{min}$, which was less than the addition rate of $1000 \mathrm{~kg} / \mathrm{min}$.

3. Carbon content of the metal during the foaming tests dropped from about $3.0 \% \mathrm{C}$ to $2.5 \% \mathrm{C}$. (This might be the metal composition for steady-state operation of the reducing half of the two-zone horizontal smelter.)

4. As a spinoff from this work, DOFAsco has increased scrap melting by about $3 / 4 \%$ by controlled use of the "free" postcombustion energy.

This work is reported in more detail in publications of the This work is reported in more detail in publications

Subsequently, another steel company has applied the postcombustion technology first studied at DOFASCO and developed further in the pilot plant to the basic-oxygen-furnace process to achieve a nearly four percent gain in steel production. Also, Praxair, working with Nucor 16 and using postcombustion technology developed in the smelting program, has demonstrated power savings of 40 to $50 \mathrm{Kwh} / \mathrm{NT}$ and productivity gains of 5 to $8 \%$. 


\section{HYL8A PREREDUCTION BTUDIES}

\section{Shaft Furnace Design}

The AIS $\mathcal{L}$ ironmaking process will employ a moving-bed shaft reducer using conditioned smelter offgas to preheat and prereduce iron ore pellets (hematite) to the wustite state, removing about $30 \%$ of the oxygen, for subsequent use in the smelter. Although shaft reducers are used around the world to produce highly metallized pellets, the production of wustite represents a new technology. Accordingly, Hylsa of Monterrey, Mexico, who has a shaft furnace pilot plant and good research and development facilities, was contracted to develop a shaft furnace process to produce wustite pellets.

Initially, a simple fixed-bed shaft reducer was explored for supplying hot wustite to the smelter at the Direct steelmaking pilot plant. The preheating and prereduction were accomplished with partially-combusted natural gas, and operating conditions to produce wustite in a fixed bed were developed. However, because of pellet swelling during reduction to wustite and the subsequent formation of pellet clusters and a bridge in the shaft, the hot wustite pellets could not be satisfactorily discharged from the fixed bed.

Tests were then conducted at Hylsa's moving-bed shaft furnace pilot plant. It was determined that the furnace could produce about 30 tonnes per day of wustite using simulated smelter gases at a $40 \%$ postcombustion level and at temperatures of 900 and $950^{\circ} \mathrm{C}$. Tests were conducted over gas flows ranging from 2000 to $800 \mathrm{NM}^{3}$ of gas per tonne of iron produced $\left(\mathrm{NM}^{3} / \mathrm{tFe}\right)$. As shown in Figure 5.1 , the conversion to wustite was reasonably constant over a wide range of gas flows but decreased dramatically at the $800 \mathrm{NM}^{3} / \mathrm{tFe}$ gas flow rate. Hylsa estimates that the minimum gas flow for good conversion to wustite is about $1050 \mathrm{NM}^{3} / \mathrm{Fe}$. This pilot plant information, in conjunction with laboratory tests, has enabled Hylsa to develop a mathematical model for a wustite shaft furnace that can be used to predict the reduction level as a function of reducing gas composition, temperature, and flow.

Based on information from the $R \& D$ program, Hylsa developed the functional engineering specifications for a pilot plant reduction shaft furnace that could be installed at the Direct steelmaking pilot plant at Universal. Further, Hylsa provided the preliminary design specifications for a shaft furnace to supply wustite to a proposed demonstration plant to produce 50 tonne per hour of hot metal. 


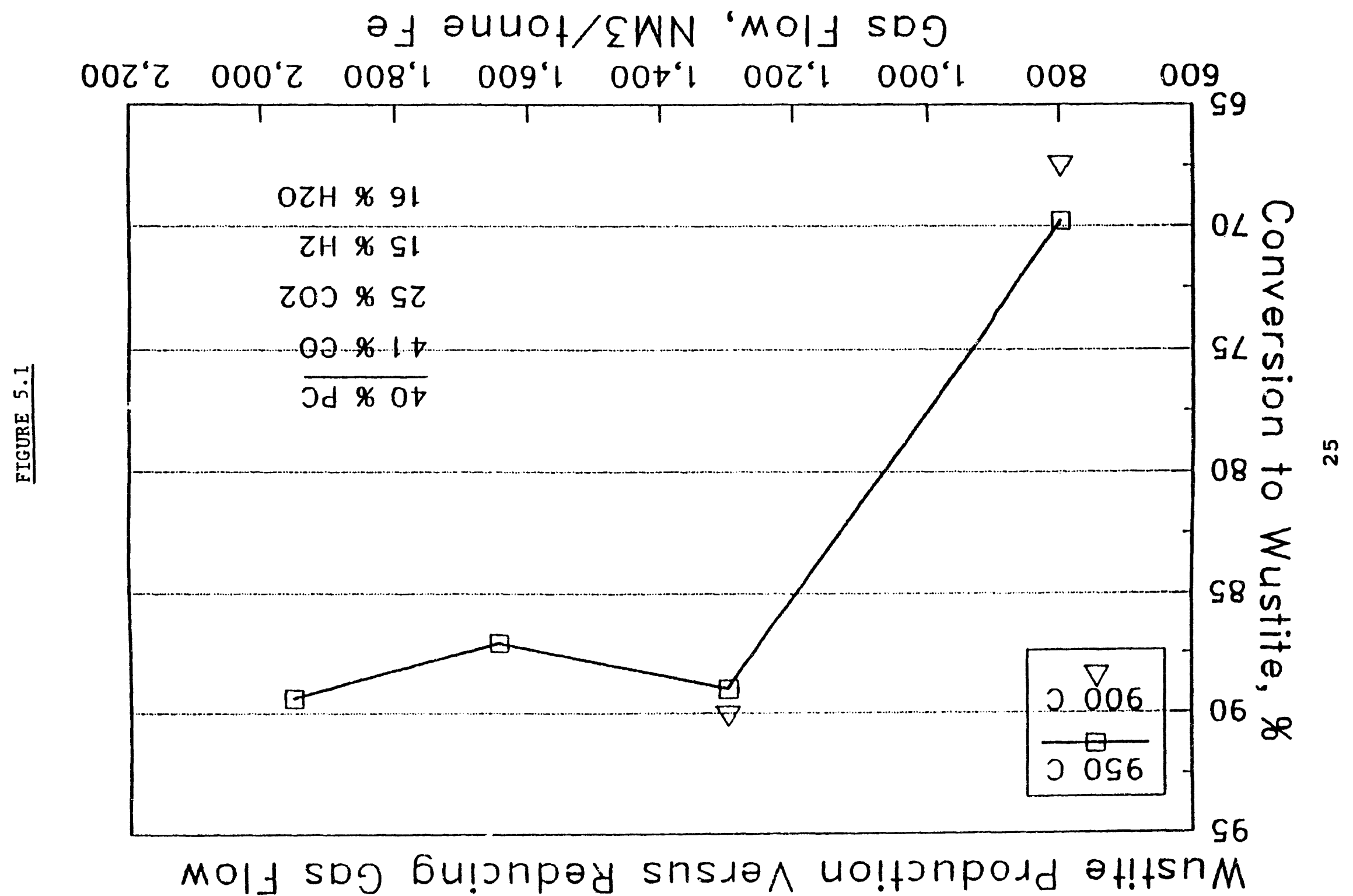




\section{Sulfur Management}

It was known that sulfur in the COREX process is retained primarily in the hot metal and slag. This is achieved by capturing sulfur in the gas phase in the reduction shaft with DRI and dolomite. The DRI and dolomite effectively return the sulfur to the melter/ gasifier where most of it is retained. Although conditions in the COREX process are different, it was believed that it may be possible to manage sulfur in a similar manner in the direct ironmaking process. Therefore, tests were conducted at Hylsa to determine if sulfur in the gas phase could be effectively removed in the shaft furnace. A description of the tests conducted and a summary of the results are as follows.

The simulated smelter gas composition (postcombustion of about $40 \%$ and temperature about $900^{\circ} \mathrm{C}$ ) used in these tests is essentially the same as that suggested by AISI and used in the previous Hylsa program to develop the design parameters for a shaft furnace to produce wustite. $\mathrm{H}_{2} \mathrm{~S}$ (the expected primary sulfur species in the smelter gas at $900^{\circ} \mathrm{C}$ ) in the gas was produced by injecting carbon disulfide. Because of limitations in the injection system, the $\mathrm{H}_{2} \mathrm{~S}$ in the gas phase was limited to about $1100 \mathrm{ppm}$, which is about onehalf of that expected from the coal in the smelter gas. The first test was conducted with only pellets charged to the shaft furnace to produce wustite. In this test, about 63 percent of the input sulfur appeared as Fes $(0.07 \% \mathrm{~S})$ in the wustite. This clarifies previous theoretical calculations, some of which indicated that Fes would not be formed. The $\mathrm{H}_{2} \mathrm{~S}$ in the shaft offgas from this test was $395 \mathrm{ppm}$, which would likely be unacceptable environmentally.

In the second test, calcined dolomite (about $85 \mathrm{Kg} / \mathrm{t} \mathrm{Fe}$ ) was added to the shaft furnace. During this test, both wustite and dolomite captured sulfur. The sulfur content of the wustite and dolomite in the shaft product were 0.078 and 0.991 percent, respectively. The sulfur was distributed approximately as follows: about 50 percent in the wustite as Fes, about 40 percent in the dolomite presumably as Cas, and about 10 percent in the shaft furnace offgas as $\mathrm{H}_{2} \mathrm{~S}$. The $\mathrm{H}_{2} \mathrm{~S}$ in the offgas was $120 \mathrm{ppm}$.

A third test was run with calcined dolomite and lime (about $88 \%$ dolomite and $12 \%$ lime). Previous theoretical calculations indicated that lime in the shaft would improve the desulfurization and possibly decrease the $\mathrm{H}_{2} \mathrm{~S}$ in the offgas. However, the results were similar to those with dolomite only. (It should be noted that revised calculations now show that lime addition will not improve desulfurization.)

These tests showed that significant quantities of sulfur in the reaucing gas going to the shaft furnace can be removed from the offgas and returned to the smelter by adding dolomite to the shaft furnace. 


\section{DESIGN, CONSTROCTION, AND OPERATION OF THE FIRST (VERTICAI BOF-SHAPED) VESSEL}

\section{Design, Construction, and startup}

The construction and startup of the pilot plant with the vertical vessel and the supporting equipment was completed on June 14, 1990, the date of the first trial. The checkout of auxiliary equipment continued in conjunction with the test program.

The pilot plant layout is shown schematically in Figure 6.1. The equipment and facilities include a vertical, refractory-lined 15 tonne smelter vessel, Figure 6.2 , and the necessary support equipment to produce five tonne of hot metal per hour. The support facilities include an ore storage and screening facility where the raw materials are stored and screened before they are put into the day bins. The bulk materials are then carefully weighed, taken to the top of the vessel by conveyor belt, and then charged into the vessel via a water-cooled chute. Raw materials may also be introduced into the process by the pneumatic injection system. There are two separate coal injection systems, an ore system, and a flux injection system.

A double venturi, wet gas cleaning system cleans the gases coming from the process. This system is able to operate in the total combustion and suppressed combustion modes. To clean the water from the gas system, a water treatment system, complete with clarifier and belt thickener, was installed. To cool the offgas hood, a totally closed, boiler-quality water system was installed. This system was designed to handle offgas temperatures of up to $1650^{\circ} \mathrm{C}$. Oxygen, nitrogen, and argon are supplied to the plant in liquid form and stored in tanks. The liquid is then vaporized and fed into the system on a demand basis.

To take metal and slag samples and temperatures during the trial, the plant is equipped with a sensor lance. There is also a gas sampling lance that samples the gas continuously from inside the vessel during operation and transfers and filters it through a heat-traced line to a mass spectrometer for analysis. To analyze the metal and slag samples in a timely fashion during a trial, an $X$-ray spectrometer, carbon/sulfur analyzer, and sample preparation equipment were installed at the pilot plant, and the crew was trained in their use.

The flows, temperatures, and pressures are measured and controlled by a PLC-based control system that is linked to the IBM RPMIS system. Most of the equipment can be started and controlled by the computer system. Set points and controllers may also be set at the back panels of the control room as a safety backup. 


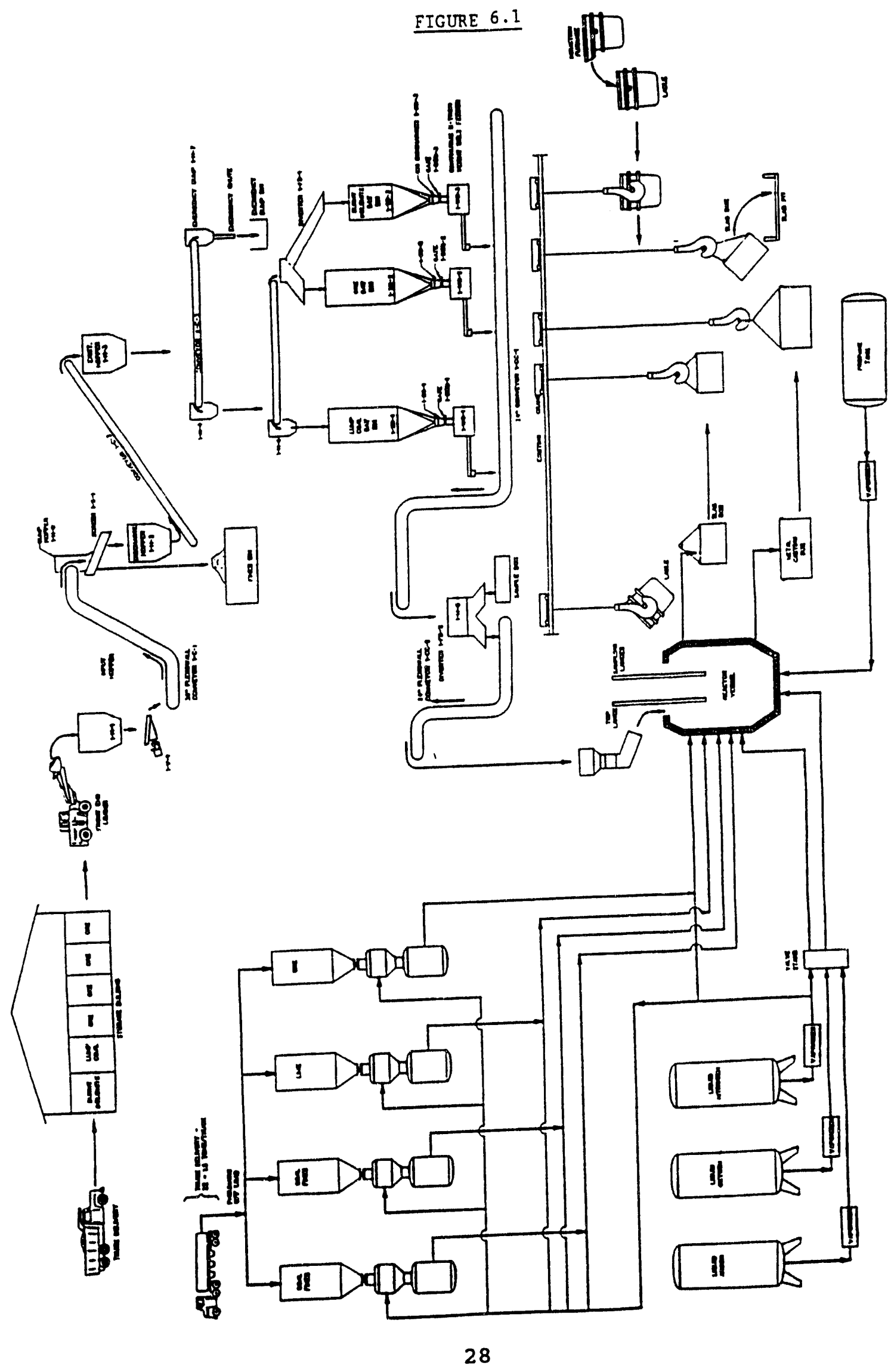




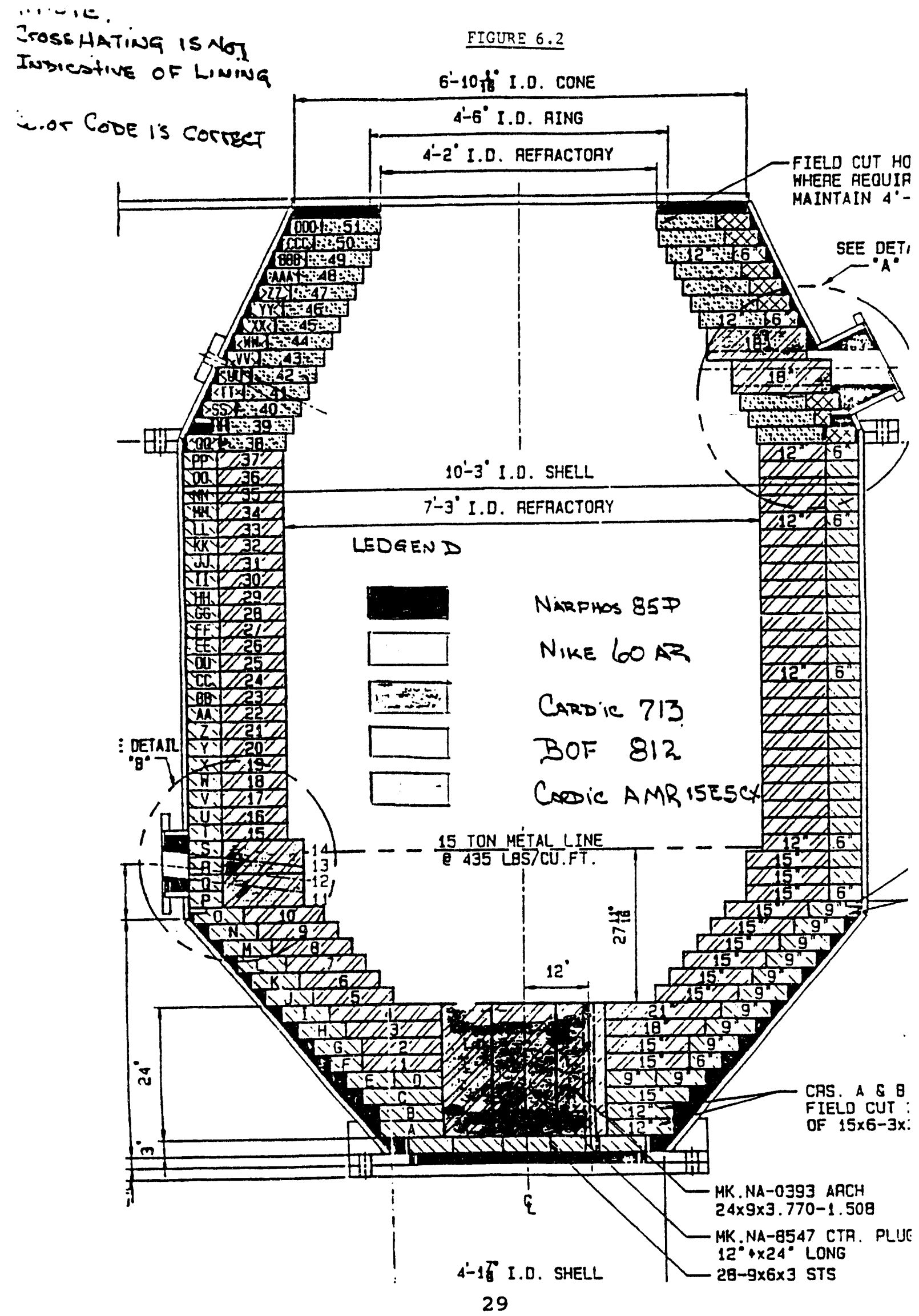


A staff of 12 trained technicians prepares the facility for the trials and operates the plant on trial days. Most members of the staff have had experience in operating steel plants. The safety of the crew has been paramount. If anything is not ready, the trial will not be started. The product of the trials is information, not metal and slag. If good data cannot be gained from a trial, there is not much purpose in running it.

Startup began in July, 1990, with three coal gasification trials to check the offgas system. Actual smelting trials began in August, 1990.

\section{Process Control strategies and system}

The process is controlled primarily by controlling the feed rate of the raw materials: ore pellets, coal, oxygen, and flux. The oxygen blowing practice that involves lance position, hard or soft blow and primary-to-secondary oxygen ratio, and nitrogen stirring energy have lesser but still significant effects and must be optimized for maximum productivity.

The oxygen rate is established by the aim production rate, which also establishes the coal rate and the ore addition rate. The coal rate and ore rate are modified according to the need to raise or lower the operating temperature or to raise or lower the char volume. The char volume must be controlled to achieve a stable foamy slag, and the slag basicity, which also affects the stability of the foam, must be controlled by flux additions.

The degree of postcombustion is largely controlled by lance position and by the primary-to-secondary oxygen ratio for a given lance design. The volatile matter bypass is controlled largely by the choice of coal, but for a given coal, the bypass is also affected by the ratio of top-fed coal to side-injected coal and by the oxygen blowing practice. The dust losses to the stack are governed to a large extent by the oxygen blowing practice and its effect on the foam turbulence and secondarily by the raw material particle size and charging or injection practices.

The process control system is composed of an IBM 9370 Model 90 computer acting as a Level 2 controller for five Allen-Bradley Level 1 Programmable Logic Controllers (PLC). PLC-1 is used for supervisory and safety functions, PLC-2 for gas cooling and cleaning functions, PLC-3 for bulk material handling functions, PLC-4 for pneumatic injection functions, and PLC-5 for gas flow systems. The PLCs interface and communicate with a large variety of analog and digital instrumentation. The Level 1 communication occurs via a data highway developed by Allen-Bradley for intercommunication among PLCs. An IBM PC is also connected to the data highway and is provided with special software to allow programming of the PLCs. 
Specially developed device-driver software was installed on the Level 2 system to provide for communication by the IBM 9370 with the five PLCs. The IBM 9370 is functionally a node on the data highway.

Additional functions have been added to the control system. Software has been installed to move files from the IBM 9370 database to the engineers' workstations for off-line data analysis. The software interfaces to PC spreadsheet programs as well as to database files for PC-based statistical software. Figure 6.3 shows the entire hierarchical control system.

The process operates on the basis of set points and aims established by the operator and feedback from sensors to control systems to achieve these set points. A control system based on an integrated process model awaits completion of the integrated model.

\section{Operating Procedures}

To maintain a stable operation with consistency from trial to trial, standard operating procedures were developed for vessel operation. These procedures helped to maximize the information obtained from each trial and assure, as closely as possible, that all trials started from the same operating conditions and parameters.

The pre-trial checklist assured that all systems were checked and verified before the trial started and helped to guarantee that the systems would perform to specifications once the trial was started. The operating procedures were designed to bring the hot metal and slag quantity and temperature to the same point at the start of each trial. The sampling procedures assured that all the necessary samples and data were collected. The operating plans for each trial were developed for that trial, depending on the variables or parameters that were to be studied. Standard procedures for controlling hot metal temperature and char (foam control) were developed and followed. Shutdown procedures allowed for a safe completion of the trial with consideration for setting the plant up for the next trial.

In most cases, detailed procedures were written and then broken down to a checklist format that was used before and during the trials. The procedures were used for training, and the checklist was used for the trial. The procedures were developed and modified to operate the plant in the safest possible manner. They also assured that the maximum amount of information from each trial was obtained and that there would be minimal equipment failures during a trial. The operating philosophy behind the procedures was to obtain the most information from a trial, but if there was a major problem, stop the trial and minimize the damage. The goal was to obtain data at steady-state operating conditions. This was 


\section{AISI-DOE Direct Steelmaking}

Hardware Diagram

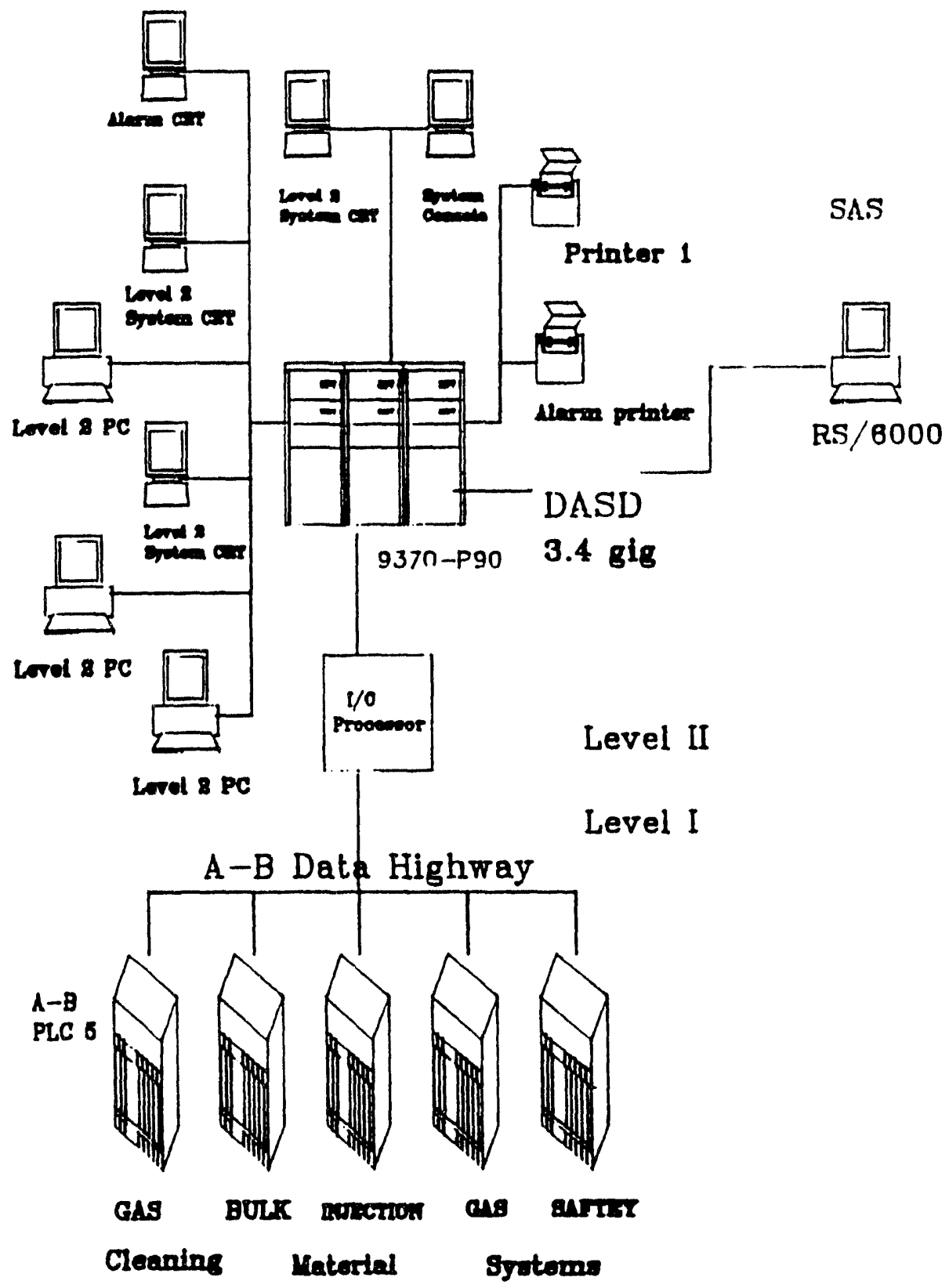

AISI-DOE Direct Steelmakdne 
generally achieved each week; the remainder of the week was used for recovery and for preparation for the next week's trial.

\section{startup and shutdown}

startup and shutdown procedures have also been developed and documented. They provide a detailed checkout of all systems in the plant and the sequence and timing for each startup and shutdown operation.

\section{Description of a Typical Trial}

A typical trial begins with a visual walk-around safety inspection and a pre-trial checkout of all systems the day before the trial. Burners are used to preheat the vessel, ladle, casting boxes, and the slag spout and slag box. About midnight, melting of the initial hot-metal charge in the 15-ton induction furnace is begun. When the hot metal is at temperature, the preheater is removed and the initial slag charge is added. The hot metal is charged next, and various platforms and shields are put in place to facilitate operation and turndown sampling. The lances are lowered, samples and measurements are taken, and a "run segment" begins with start of the oxygen blow.

The segments are typically separated by vessel turndowns for sampling and adjustments, but a run segment is officially defined as the time from start to stop of the oxygen blow, typically requiring from 30 minutes to two hours. At turndown, slag and metal temperatures are measured, and metal, slag, and char are sampled. Slag is poured off if appropriate.

The first three segments (approximately 1-1/2 to 2 hours) are used to melt and condition the initial slag charge, thermally soak out the vessel lining, build up the char, and bring the vessel to the designated stable condition. The coal, the fluxed wustite or hematite pellets, and any additional fluxes are added from the top, falling into the vessel by gravity. oxygen is blown through a dual-pressure-system lance with a higher pressure for the jet exiting from the bottom (primary) and lower pressure for the jets exiting from the side (secondary) of the lance. The hot metal is stirred by bottom-blown nitrogen. These segments are considered to be preparation for the experiments, and data from these segments are not included in the analysis of operations discussed later.

The remaining segments are for the planned experimental conditions and may last for 30 minutes or as much as two hours at a given set of conditions. When the hot metal reaches the casting level, the taphole is opened, and casting is continuous.

Temperatures, samples, and foam-height measurements are taken every 15 to 30 minutes, and vessel gas analysis takes place when the sensor lance is not in use. 
Figure 6.4 is a typical operating plan, in this case for trial number 40. The objective of this trial was to maintain high degrees of postcombustion by either adjusting the lance height (condition 1) or by adjusting the ratio of primary-to-secondary oxygen in the jet (condition 2). If stable baseline conditions are not maintained for a given segment, that segment is repeated until stable conditions are achieved.

To control the metal temperature during a segment, the total amount of coal and ore is varied while the amount of oxygen blown is held constant. For example, a too high temperature calls for an increase in the total amount of coal and ore. Too little char, which leads to excessive slag foaming, requires an increase in the ratio of coal to ore, keeping the total constant to maintain a constant temperature. offgas temperature must be controlled to remain under $1650^{\circ} \mathrm{C}$ to minimize refractory loss. This is best achieved by controlling the degree of postcombustion, which is controlled by lance-height adjustments.

At the end of: a trial, the slag is poured off into slag pots, and the metal is tapped into the ladle and transferred to refractorylined boxes for solidification and reuse for the next trial.

The process is quite forgiving, in that recovery from upsets and transition to rather different operating conditions $c$ in be readily accomplished. In one case involving malfunction of the coal injection system, the vessel was put on hold for almost three hours with only the nitrogen stirring tuyeres activated. When the injection system was restored, the vessel was brought back to the desired steady-state operation within 30 minutes.

\section{Energy and Mass Balance}

Energy and mass balance models have been developed and applied to pilot plant data essentially independently by three organizations using their own systems for building the model. The CMU smelting model is an analytic model that was initially developed by Ito and Fruehan. Subsequently, Myers developed a model more applicable to the pilot plant. The analytic model is capable of incorporating the measured process data and using them to 1) estimate the value of unmeasurable process parameters and 2) calculate the mass and energy inputs and outputs in the smelting process. Zhiyou Du of Praxair has developed a parametric model independently that has been applied to pilot plant data.

The parametric model, by performing the mass and heat balance, can be used to 1) project the change in material input required, as well as the change in offgas volume and composition resulting from a process parameter change, and 2) estimate the heat transfer requirements within the smelter. 


\section{OPERATING PLAN FOR TRIAL 40}

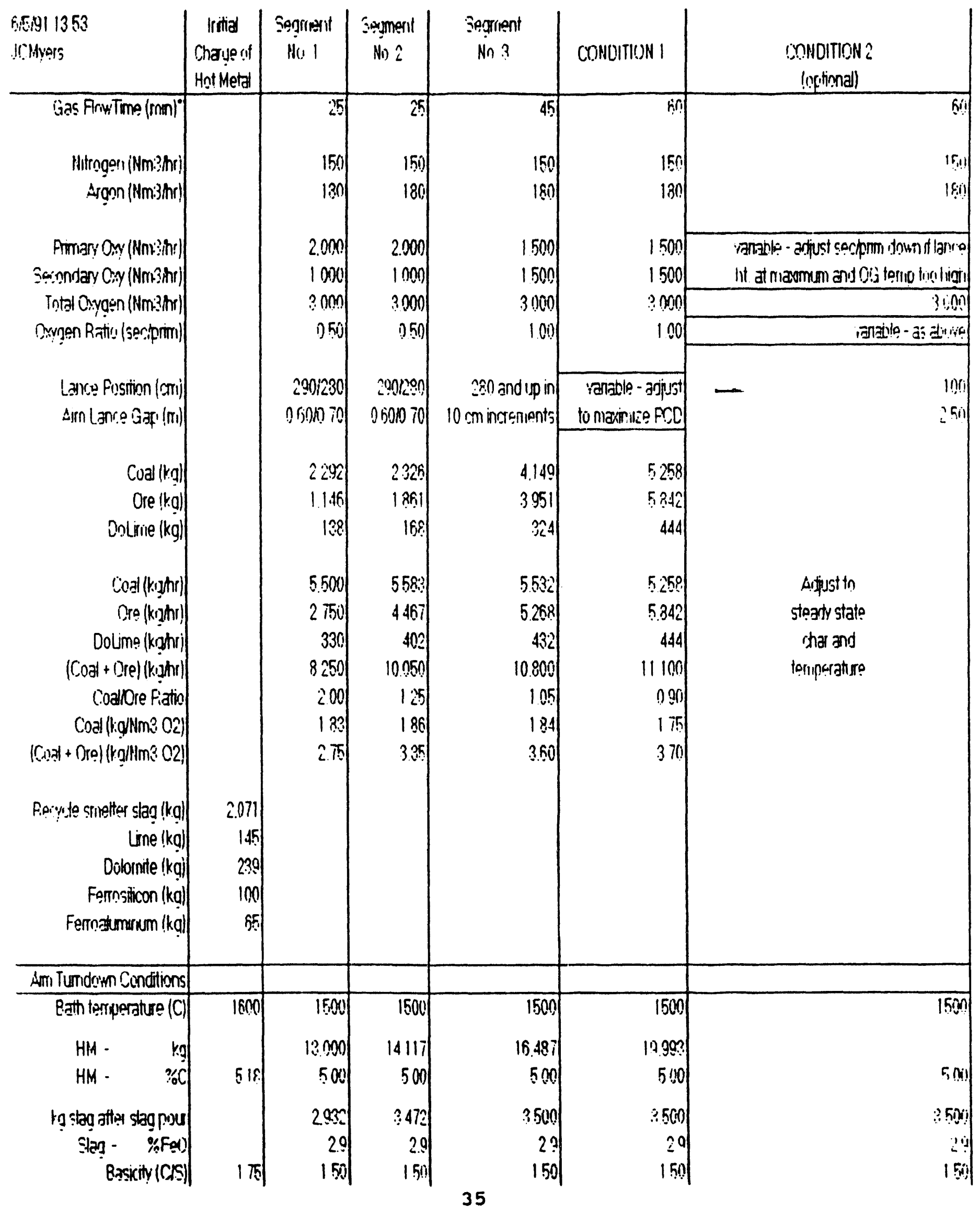


Both models treat the smelting system as two zones shown in Figure 6.5. The smelting zone is the entire smelter where reduction and postcombustion occur. The offgas zone is defined as the gas phase in duct. A schematic of the smelting system in operation is sketched in Figure 6.6. Oxygen is directly fed into the smelting zone and consumed there. Coal is top charged into the smelter via the offgas zone. Upon contact with the hot offgas, the coal is partially devolatilized, and a certain amount of coal volatile, called VM bypass, directly evolves into the offgas zone without participating in the smelter reactions. The offgas leaving the smelter and entering the offgas zone results from ore reduction, char oxidation, and postcombustion reactions in the smelter. This offgas then further reacts with bypassed coal volatiles and infiltrated air in the offgas zone. Compositions of the offgas leaving the smelting and offgas zone are simultaneously measured in the trials, and the results are called vessel gas and duct gas analysis, respectively.

\section{Assumptions in the Models}

The following major assumptions were employed in both analytical and parametric models:

1. The composition of coal volatile evolved in the offgas zone is the same as that evolved in the smelting zone.

2. The heat of coal devolatilization is assumed to be zero.

3. When leaving the smelting zone, the offgas mixture consisting of $\mathrm{CO}, \mathrm{CO}_{2}, \mathrm{H}_{2}, \mathrm{H}_{2} \mathrm{O}, \mathrm{N}_{2}$, and $\mathrm{Ar}$ is in chemical equilibrium for the water-gas shift reaction at the local. gas temperature.

4. The ore reduction rate is fast enough such that the feeding ore can be "instantaneously" reduced to $\mathrm{Fe}$.

Mannesmann Demag has adapted its generic ironmaking model to the AISI process and applied it to data generated at the pilot plant. The models are in excellent agreement with respect to energy requirements and energy balances as applied to the pilot plant data.

The mass balances are more difficult to close because assumptions and corrections must be made, especially to the gas composition and gas flow data. The variability of gas composition as determined by the gas analyzer for the gas sampled at the sensor lance indicates that the gas composition in the freeboard is quite sensitive to where the materials are reacting and the gas flows created by the volatile matter in the coal. Both this gas analysis and the stack gas analysis must be corrected for the water-gas shift for the sampling temperature and the analyzing temperature. The assumption 
FIGURE 6.5

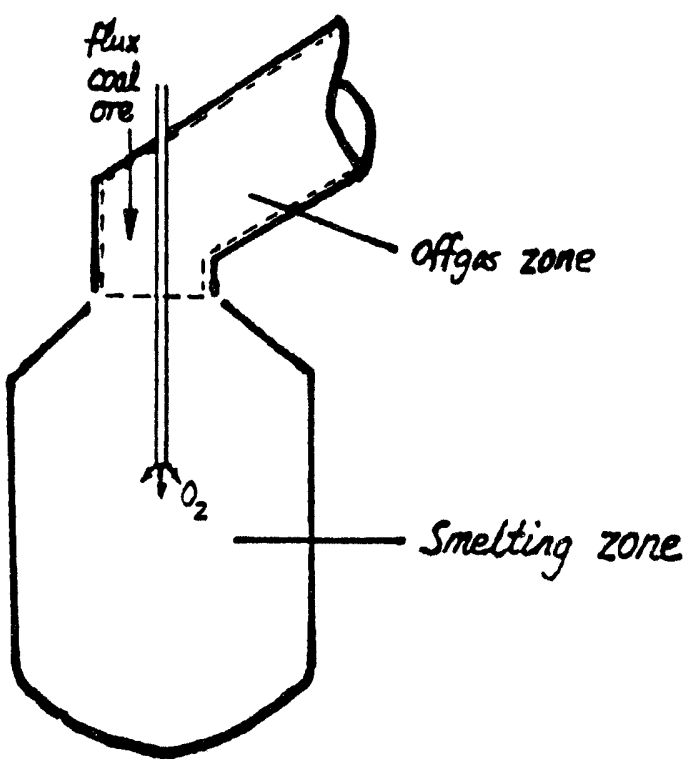

Zone Description

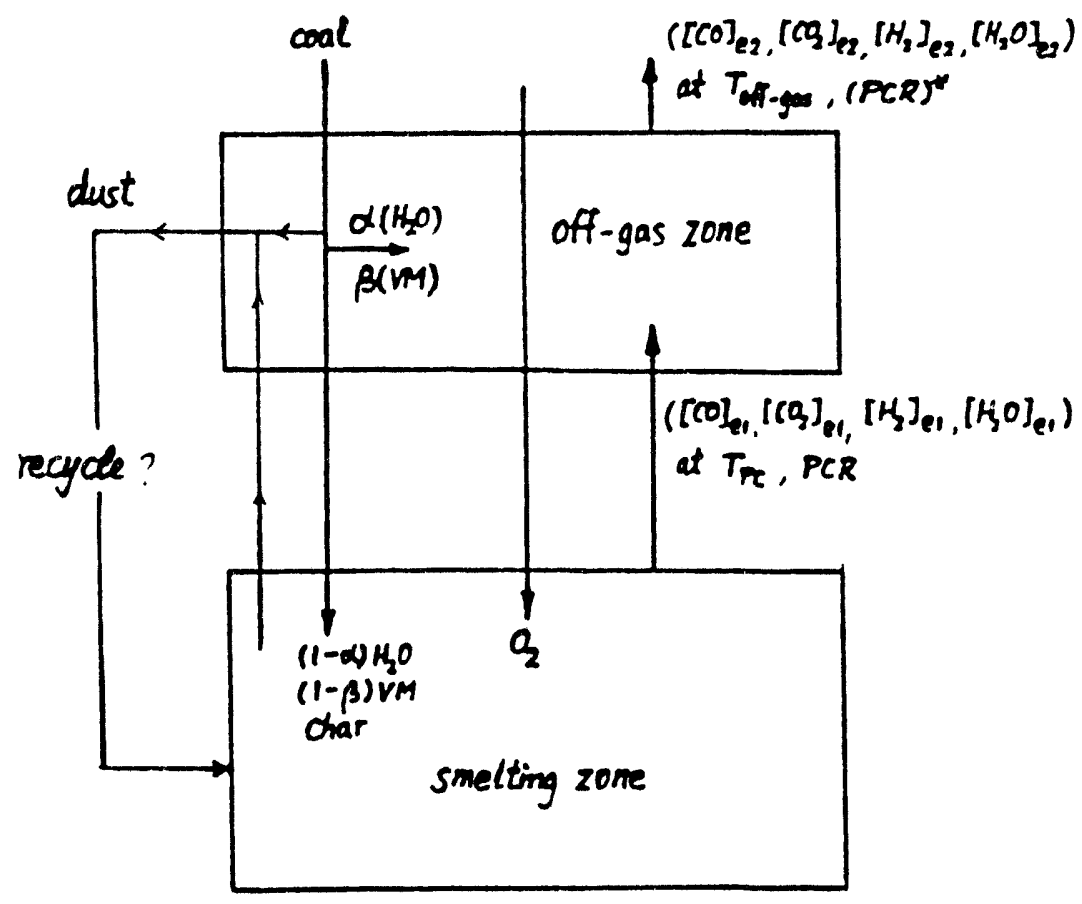

Flow chart of cool and gases in a smelter 
FIGURE 6.6

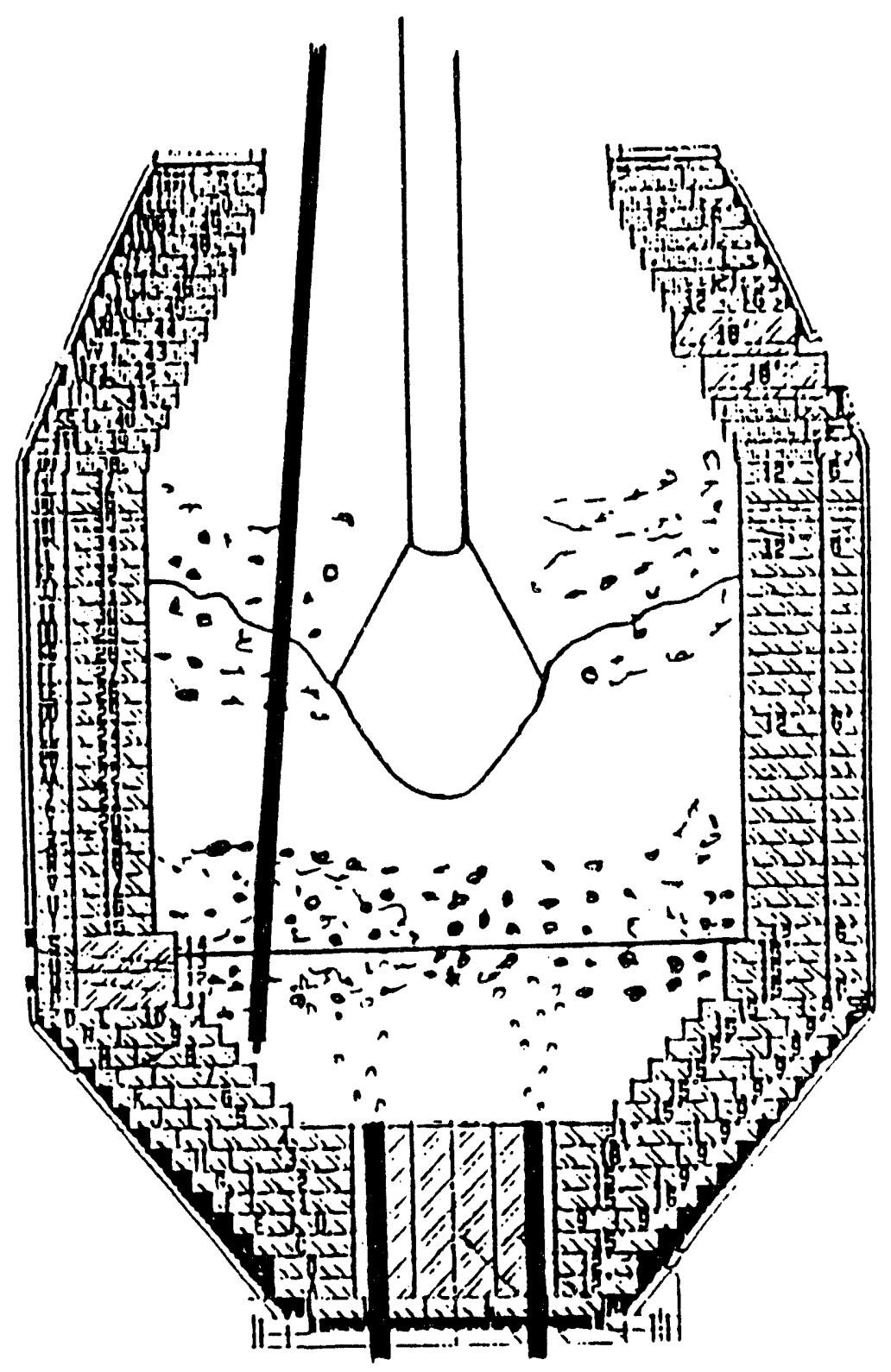


that equilibrium among the gas constituents exists, especially in the vessel freeboard, is also questionable.

Despite these concerns, there is general agreement that the process is understood and that the reaction rates measured can be converted and scaled up to those for a larger vessel. The analysis assumes recycling of the fines that currently exit by way of the stack. operation demonstrated the achievement of a 408 degree of postcombustion and a heat transfer efficiency of 85 to 908 .

\section{Fuel Rates - Pilot Plant, Projected Commercial plant}

Pilot plant datz for trials 12 - 49 were surveyed to examine coal rates for different coal types. Data included in the survey were selected from trials in which wustite pellets were the ore feed. For each trial, the total coal, ore, and oxygen feeds were tabulated along with the total operating time. In addition, departures from steady-state conditions with regard to temperature and char were recorded. Finally, carbon losses in the dust were tabulated where data were available. All of these totals were divided by the operating time and are represented as rates.

Table 6.1 provides fuel rate averages by coal type for a coke and coal combination, an anthracite, medium-vol coals $A$ and $B$, and high-vol coals $C$ and $D$. Steady-state coal rates are calculated to account for non-steady-state conditions with respect to temperature and char, which may each be increasing or decreasing during a run segment or a series of segments. The fuel rates are also corrected for the dust losses up the stack, as measured in the scrubber water. In an integrated plant, these dusts would be recycled. The data in the four rows at the bottom of the table have been calculated on a dry basis, correcting for the moisture in the coal. The raw data and the net fuel rates are summarized in the bar chart, Figure 6.7.

\section{Projected Fuel Rate for Commercial Plant}

The pilot plant model was used to calculate a projected fuel rate for a 50 tonne per hour commercial plant for producing hot metal, starting with segments 8,9 , and 10 of trial 36 as a base case. This trial was conducted with ambient temperature wustite as the ore feed and coal $C$ as the fuel. Table 6.2 presents the measured values in the column labeled "base" and progresses to the projected commercial fuel rate in five steps. Each of the steps corrects for a particular difference between pilot plant operation and the expectations of a commercial plant, and the table presents the new value for each of the process variables as calculated by the parametric model.

The first step corrects for a char-loss penalty that may arise from continuous slag tapping. In the pilot plant, slag is tapped at turndown when the slag is quiescent, and any char floating on top 


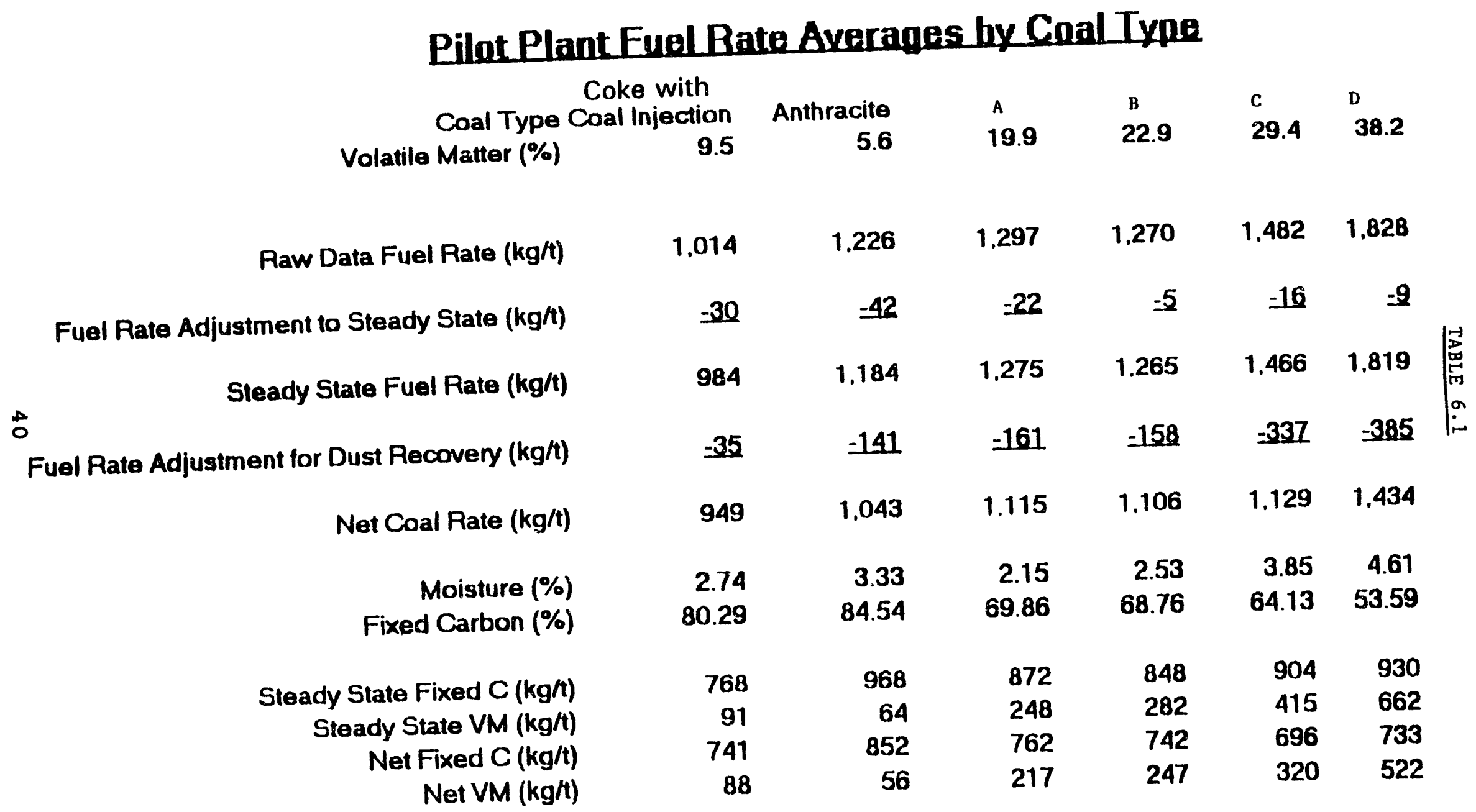


FIGURE 6.7

\section{Pilot Plant Fuel Rates}

$\square$ Raw Data Net

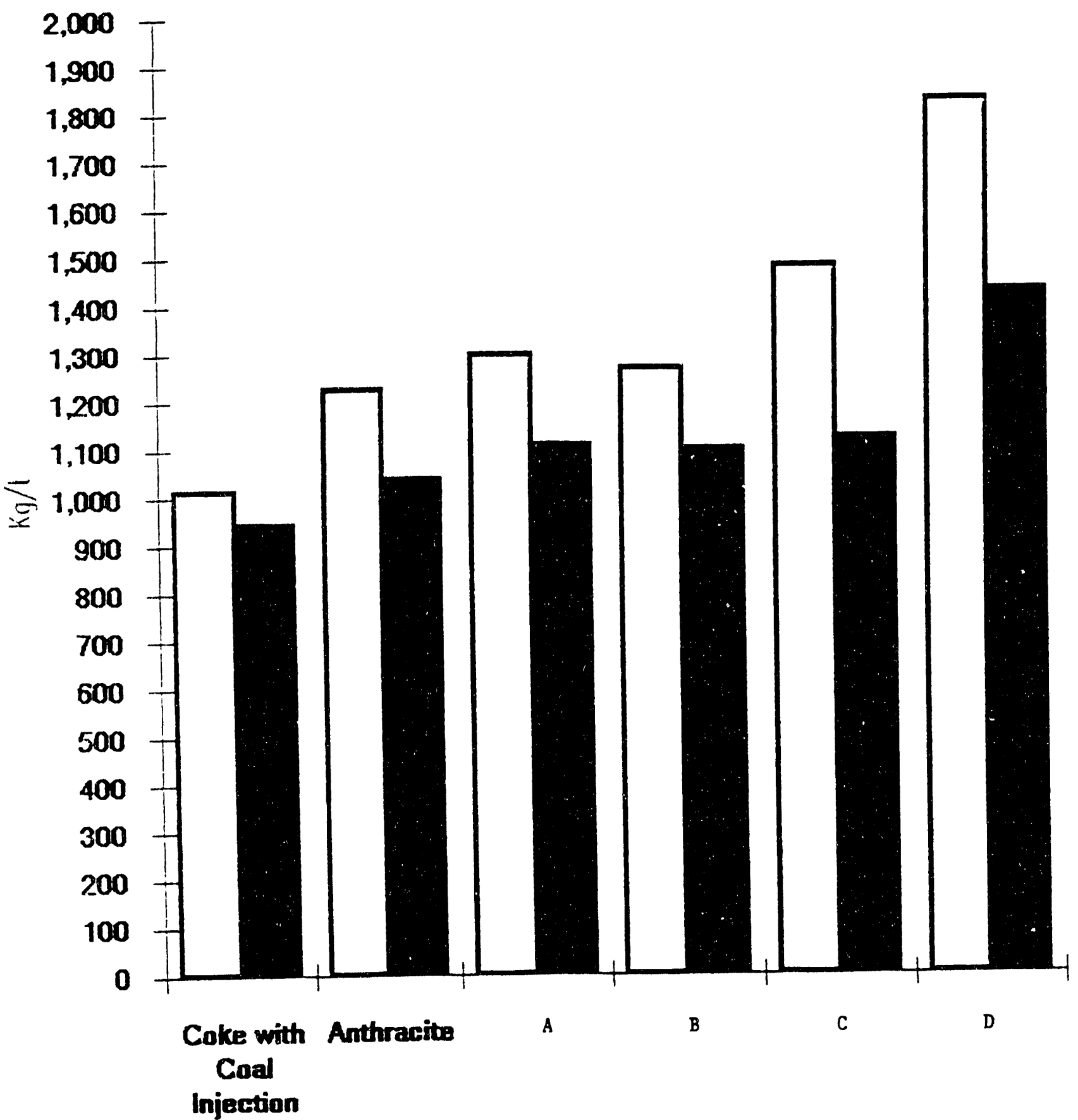




\section{Scale-up from Pilot Plant to Commercial}

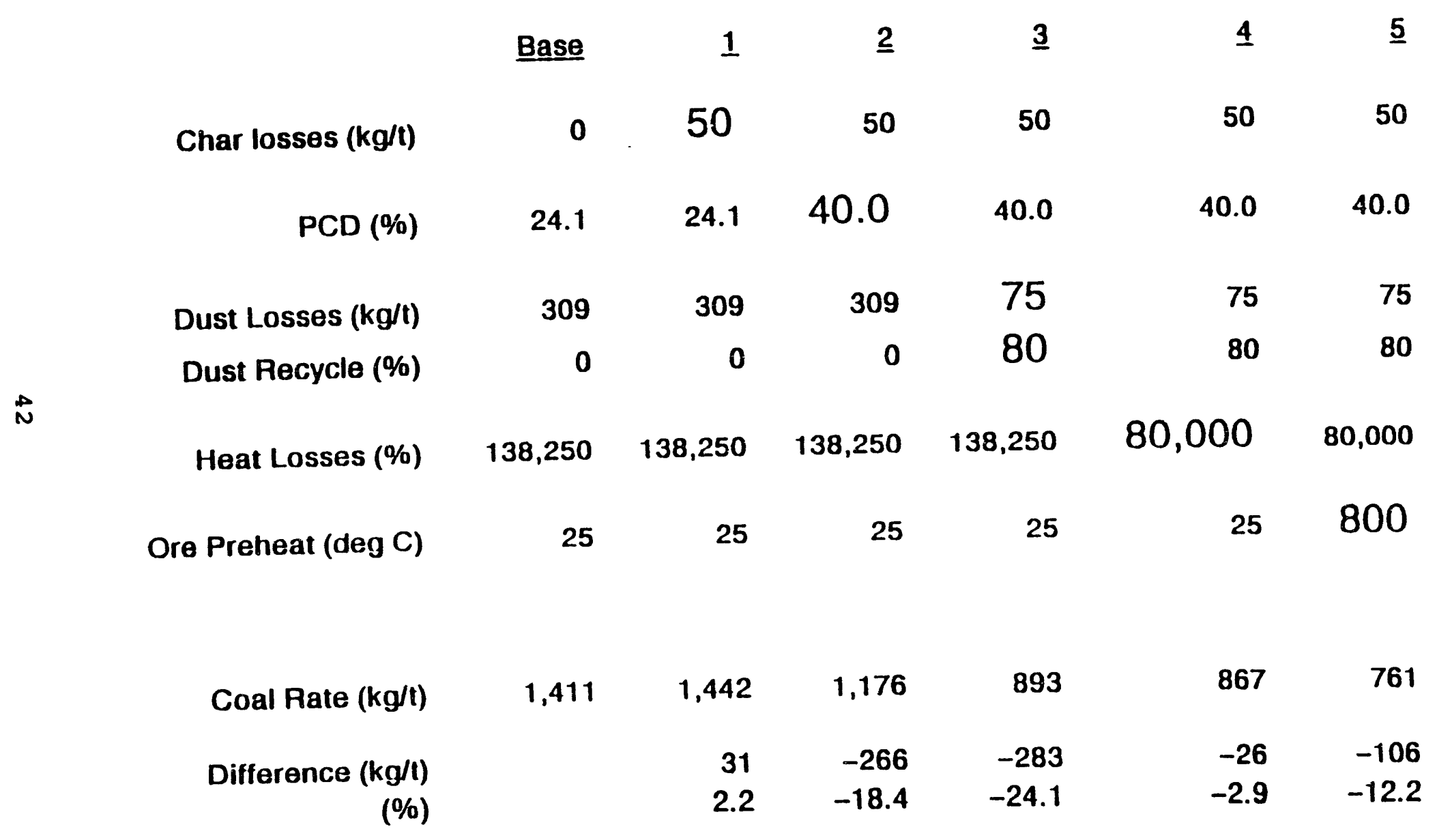


of the slag is not tapped. With continuous operation, the slag is foamy and may contain entrained char that would be tapped along with the continuous slag being tapped. This char penalty is estimated to be $50 \mathrm{~kg}$ per tonne of slag, which converts to $31 \mathrm{~kg}$ per tonne of hot metal. (Subsequent operation demonstrated that char entrainment is not a problem.)

In step 2, the degree of postcombustion is increased to $40 \%$ to reflect optimum blowing conditions and a vessel design accommodating a larger foamy slag volume. (A $40 \%$ PCD was achieved in trial 40 with a "soft" blow.) The increased PCD reduces the fuel rate by $266 \mathrm{~kg} / \mathrm{t}$.

In step 3, correction is made for improved treatment of the dust. With improved charging and offgas collection techniques in a commercial plant, it should be possible to reduce dust losses to $75 \mathrm{~kg} / \mathrm{t}$. In addition, most of the dust (estimated at $80 \%$ ) would be collected in hot cyclones and recycled to the smelter. since most of the dust is carbon and iron, prevention of the losses as experienced at the pilot plant would result in decreases in carbon losses of $229 \mathrm{~kg} / \mathrm{t}$, which is equivalent to a $283 \mathrm{~kg} / \mathrm{t}$ fuel rate savings for coal $C$, or $24 \%$.

In step 4, the heat loss per tonne of hot metal for the larger vessel is assumed to be $80,000 \mathrm{kcal} / \mathrm{t}$ rather than the $138,250 \mathrm{kcal} / \mathrm{t}$ calculated for the pilot plant from energy balances. This is approximately equivalent to a 0.75 power scaling law. The coal saving per tonne for these reduced heat losses per tonne is about $26 \mathrm{~kg}$.

In step 5, credit is taken for the fact that the wustite from the shaft furnace supplying the smelter in the commercial plant will be charged at $800^{\circ} \mathrm{C}$, rather than at $25^{\circ} \mathrm{C}$ as in the pilot plant. Coal savings for this credit are about $106 \mathrm{~kg} / \mathrm{t}$.

Thus, the fuel rate per tonne of hot metal for this coal, about $29 \%$ volatile matter, would be approximately $760 \mathrm{~kg} / \mathrm{t}$.

\section{Production Rate and Production Intensity}

The successful development and subsequent implementation of a special pipe sampling device, which enabled sampling the slag during blowing, led to an estimate of the quantity of metal droplets in the slag originating from the metal bath. These estimates indicate that the quantity of metal droplets suspended in the slag phase during the blow represents 0.6 and 1.2 percent of the weight of the metal bath contained in the converter under socalled "soft" and "hard" blowing conditions, respectively. This is much less than the fraction of the metal bath weight ( 4 percent) suspended as metal droplets in the slag phase as observed in the DIOS program. The difference can possibly be explained by the relatively low stirring energy ( $1 \mathrm{kw} /$ tonne) from the bottom gas 
stirring employed in the AISI smelter, as opposed to the DIOS practice in which bottom stirring energies up to about $5 \mathrm{~kW} /$ tonne are employed.

Following the analysis of Ibaraki et $a I^{7}$ published in the proceedings of the 1990 Ironmaking Conference, the overall apparent rate constant for reduction $\left(\mathrm{kmol} / \mathrm{m}^{2} \mathrm{~min}(\% \mathrm{Fe})_{\mathrm{T}}\right)$ is shown as a function of the specific slag weight $\left(\mathrm{kg} / \mathrm{m}^{2}\right.$ of vessel crosssectional area) in Figure 6.8. The data derived from the AISI trials are indicated by the various symbols and compared with the data obtained by Ibaraki et al represented by the upper straight line. It is seen that the apparent rate constant for the AISI data is not significantly affected by the type of pellet feed used (Feo or $\mathrm{Fe}_{2} \mathrm{O}_{3}$ ) nor by the blowing conditions ("soft" versus "hard"). The lower straight line represents the average of the AISI data.

Pilot plant production rates of 5 tonnes per hour were achieved. Limitations in oxygen supply and in the offgas handling system prevented greater production rates. Fruehan has converted the reaction rates of Figure 6.8 to production rates at operating pressures of one and three atmospheres and obtained rates of 40 and 62 tonnes per hour, respectively, Figure 6.9. For a 100 cubic meter vessel, the production intensities would be 9.6 and 15 tonnes per cubic meter per day, at one and three atmospheres, respectively.

The special pipe sampling device, which enabled the sampling of foamy slag during operation, was also used in a few trials in which copper was added to the hot metal. In general, the metallic iron in the foamy slag ranged from $10 \%$ to $20 \%$ by weight, and the copper concentration in the aggregated droplets was about half that of the hot metal, indicating that roughly half of the metal droplets in the foamy slag came from the bath and about half of the metal droplets formed in the slag from reduction of Feo.

The droplets ranged in size from a few microns to several millimeters. Metallographic examination indicated that the larger droplets were carbon-saturated and contained graphite flakes typical of those in carbon-saturated cast iron. The smaller particles showed various microstructures ranging from a lamellar eutectic microstructure to no apparent structure.

\section{Refractory Wear}

The original refractories in the smelter were selected based on expected conditions and oxygen converter experience. During the four lining campaigns, changes were made to the lining based on observed wear behavior, post-mortem analysis, simulated laboratory tests, and thermal and finite element analysis. Table 6.3 provides a listing of the lining components during the four lining campaigns, and Figure 6.2, presented earlier, shows a generic view of the lining construction. 
FIGURE 6.8

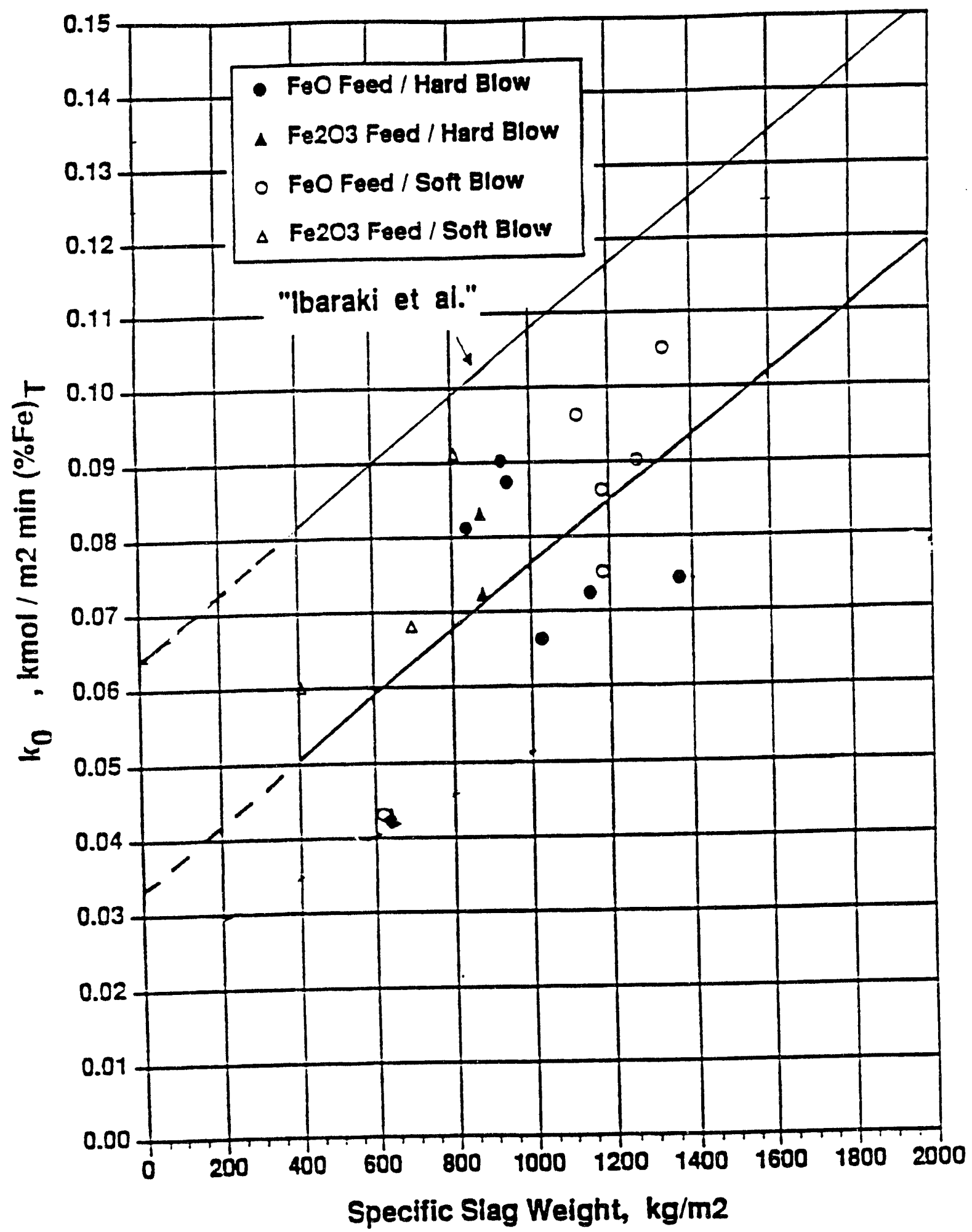


FIGURE 6.9

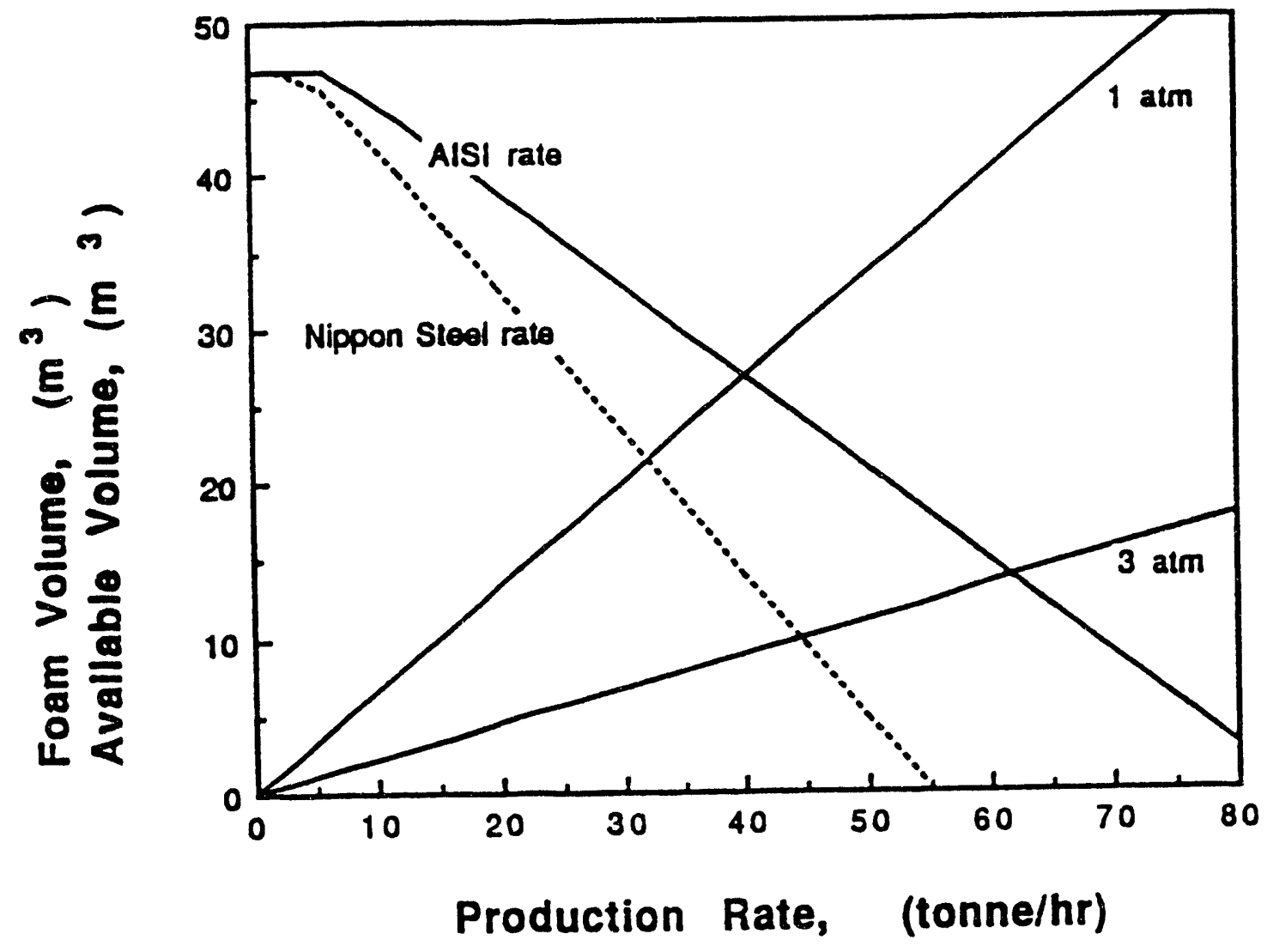

Production rate for a $100 \mathrm{~m}^{3}$ reactor using $60-65 \mathrm{~m}^{3}$. 
TABLE 6.3

\section{BARREL LINING CONSTRUCTION IN AISI SMELTER}

FOR INDICATED CAMPAIGNS

Item

Campaign

1234

Safety Lining

Working Lining

$\begin{array}{lllll} & \text { NARTAR } & \text { CARDIC } & & \\ \text { Stadium } & \text { PAD } & 713 & \text { BOF } 812 & \text { BOF } 812 \\ & \text { NARTAR } & \text { CARDIC } & & \\ \text { Barrel } & \text { PAD } & 713 & \text { BOF } 812 & \text { BOF } 812 \\ \text { Cone } & \text { AMR15E5CX } & & & \\ & & & \end{array}$

Improvements in refractory design and construction were made to provide increased wear resistance in the barrel and stadium zones and to increase the smelter volume. In all four lining campaigns, refractory wear was significantly influenced by smelter operating parameters, and AISI studies are still in progress to relate operating conditions to refractory wear. It would appear that satisfactory refractory wear rates may be obtained in the stadium and barrel sections of the smelter using high-quality magnesiagraphite refractories. Alternate containment methods such as water-cooled panels may be required in the combustion zone (cone and cone-barrel junction sections).

All of these products for the working lining are proven state-ofthe-art products for BOP/Q-BOP converters. The high-alumina safety lining products were proven in steel ladles and other environments.

The construction of these linings followed standard BOF construction techniques. On the last two linings, cardboard spacers were installed to permit additional vertical expansion and to prevent damage to the bolts holding the cone to the barrel.

During the four smelter campaigns, 49 separate trials were conducted to study different smelter performance characteristics and process variations which significantly influenced refractory performance. Each run involved a long smelter preheat followed by a sequence of process experiments. Figure 6.10 shows measurements taken inside the smelter in the fourth campaign as a function of 


\section{AISI SMELTER REFRACTORY WEAR}

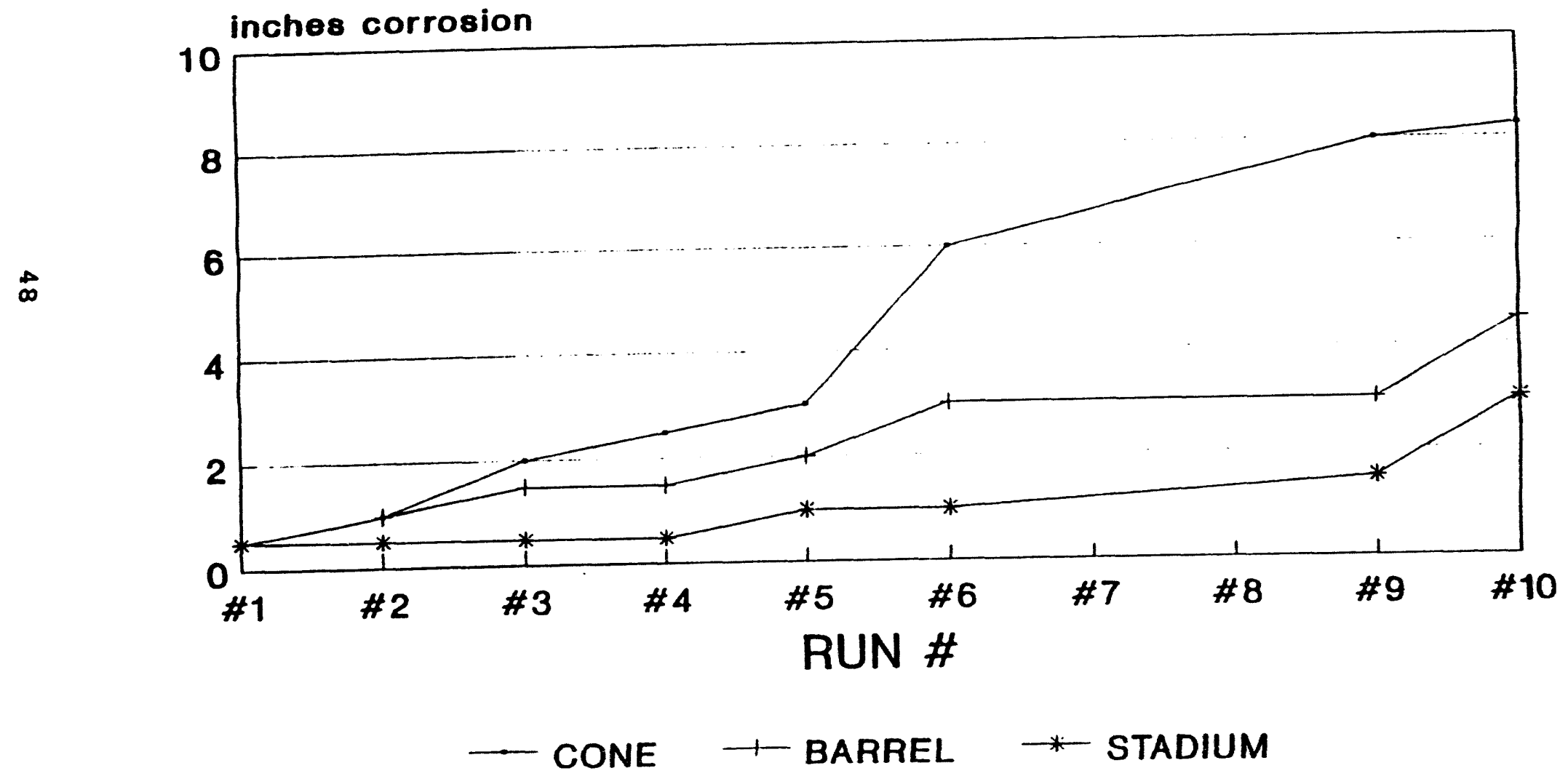


the trials indicated. As shown, the wear rates on individual trials vary considerably.

Because maximum wear rates are expected in the postcombustion $z$ one, alternative containment methods, such as the use of water-cooled panels (like those in electric arc furnaces), are under consideration.

The wear rates observed in the AISI smelter were undoubtedly influenced by the periodic nature of the operations. Some oxidation and accelerated wear were obvious on the initial preheat on magnesia-graphite refractories. The extent of oxidation on subsequent preheats on a given lining are not known but undoubtedly were reduced by the presence of a slag coating. On any commercial smelter, this effect would obviously be minimized. (Refractory samples from used brick at the end of a given campaign did not show any obvious hot face carbon loss.)

Thermal spalling or cracking effects from the periodic operation were also not obvious on the magnesia-graphite refractories but were apparent as spalling on the original burned-impregnated brick.

Used sample examination on the magnesia-graphite brick indicated that the main wear mechanism was related to high-temperature erosion-corrosion. This type of mechanism is known to be very temperature dependent. Wear increased by several orders of magnitude between 1600 and $1800^{\circ} \mathrm{C}$. The most wear appears to have occurred in the postcombustion areas where temperatures were maximum. Control of process temperature in this zone will be the most important factor in smelter refractory life.

In the cone and upper barrel, some accelerated vertical and horizontal joint erosion was also noted. The vertical joint erosion may indicate that too much expansion allowance was made between brick in a ring, and consideration will be given to reducing this allowance on similar future linings. The horizontal joint erosion observed mainly on lining \#4 was related to weakness in the patched upper cone flange which allowed the lining to loosen vertically. 


\section{TWO-2OLB 8KELTINO REACTOR: COMCEPT AND REBULTB OF PHYBICAI MODELIMG}

AISI developed a two-zone horizontal smelting reactor concept which consists of an ironmaking zone and a steelmaking zone separated by a vertical barrier with openings in it. The reactor acts as a twozone countercurrent smelter in which oxygen, iron ore, flux, and coal are added to both zones, such that there is no need for heat transfer across the zones. slag moves across the smelter in a direction opposite to the direction that the molten metal is moving (i.e., countercurrent). Slag in the oxidizing zone has a higher Feo content (about $15-20 \%$ ) than in the reducing zone (about 5\%). As the slag flows from the oxidizing zone to the reducing zone, the Feo is reduced out of the slag, and the slag is tapped at about 58 Feo or less. Therefore, there is no high feo content in the tapped slag to decrease yield. In the reducing zone, there is excess coal in the slag to permit fast reactions, and the metal is carbon-saturated. As the metal flows from the reducing zone to the oxidizing zone, the carbon content decreases to about $1-28$, and the metal is tapped out of the oxidizing zone. An Energy Materials-Kinetic model of the process suggests that the reduction (or production) rate may be twice as fast as for a single-zone smelter of a similar size.

The critical factor in the operation of the two-zone smelter is the crossmixing flow rate between the two zones. If there were no crossmixing of metal between the two zones, the flow from the ironmaking zone to the steelmaking zone would be equal to a fraction of the production rate in the ironmaking zone. However, due to bottom gas stirring and other operating conditions, wave motions are induced in the liquid metal and, consequently, backmixing occurs. To understand the phenomenon of backmixing and the effect of operating parameters on it, water modeling studies were conducted on a $1 / 2$ linear scale physical cold model.

\section{Experimental}

Figure 7.1 shows a schematic of the experimental set-up, and the experimental conditions are listed in Table 7.1. Water and oil were used to simulate steel and slag, respectively. The vessel was divided into two zones separated by a physical barrier. Potassium chloride was added to either of the zones as a tracer. Conductivity probes were used to determine the change in concentration with time in both of the zones. The effect of the following parameters on the backmixing rate was investigated: i) bottom blowing rate, ii) barrier design - number and area of openings, and iii) water and oil flow rates. 


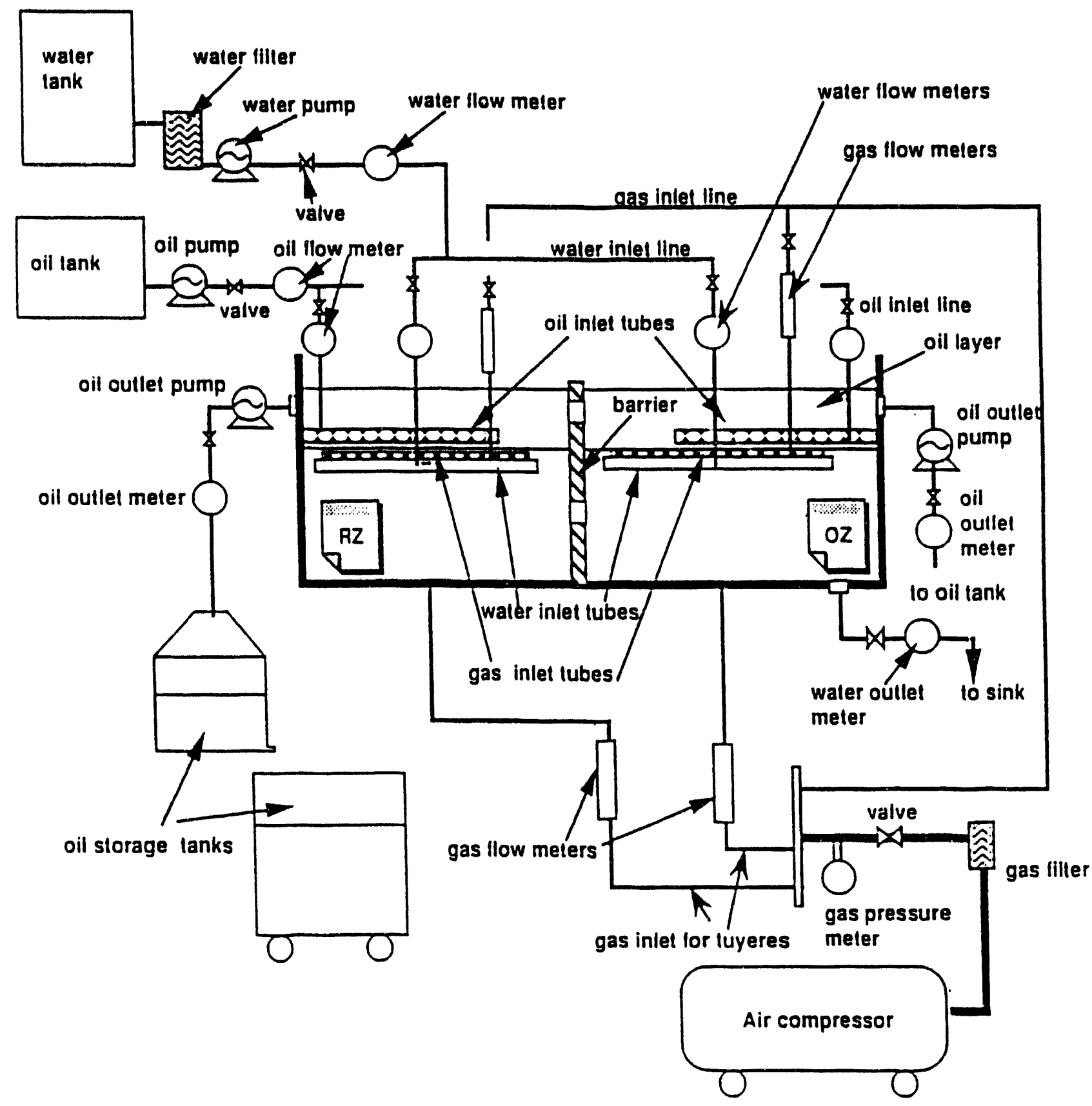

Physical model of two zone smelter 


\begin{tabular}{|l|l|}
\hline Table 7.1 Experimental Conditions \\
\hline Barrier Design & $\begin{array}{l}\text { Hole type barrier (water phase) } i \\
\text { Window type barrier (water phase) } \\
1 \text { inch over flow barrier (oil phase); } \\
1 \text { inch gap barrier (oil phase) }\end{array}$ \\
\hline $\begin{array}{l}\text { Water flow rate total } \\
\text { (l/min.) }\end{array}$ & $2--8$ \\
\hline $\begin{array}{l}\text { Bottom gas flow total } \\
\text { rate (l/min.) }\end{array}$ & $28.4--311.5$ (1 -- 11 scfm) \\
\hline $\begin{array}{l}\text { Top gas flow rate total } \\
\text { (l/min.) }\end{array}$ & $1133--1700$ (40-- 60 scfm) \\
\hline $\begin{array}{l}\text { oil flow rate total } \\
\text { (l/min.) }\end{array}$ & $1-4$ \\
\hline $\begin{array}{l}\text { Total water volume } \\
\text { (liters) }\end{array}$ & 440 \\
\hline Total oil volume (liters) & 62 \\
\hline
\end{tabular}

\section{Results}

Water modeling work indicated that the required concentration gradients between the two zones can be achieved by a simple shaped barrier. Backmixing in the water (metal) phase is proportional to the open area of the barrier and is independent of the number of openings. The backmixing flow rate was found to be expressed by equation (1), which was obtained from the solution of dimensionless mass balance equations for the tracer.

$$
Q_{B}=1.85 \times 10^{4}\left(\frac{S_{L}}{S_{L}-S_{g}}\right)^{0.4} \frac{A_{0}^{0.8}}{H_{L}^{0.2} W^{0.3}} \frac{Q_{g}^{0.3}}{Q_{f}^{0.56}} A^{1.15} S_{L}
$$

where,

$Q_{B}$ - backmixing flow rate (tph)

$H_{L}$ - depth of the bath (m)

$w$ - width of the bath (m)

$s_{L}$ - density of metal $\left(\mathrm{kg} / \mathrm{m}^{3}\right)$

$s_{g}$ - density of bottom stirring gas $\left(\mathrm{kg} / \mathrm{m}^{3}\right)$

$A^{g}$ - open area of the barrier $\left(\mathrm{m}^{2}\right)$

$A_{0}$ - area of the barrier in contact with metal $\left(\mathrm{m}^{2}\right)$

$Q_{\text {, }}$ - bottom gas flow rate $\left(\mathrm{Nm}^{3} / \mathrm{h}\right)$

$Q_{f}$ - production rate in ironmaking zone $\left(\mathrm{Nm}^{3} / \mathrm{h}\right)$ 


\section{CONSTRUCTION AND OPERATION OF THE HORIZONTAL VESSEL}

\section{Smelter Design}

The horizontal smelter consisted of an upper, water-cooled section and a lower, refractory-lined section. As shown in Figure 8.1 , the lower section was rounded at both ends and narrowed somewhat at the bottom in the cross section. Holes through the refractory were provided for charging of the vessel at the beginning of the experiments, for tapping of slag and hot metal, and for draining of slag and hot metal at the end of the experiment. The upper section was an enclosed, water-spray-cooled chamber with openings for the offgas system, material feed systems, oxygen lances, and sampling devices. The water system to the roof was equipped with flowmeters and thermocouples to accurately measure the roof heat losses. A radar slag foam height detector was installed for the last six trials. An infrared thermometer was also mounted on the roof to measure the gas temperature. A quartz window was installed for visual observation of the process.

\section{Construction}

Engineering for the horizontal vessel began in early 1991. A schedule was developed to accommodate vertical vessel operation through August, 1991. By mid-November, commissioning of the equipment was underway, and operations personnel began refractory dryout procedures and equipment checkout in the first week of December.

\section{Overview of Test work}

Twenty-one experimental trials were conducted. Table 8.1 lists the numbers of trials performed for the specified conditions:

\section{TABLE 8.1}

Number of Trials Number of Zones Number of Lances Iron Source

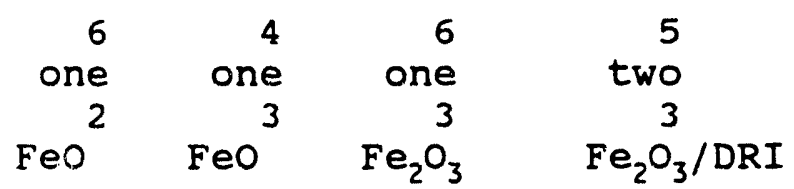

two lances, which was found to be The remaining fifteen trials were Ten of those trials were run with Five trials were run with a dam into two zones (steelmaking mode).

\section{one Zone Ironmaking}

The primary goals in the early ironmaking trials were to insure equipment reliability, verify heat and mass balances, and practice 

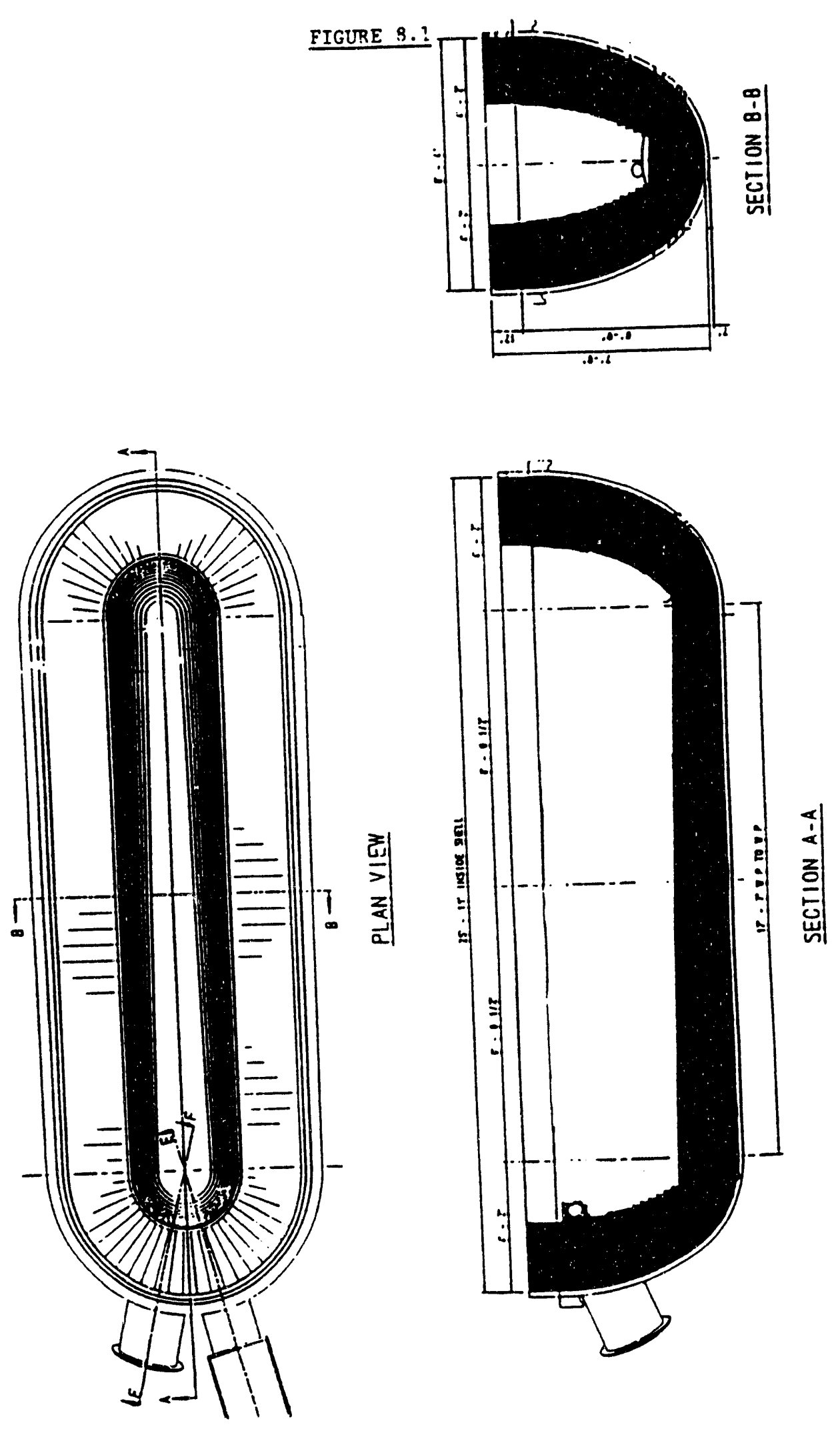
stable operation in preparation for the steelmaking trials. The third lance was installed after trial 6. It was difficult to achieve proper oxygen distribution and mixing at the center of the vessel, even after the installation of side air tuyeres. The problem was compounded by the raw materials entering the vessel between the lances and being moved toward the center of the vessel. The installation of the center oxygen lance solved this problem, and the process reacted in very much the same fashion as it did with the vertical vessel.

The last three trials, conducted after the steelmaking trials, focused on definition of the sulfur distribution between the hot metal, slag, dust, and offgas. Practices at both $30 \%$ and $40 \%$ PCD were established by adjustment of the lance with respect to slag foam height. Production rates in excess of $7 \mathrm{tph}$ were achieved. operating data were consistent with heat and mass balance models, with heat balance agreement generally within $5 \%$.

\section{Two zone steelmaking}

For steelmaking experiments, the vessel was divided into two zones by installing a refractory dam (see Figure 8.2 ). Two of the oxygen lances were located in the ironmaking zone along with the raw material feed chutes. The steelmaking zone was located at the end of the vessel directly under the offgas system. The single oxygen lance in the steelmaking zone was modified for the projected flow rates required for decarbonization. Provisions were made for manual feeding of raw materials into the steelmaking zone.

The concept was to operate each zone of the vessel relatively independently. The ironmaking zone was operated as steadily as possible, maintaining carbon saturation (excess char) and thermal control using the control strategies employed in previous experimentation. Carbon-saturated iron produced in the ironmaking zone flowed through a hole in the bottom of the dam into the steelmaking zone. There the metal was decarbonized by the oxygen lance, and low carbon metal was tapped from the steelmaking zone.

\section{Slag Management}

Slagmaking ingredients were added to the steelmaking zone at the beginning of each experiment to establish a small slag volume with a basicity $\left(\mathrm{CaO} / \mathrm{SiO}_{2}\right)$ of 1.6 or greater. slag in the ironmaking zone was maintained at basicities of 1.0 to 1.2 . When necessary to control the amount of slag in the ironmaking zone, slag was drained through a slag hole.

\section{Dam Hole size and Backmixing}

The two zone configuration of the horizontal vessel involved the physical separation of the ironmaking side from the steelmaking side by a refractory dam. Hot metal produced in the iron side 


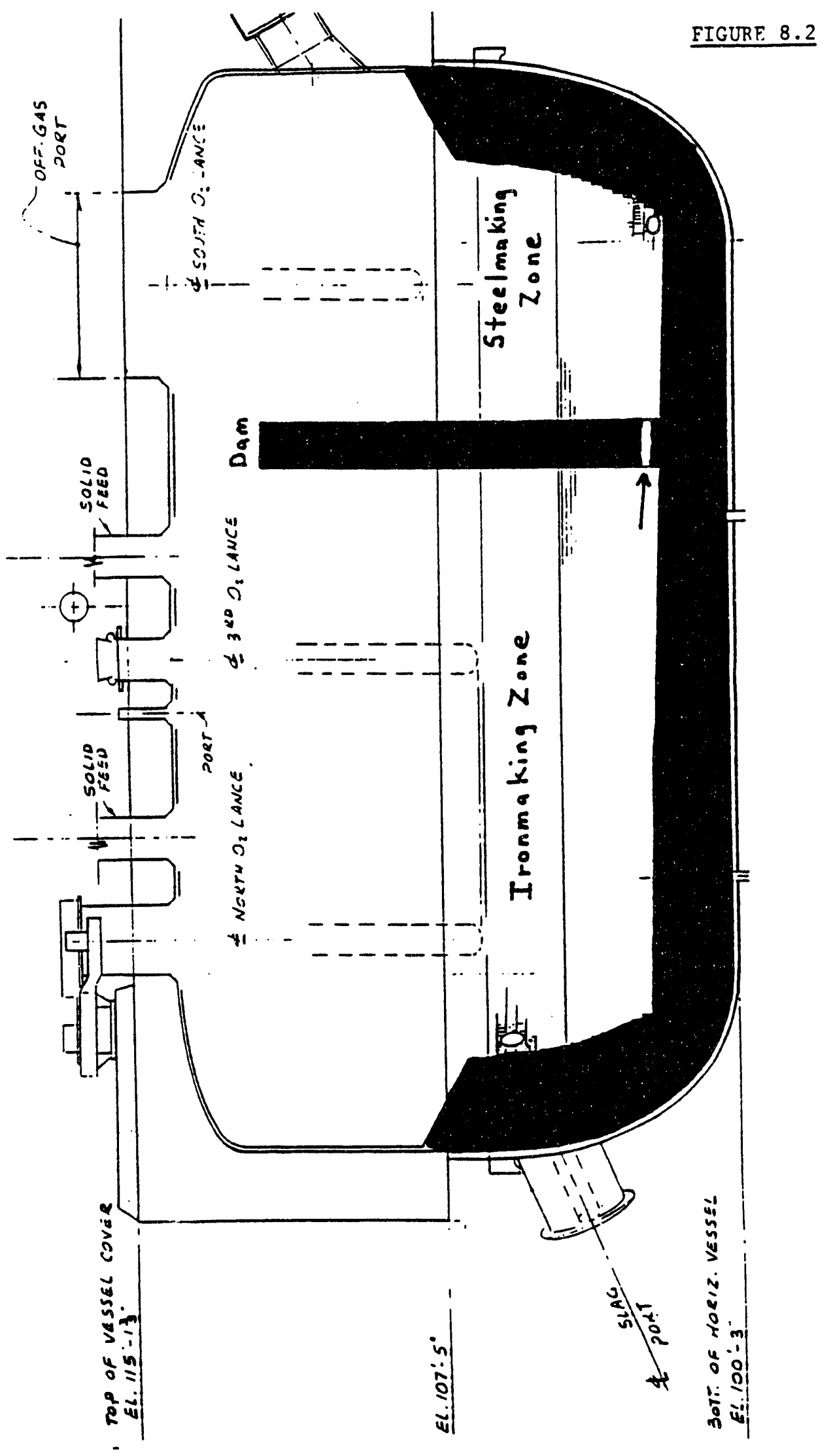


flowed through an opening at the bottom of the dam to the steel side where decarbonization was performed. Water modeling studies conducted by CMU and USS researchers reported in section 7 of this report indicated that the prevailing turbulent conditions would cause metal to flow from the steel side back to the iron side, and the rate of this backmixing or backflow was found to be proportional to the area of the opening under the dam. A knowledge of the backflow rate is required to be able to control the carbon content on the steel side.

In order to determine the backmixing rate, copper was used as a tracer and added to the steel side. Metal samples were collected periodically from the iron and steel sides and analyzed for the copper content. The rate of change of the copper content in the metal on the iron and steel sides is given by equations (2) and (3), respectively. These equations were obtained by solving the mass balance for copper.

(2)

$$
\frac{d C_{i}}{d t}=\frac{Q_{b}}{(1-x)\left(W_{T, 0}+W_{p} t\right)}\left[\frac{W_{T, 0}\left(C_{i, 0}+x\left(C_{s, 0}-C_{i, 0}\right)\right)-\left(W_{T, 0}+W_{P} t\right) C_{i}}{x\left(W_{T, 0}+W_{p} t\right)}-W_{P} C_{i}\right]
$$

$$
\frac{d C_{s}}{d t}=\frac{Q_{b}+x W_{P}}{x(1-x)\left(W_{T, 0}+W_{P} t\right)^{2}}\left[W_{T, 0}\left(C_{i, 0}+x\left(C_{s, 0}-C_{i, 0}\right)\right)-\left(W_{T, 0}+W_{P} t\right) C_{s}\right]
$$

where,

$Q_{B}=$ backmixing flow rate (tph)

$W_{p}=$ production rate in ironmaking side ( $\left.t p h\right)$

$\mathrm{W}_{\mathrm{T}, 0}=$ initial weight of liquid metal

$c_{s, 0} \& C_{i, 0}=$ initial concentration of $\mathrm{Cu}$ in steel and iron sides

$c_{s} \& C_{i}=$ concentration of $c u$ at time $t$ in steel and iron sides

and $\quad \mathbf{x}=$ weight fraction of steel side.

Equations (2) and (3) were solved numerically to obtain the rate of backmixing from the data obtained in the copper tracer experiments.

Figure 8.3 shows the data obtained along with the predicted concentrations (represented by lines). The dam opening was successively reduced for the next three trials to result in backflow rates of $5 \mathrm{tph}$.

In Figure 8.4, the backflow index is plotted against the initial area index of the opening under the dam. A linear relationship 


\section{$H-14$, casting rate $=0$, tracer input in steelmaking side}

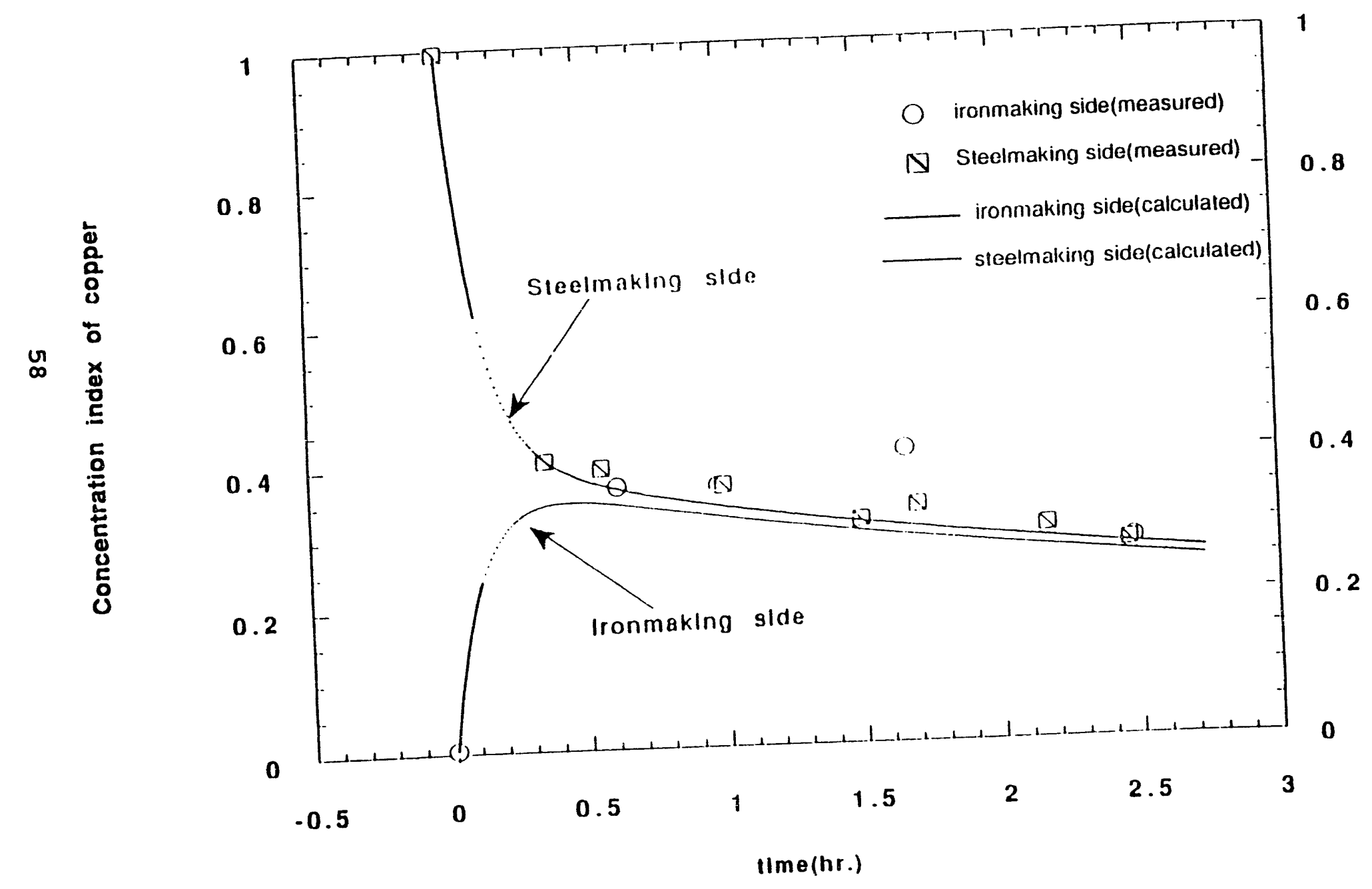


Back flow Index vs. Open area Index In the dam

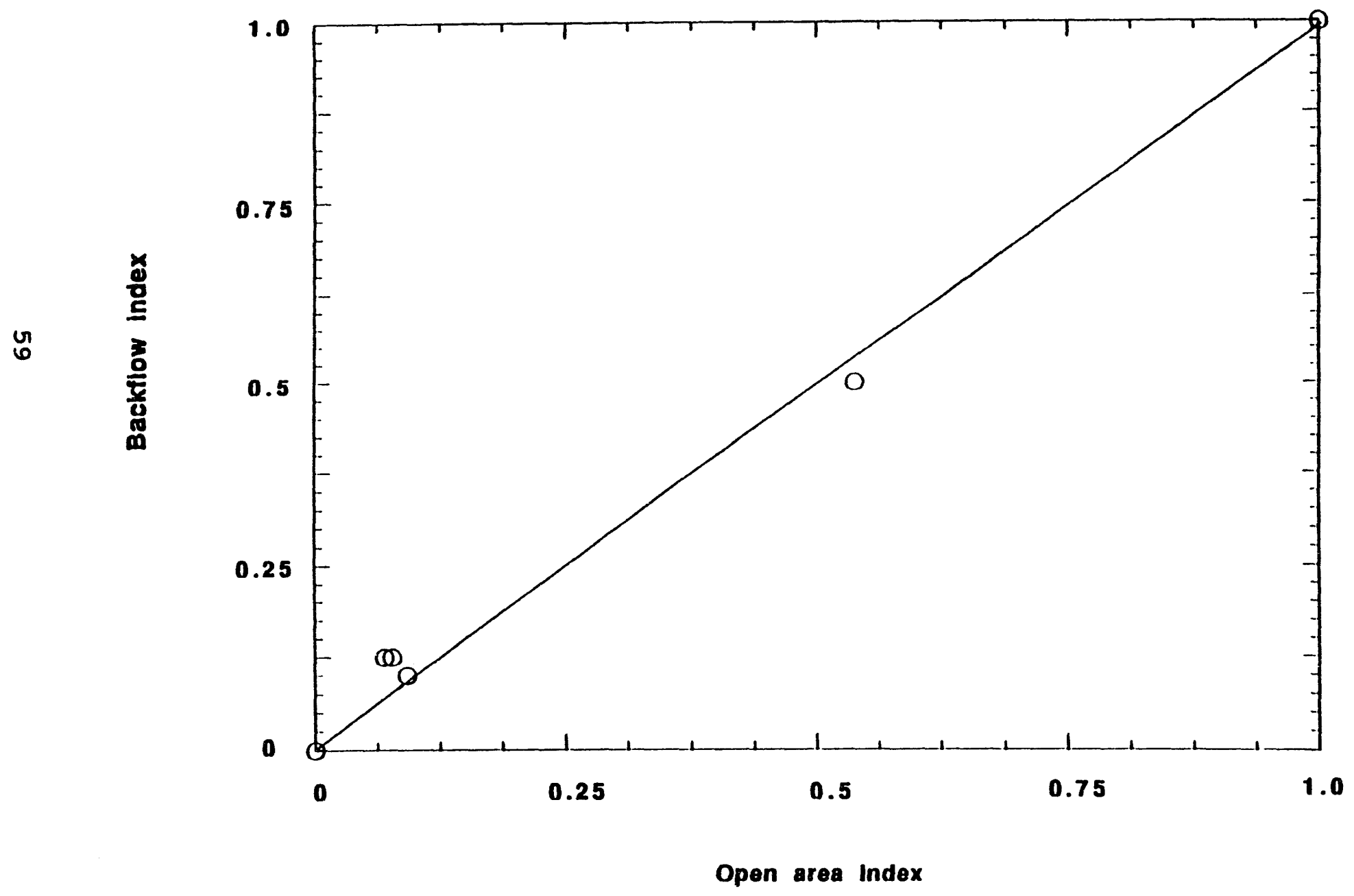


between the backflow index and the opening area index was obtained. This was consistent with the results obtained from the water model studies. Thus, based on mass balance equations and copper tracer experiments, it was possible to design the opening of the area under the dam to obtain a backflow rate of $5 \mathrm{tph}$.

\section{operating practices}

Coke was used with hematite and DRI to achieve high production rates with the reduced volume (about $2 / 3$ of the vessel) of the ironmaking zone. Stable operation was achieved at $40-60 \%$ PCD with production rates of 7 - $9 \mathrm{tph}$.

\section{Carbon Balance and control}

All of the elements of the carbon balance may be measured directly from operating parameters except the sum of the carbon from backmixing and from dissolution, which may be calculated by difference. By projecting the carbon from backmixing and dissolution from previous values, it may be possible to predict the expected carbon accumulation (or depletion) in the steelmaking zone. This would then serve as the basis for a carbon control strategy in which the oxygen flow rate would be adjusted to achieve the desired carbon accumulation or depletion (zero at steady state).

\section{Application of Carbon Control Principles to operating Data}

Data from the steelmaking trials were used to evaluate the prediction of the carbon level from previous operating data. For each sample period, the carbon from backmixing and dissolution was calculated by difference. Weighted averages of the last three sample periods were used to estimate the carbon from backmixing and dissolution for the next sample period. The predicted carbon level for the end of the next sample period was then calculated from the carbon balance.

\section{Discussion of Operating Results}

During the experiments, oxygen flow rates were adjusted in increments of $100 \mathrm{Nm}^{3}$ to observe the effect on carbon level in the steelmaking zone. Other factors, such as variations in production, casting, backmixing, and dissolution, affected the carbon levels as described by the carbon balance. In this manner, carbon levels down to $1.0 \%$ were achieved, and the principle of carbon control by oxygen flow rate adjustment was demonstrated. Equipment and time limitations prevented extended periods of control at low carbon levels, however. 


\section{Conclusions}

The feasibility of producing low carbon iron in a two-zone smelter was demonstrated. It was also apparent that separation of the vessel into high and low carbon zones would be impossible without physical separation by the dam and that considerable backmixing would result due to the turbulent conditions, despite the presence of a dam. 


\section{DVALUATION OF DIRECT gTEELMARING PROCES8ES}

The AISI Direct steelmaking Program formed a task force to examine existing and some proposed processes for refining the metal produced from the AISI smelter; the analysis is also applicable to blast furnace hot metal. After initial screening, the following processes were examined in detail: Trough Processes (COSMOS, WORCRA, etc.), Posthearth Refining, IRSID Continuous steelmaking, EAF, and EOF (Energy Optimizing Furnace). The detailed technical analysis included development status and critical issues such as productivity, yield, and degree of refining.

The major findings are summarized below:

Trough Processes -- The detailed analyses indicated that these processes may work in theory, but heat losses would be excessive and the complications far exceed any advantages. The processes were not as promising as the IRSID process.

Posthearth Refining -- There are potential advantages and considerable complications associated with refining in the posthearth of the smelter. Subsequent experiments showed that there is adequate slag/metal separation and virtually no char entrainment, so that a posthearth will not be required.

IRSID -- The IRSID process is a reasonably well proven process that continuously produces metal similar to a BOF. It has similar operating costs and considerably lower capital costs as compared to the BOF. In the IRSID process, hot metal is continuously fed into a reactor. An oxygen jet impinges onto the metal, causing almost all of the metal to be emulsified. The emulsion overflows into a decanter or settling vessel in which slag-metal separation takes place and the metal is tapped. Carbon in the metal droplets in the emulsion reacts with the oxygen to decarbonize the droplets. The average residence time of the droplets in the emulsion determines the degree of decarbonization.

EAF -- The EAF process is well proven. Some overseas steel companies are making extensive use of hot metal in their EAF shops to provide additional iron units.

EOF -- The EOF produces steel higher in sulfur, and scrap must be Iimited to 50 - $60 \%$ to avoid operational and residual element problems. The EOF has similar operating costs to the BOF and may have considerably lower capital costs.

The study concluded that there is insufficient technical or economic incentive to replace a working BOF with any of these processes to refine hot metal. However, if new or incremental steelmaking capacity is required, the IRSID and EOF should be considered. Both have lower capital costs, and the EOF has the 
flexibility to melt more scrap. The IRSID process could be developed with a pilot plant associated with the AISI smelter. The EOF could be further evaluated with well designed and controlled tests at an existing EOF facility.

A fully continuous process from ironmaking to casting was considered. The capital and operating cost savings that could be achieved beyond those for direct ironmaking and continuous refining are relatively small. A fully continuous process should not be considered until direct ironmaking and continuous refining are perfected.

The Evaluation of steelmaking Processes was issued as a topical report [DOE/ID/12847-5 (DE94005368)] in January, 1994, and is available from the office of scientific and Technical Information, P.O. Box 62 , Oak Ridge, TN 37831 . 


\section{COIBTROCTIOA NWD OPERATIOA OF PRESBURIZED VERTICAL VES8EL AND OFTOAB BY8TEA}

\section{Desion and Construction}

Mannesmann Demag designed, detailed, and supplied the major components for the pressurized smelter, lances, and associated material feeding systems, designed to operate at a pressure of 1.7 atmosphere absolute.

Hatch Associates managed the engineering and construction of the project as well as designing the offgas system. Figure 10.1 is a schematic of the overall system. The system began operation in July, 1993, after work was completed to assure the integrity of the pressurized system.

\section{operations}

Various modifications to the feed systems, the lance, the vessel itself, and the offgas system were carried out as dictated by the early trials. By the tenth trial, controlled stable operation was routine.

Because the smelting reduction mainly takes place in the foamy slag and is proportional to the Feo content of the slag, it is important to know the volume of the slag as well as its Feo content for good process control. The radar foam height detector mentioned in the section on the horizontal vessel had proven unsatisfactory as a foam height detector. Fortunately, the process model can predict the slag volume, although it is a function of many variables, and these predictions are used for process control.

Perhaps the most significant result from the first twelve trial: is that the process model works and that it can be successfully used as the basis for process control. Its success confirms that the process is well understood and that the model can be used for scale-up purposes.

Because the model requires the offgas composition as input, much of the success of the model is due to the accuracy and reliability of the offgas analysis system. Smelter offgas is sampled both in the offtake hood and in the duct after the hot cyclone. Sampies are taken constantly through heat-traced lines and are either vented or presented to two mass spectrometers. Dual filters with back-flusl: features are provided for each line with automatic back-flush cycles. The heat tracing is important to prevent condensation of water vapor in the lines prior to analysis so that the true degree of postcombustion can be properly inferred. 


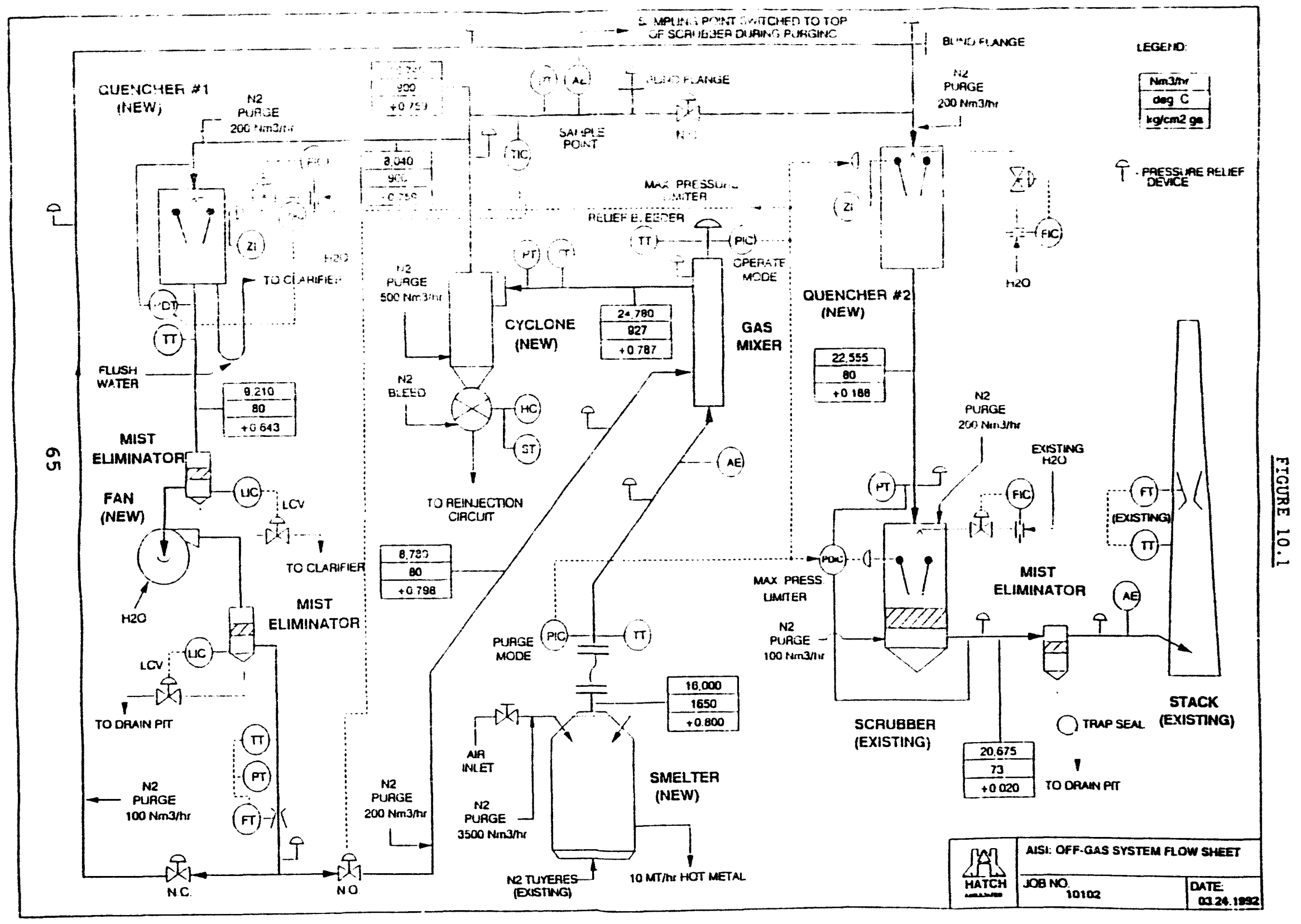




\section{Slag}

Considerable problems have been experienced in tapping slag from the smelter and in runner cleanup following a cast. The slag used in the process has a lime-to-silica ratio ranging from 0.8 to 1.3 and is saturated with Mgo to minimize dissolution of the magnesia lining. This slag has a tendency to freeze in the tap hole and in the runner. Physical changes were made in tap hole length and insulation to minimize the heat losses. The diameter of the tap hole has also been increased, and the mud gun has been remounted to facilitate closing the tap hole. These changes have largely eliminated the slag tapping problem.

\section{Gas conditioning Loop}

The pilot plant does not have a prereduction shaft furnace but was designed with a gas conditioning loop to simulate the loop that must be used to condition the smelter gas before it can be used in a prereduction shaft furnace. such conditioning involves controlling the gas temperature as well as removing some of the dust and alkalis contained in the smelter offgas. This is accomplished by passing part of the gas exiting the cyclone through a scrubber. The cooled gas then is mixed with smelter of fgas in a mixing chamber located before the cyclone to control the gas temperature. Several changes have been made in this system to obtain proper operation.

\section{Cyclone Dust Re-injection}

The dust collected by the cyclone has ranged from $100-400 \mathrm{~kg} / \mathrm{hr}$, depending on the carbon source. For the process to be efficient, the iron and carbon in this dust must be recovered by re-injection into the smelter. Re-injection rates of $400 \mathrm{~kg} / \mathrm{hr}$ have been achieved for several hours of operation. However, dust re-injection is complicated by stops in the process, during which time re-injection must also be stopped. During these stops, slag has a tendency to build up on the re-injection tuyere which decreases and/or stops the dust re-injection.

\section{Improved Process Thermal Efficiency}

For the first 11 trials, the water-cooled hood on the smelter was not insulated, resulting in heat losses of from 1.2 to $2.2 \mathrm{giga}$ calories per hour (Gcal/hr). During the vessel reline after trial 11, it was decided to insulate the hood with 3 to 4 inches of gunned refractory to increase the duct temperature sufficiently to allow operation of the gas loop at design conditions. prior to installing this insulation, the high heat losses resulted in a low duct temperature precluding the operation of the recycle system to provide a simulated shaft furnace gas at a temperature of $900 \mathrm{C}$. In trial 12, the insulation in the hood increased the duct temperature to as high as $1200 \mathrm{c}$, permitting operation of the 
recycle system at design conditions, although the cyclone temperature was higher than the design of $900 \mathrm{C}$ because of problems in getting adequate gas flow in the recirculating loop. This has subsequently been resolved. The insulation also decreased the heat losses to 0.5 to $1.0 \mathrm{Gcal} / \mathrm{hr}$ for a saving in process heat of 0.2 to $1.2 \mathrm{Gcal} / \mathrm{hr}$.

\section{Refractories}

The design of the refractory lining for the third vessel was based on experience with the first vertical vessel and the second (horizontal) vessel. Special attention was paid to reducing lining and shell stresses based on finite element analysis and to providing the best cooling for the magnesia-graphite brick used in front of the copper stave coolers in the upper part of the vessel. The initial lining was replaced after the tenth trial.

Used magnesia-graphite brick from the uncooled areas showed no cracking and showed similar wear mechanisms to prior campaigns. Brick from the stave-cooled areas showed less wear. Retention of metallic phases and less oxidation of the brick provided obvious evidence of the steeper temperature gradients.

The good performance of the water-cooled copper panels in the cone and upper barrel section of the vessel suggest that the panels should be extended to the mid-barrel section where refractory wear is high.

\section{Environmental}

An environmental assessment of the process indicates that it will place little stress on the environment. The solids are hot metal, slag, and sludge which can be sold or disposed of normally. It may be possible to recycle the sludge after appropriate dewatering.

The water effluent meets the current iron and steelmaking standards and the specific pollutant limitations of the Allegheny County (PA) Sanitary District (ALCOSAN), see Table 10.1, below.

\section{TABLE 10.1}

\begin{tabular}{lccc} 
Pollutant & $\begin{array}{c}\text { Pretreatment } \\
\text { Standard }\end{array}$ & $\begin{array}{c}\text { ALCOSAN } \\
\text { Limits }\end{array}$ & $\begin{array}{c}\text { Scrubber } \\
\text { outlet }\end{array}$ \\
\cline { 2 - 3 } (milligrams per liter) & & \\
Ammonia-n & 29.8 & -- & 5 to 6 \\
Cyanide & 2.0 & 1.5 & $<0.12$ \\
Phenols & 0.2 & 60 & $<0.13$ \\
Lead & 0.9 & -- & $<0.4$ \\
Zinc & 1.3 & -- & $<0.4$
\end{tabular}


Below is a brief description of the process control system, the Data Acquisition system, the Sampling and Analytical Procedures, and the Sublance performance.

\section{Process Control}

The process control system includes a backpanel that has the controllers and digital readouts necessary to enable the operator to safely operate or shut down the facility in the event of a computer failure. All critical valves are fail-safe to open or close in the proper direction to put the plant into a safe, stable condition in the event of a power or control failure. The safety circuits in the Level 1 computer system interlock all critical valves and sequences.

The plant is controlled from the pulpit that is equipped with five monitors connected to the Level 2 computer and an alarm screen. The process is almost "operator ready" as opposed to being operated by engineers. The process is controlled $90 \%$ of the time through three overview screens and one data trend plot. During a trial, the process is also monitored by the process engineers using four additional monitors and two PCs.

The Level 2 computer system is also used to control and monitor the operation of the process through graphical representation of several systems and sequences. Examples of these are: 1) cooling water flows and temperatures in and out of the cooling water circuits, 2) vessel refractory thermocouples in the working lining and on the shell, 3) operator startup and shutdown sequencing screens, 4) alarm screens with red and yellow alarms to indicate different levels of alarms, 5) graphic screens to represent different equipment groups and control systems, and 6) screens to start and stop equipment and to change set points.

Sensors that were needed for scale-up criteria or plant operation were installed and kept calibrated. Cross checks, i.e. a nitrogen flow transmitter that reads the total flow of nitrogen to the plant to check the individual flow transmitters, were installed to verify flow rates. Redundant sensors were installed in areas where a critical variable was being measured, $i . e$. three offgas temperature thermocouples and dual filter streams for the offgas analysis.

A safety analysis of the control systems and operating procedures was also conducted that included additional sensors to protect personnel and equipment. The instrument and control systems have been very carefully studied and reviewed and are as good as or better than many systems that are being used to run full-size plants. 


\section{Data Acquisition System}

The pilot plant data acquisition system provides on-line and historical process data for evaluation and analysis. These data consist of:

- Continuous measurements provided by modern industrial transmitters/controllers and analyzers connected through the plant's programmable logic controllers.

- Laboratory chemical analysis provided through a communications link to the laboratory computer.

- Manually entered data, such as raw material composition, tap weights, and tare weights.

- Calculated values based on the sensor inputs, i.e. heat losses, flow rates, and feed rates.

There are 313 analog points, i.e. pressures, temperatures, and flows, that are scanned by the Level 2 system every four seconds. The historical database then stores the one-minute averages of the four-second scans. For detailed evaluation for selected points, the four-second scans are stored in a special file. The screens that are used to monitor and control the process are updated every eight. seconds.

There are 916 digital points, i.e. pressure switches and on/off switches or controls, that are scanned every second to determine when they change state. These are used during the evaluations to tell when equipment is running, e.g. West rotary valve. They are aiso used by the operators or the control logic to start and stop equipment or sequences of events.

There are roughly 2000 calculated variables that are kept in the historical database. About one-half of these are calculated every four seconds, and the one-minute averages are stored, e.g. lance heat loss. The other half are balance-type variables that are run and stored once a minute, e.g. oxygen balance. These variables are stored to make the on-line and post-evaluation of the trial more manageable. The variables are calculated with the real-time data and can be plotted in real time or as a four-hour historical plot.

\section{Transmitters Accuracy}

The pilot plant staff services, maintains, and calibrates all of the transmitters, controllers, sensors, and thermocouples and maintains records to ensure that every instrument is maintained and calibrated. During calibration checks, the instruments within $0.5 \%$ of range are not recalibrated. It has been found that $90 \%$ of the transmitters meet the $0.5 \%$ criteria and do not require recalibration when checked. All calibration instruments are 
maintained and calibrated by a local instrument contractor with standards certified by the National Bureau of standards.

\section{Gas Analyzer Accuracy}

The two Perkin-Elmer Mass Spectrometer Gas Analyzers are calibrated with certified analysis gas samples before and after each trial run. In addition to the calibration, the computer maintains a calculated bias between a measured standard sample analysis and a gas with a certified analysis. This bias is applied to the analyzer-reported values to provide a corrected analysis value due to analyzer drift.

The analyzers are equipped with state-of-the-art sample conditioning systems which include dual filter streams with dual pumps and filters for each system and a full heat tracing system from the duct to the analyzer to prevent condensation of water vapor. This dual redundant system is necessary to assure that accurate gas analysis is always available for the mass balance, postcombustion control, and safe operation of the offgas system.

\section{Laboratory Sampling Procedures}

To provide the most accurate and timely data possible for both operations and research, a set of guidelines for sample collection and preparation and for analysis reporting has been prepared. The key points of these guidelines are proper identification and recording of samples to allow for proper tracking and to ensure that the analyses are conveyed to the appropriate personnel upon completion.

A Sample Record Log is kept in the Sample Lab which provides an audit trail to connect analyses with samples. Samples are entered into the log on arrival, and a unique, sequential Sample Identification Number is assigned. This sample ID is noted in the $\log$ and on either the sample or the sample container. This number is also used to identify samples when they are sent to outside laboratories and to identify the analyses upon return.

Turnaround time for outside analyses is somewhat variable, but most analyses are complete within five working days of receipt of sample. Samples are normally sent out one or two days following the trial. Samples that are routinely sent out for analysis include raw materials, clarifier and scrubber sludge, slag samples, cyclone dust, and water. Samples that are analyzed in-house include hot metal, slag, cyclone dust, clarifier sludge, and scrubber sludge.

Raw material sampling -- To provide the data required for the material balance programs, it is necessary to analyze the raw materials used for the trial. Samples of each raw material are analyzed both upon delivery and the day before the trial. Samples 
are also collected during the trial; these samples are screened for size (if appropriate) and stored for future analysis, if necessary.

Hot metal samples are taken using the sublance probe during normal operation. other samples are taken during casting. These consist of a "lollipop" sample taken at the beginning of each cast and a mold sample taken with a spoon at roughly the midpoint of the cast. The in-trial analyses are transmitted from the spectrometer control computer to the mainframe computer as soon as posible. The slag sampling practice for the vessel calls for spoon samples to be taken during casting operations using the sublance probe.

In addition to the raw materials, metals, and slags, there are samples that are primarily concerned with the offgas dust system. The materials which are normally sampled are the cyclone dust, clarifier sludge, and scrubber sludge.

Cyclone dust is sampled during and after the trial. Clarifier sludge is sampled from the vacuum belt as the clarifier is emptied. Scrubber sludge samples are taken at least once an hour during the period of sludge output. Contact water samples are collected at the inlet pump and two other locations. The samples are collected in a one-galion plastic container. Scrubber sludge samples are vacuum-filtered through a 20 micron filter. The solids are then baked in the oven at $135 \mathrm{C}$ for 24 hours. The dry solids are weighed, and the weight is recorded as grams per gallon in the clarifier/scrubber sludge. These samples are then taken to the spec Lab for carbon and sulfur determination and additional analysis.

Raw material feeder samples -- During a trial, samples are collected from the raw material feed system every hour in order to provide information regarding material size distribution and to collect samples to be stored for possible future analysis.

The Spec Lab is well-equipped with a broad array of certified standards for use in calibration of the Leco CS-444 Carbon/Sulfur Analyzer and the Philips $1480 \mathrm{X}$-ray spectrometer.

Review of Information Obtained with the sublance

Three different types of probes are used with the sublance, all of which are supplied by the Electro-Nite Company. They are:

1. TEMPERATURE ONLY

This probe normally provides a single measurement of the metal temperature.

2. TEMPERATURE - SLAG - SAMPLE

This probe also provides a metal temperature measurement. In addition, it retrieves physical samples of the metal and slag for laboratory analysis. 
3. BATH LEVEL

This probe has two electrodes spaced apart at the tip. The height of the probe relative to the smelter floor is continuously monitored while the probe is lowered into the smelter. The bath level is detected by recording the probe tip height when the tip first contacts the slag or metal surface as evidenced by the establishment of electrical continuity between the electrodes.

Experience has shown that a good temperature reading is obtained during $70 \%$ of the attempts, and a good slag sample is obtained $75 \%$ of the time, but the bath level detector has only worked $50 \%$ of the time and a good metal sample was obtained only $25 \%$ of the time.

When a probe fails, the reasons for the failure are evident in many cases. Several failed probes were clearly bent and/or broken, apparently due to collisions with a solidified skull or some other solid material in the smelter. Also, in trial 7, several probes were clearly burned up due to direct impingement by the oxygen lance jets; this problem was averted in subsequent trials by checking the clearances in front of the secondary oxygen lance nozzles and raising the oxygen lance to a safe position before lowering the sensor lance. In several cases, there was no clear indication of the causes of probe failures.

The problem with the bath level measurements was not solved by the end of the trial program. However, the root cause was later found to be a new cement that was used on the entire last shipment of probes to seal the tips into the base of the probe. The cement failed, allowing the metal to get around the tips and melt the wires before a signal could be sent. The entire shipment of probes was returned, and new probes will be assembled for the Recycling Program.

A problem with many of the metal samples is that the metal sample either has slag in it or is too porous to make a good button for the $X$-ray spectrometer. However, enough metal is usually obtained to run a carbon analysis. There have been times when a carbon analysis was run to help determine that the process was in control, i.e. that the metal was carbon-saturated. For on-line control, the data needed from the sensor lance are temperature, slag basicity, slag Feo, and hot metal carbon. During later trials, the success rate of temperature and slag samplings has reached the $90 \%$ level, and the sublance has been quite reliable.

\section{Trials}

Nineteen trials were conducted with the third vessel for the period from July 8, 1993, through March 27, 1994. Table 10.2 lists the coal type, ore type, lance type, and duration of each trial. The early trials were directed toward identifying and remedying operating problems, the middle trials were directed at exploring 
TABLE 10.2

Trial summary

\begin{tabular}{|c|c|c|c|c|c|}
\hline Trial No. & Date & $\begin{array}{l}\text { Coal } \\
\text { Type }\end{array}$ & $\begin{array}{l}\text { Ore } \\
\text { Type }\end{array}$ & $\begin{array}{l}\text { Lance } \\
\text { Type }\end{array}$ & Duratior. \\
\hline 1 & $7 / 8 / 93$ & Mid-Vol & Hematite & L1 & $3.3 \mathrm{hr}$ \\
\hline 2 & $7 / 21 / 93$ & Mid-Vol & Hematite & L1 & $5.4 \mathrm{hr}$ \\
\hline 3 & $7 / 30 / 93$ & Mid-Vol & Hematite & L1 & $4.5 \mathrm{hr}$ \\
\hline 4 & $8 / 12 / 93$ & Mid-Vol & Hematite & LI & $1.9 \mathrm{hr}$ \\
\hline 5 & $8 / 24 / 93$ & Mid-Vol & Hematite & L1 & $10.2 \mathrm{hr}$ \\
\hline 6 & $9 / 1 . / 93$ & Mid-Vol & Hematite & L1 & $6.2 \mathrm{hr}$ \\
\hline 7 & $9 / 14 / 93$ & Mid-Vol & Hematite & $\mathrm{L} 2$ & $3.0 \mathrm{hr}$ \\
\hline 8 & $9 / 9 / 93$ & Mid-Vol & Hematite & L3 & $7.0 \mathrm{hr}$ \\
\hline 9 & $10 / 5 / 93$ & Mid-Vol & Hematite & L3 & $10.0 \mathrm{hr}$ \\
\hline 10 & $10 / 14 / 93$ & Mid-Vol & Hematite & L3 & $11.3 \mathrm{hr}$ \\
\hline 11 & $11 / 9 / 93$ & $\mathrm{High-Vol}$ & Hematite & L4 & $8.0 \mathrm{hr}$ \\
\hline 12 & $3.1 / 18 / 93$ & High-Vol & Hematite & I4 & $8.3 \mathrm{hr}$ \\
\hline 1.3 & $12 / 7 / 93$ & High-Vol & Hematite & L5 & $10.0 \mathrm{hr}$ \\
\hline 14 & $12 / 17 / 93$ & Low-Vol & Hematite & L5 & $9.4 \mathrm{hr}$ \\
\hline 15 & $i / 13 / 94$ & $\begin{array}{l}\text { Coke, } \\
\text { low- \& } \\
\text { hLgh-vol }\end{array}$ & Hematite & L6 & $12.0 \mathrm{hr}$ \\
\hline 25 & $1 / 27 / 94$ & $\begin{array}{l}\text { Coke, } \\
\text { low- \& } \\
\text { high-vol }\end{array}$ & Hematite & L6 & $7.8 \mathrm{hr}$ \\
\hline 1.7 & $2 / 24 / 94$ & $\begin{array}{l}\text { coke \& } \\
\text { high-vol }\end{array}$ & Hematite & L6 & $5.3 \mathrm{hr}$ \\
\hline 18 & $3 / 9 / 94$ & $\begin{array}{l}\text { High- \& } \\
\text { mid-vol }\end{array}$ & Wustite & L6 & $12.0 \mathrm{hr}$ \\
\hline 19 & $3 / 23 / 04$ & $\begin{array}{l}\text { High-\& } \\
\text { mid-vol }\end{array}$ & wustite & L6 & 11.0 \\
\hline
\end{tabular}


limits of operation with medium volatile and high volatile coals, and the final three trials were intended as endurance runs to identify problems associated with extended operation.

The process assessment panel, composed of H. R. Pratt (ex-USS and an AISI consultant), N. Daneliak (Stelco, Inc.), and D. Kwasnoski (Bethlehem steel Corporation), reviewed the trial results and selected four stable periods from three trials for detailed analysis. Their conclusions were:

- Pilot plant data acquisition and most process control systems are excellent. Process reliability requires the development of slag foam height and char content control. Sensors to monitor slag foam height continuously have not been developed. Models to control the char content of the slag have been developed but must be validated and enhanced through better knowledge of dust generation and composition.

- The goals of smelting productivity and fuel rate have not been achieved; the shortfalls in production and fuel rates are in the order of 40 percent. (Recent information indicates that the expected production rates and fuel rates with high volatile coal can be achieved with better coal and ore feeds and with an operating pressure of 3 atmospheres absolute.)

- Recently, the pilot plant equipment has performed well allowing longer, more stable process trials; however, these trials utilizing a range of process parameters have not provided clear solutions to the postcombustion, fuel rate, and productivity shortfalls.

- The best postcombustion (PCD) rates achieved with coal are about 33 percent, which is somewhat less than the smelter goal of 40 percent. Consequently, the fuel rate is higher and the production rate is lower than anticipated.

- The sulfur content in the hot metal is higher than that of the blast furnace because the high oxidation level in the slag results in a low slag/metal sulfur partition ratio. This high oxidation level is required to provide smelter productivity.

- High dust losses and slag volume and problems with metal/slag separation and weighing associated with the relatively short pilot plant operating periods have resulted in the calculation of relatively low iron yields. 
Some of their specific conclusions were that the best production and fuel rates were obtained during the 1.5-hour segment in trial 16 using hematite pellets with 76 percent top-charged coke and 24 percent injected high volatile coal. A production rate of 6.0 tonnes per hour ( $t p h$ ) was achieved. Coke was used to obtain a better understanding of the impact of coal volatile matter on postcombustion and the process. A fuel rate of $1088 \mathrm{~kg} / \mathrm{t}$ was obtained for the same segment.

The best performance with an all coal charge was obtained during the 2.8-hour segment of trial 18 with wustite pellets and with 61 percent top-charged medium volatile coal and 39 percent injected high volatile coal. A production rate of $5.7 \mathrm{tph}$ was achieved versus the target of $10 \mathrm{tph}$. A fuel rate of $1314 \mathrm{~kg} / \mathrm{thm}$ was achieved versus a target of $920 \mathrm{~kg} / \mathrm{thm}$ with high volatile coal and $820 \mathrm{~kg} /$ thm with medium volatile coal. A PCD level of 33 percent was achieved versus the target of 40 percent. Heat loss was high with 33 percent of the heat generated lost to the cooling water in the lance, barrel, cone, and hood, and through the refractory. The panel identified the following process issues that require further development:

- Heat generation and recovery at high levels of postccimbustion.

- Precise monitoring and control of slag foam height and char content of the slag.

- The impact of the Feo content in the slag.

- The target of 90 percent recovery of the dust from the smelter offgas by the cyclone has not been demonstrated. The dust contains extremely fine particles (dust passing through cyclone contains by volume about 60 percent minus 26 microns) which has resulted in only about 30 to 50 percent recovery of the dust exiting the smelter in the gas. The remainder is passed through to the quenchers, and consequently, the sludge rates are higher than anticipated.

- The demonstration of recycling 100 percent of the cyclone dust back to the process. (Such recycling has now been demonstrated in the current waste oxide Recycling Program. )

- The demonstration of external hot metal desulfurization.

It was also recognized, as the result of refractory wear below the water-cooled panels in the foamy slag area, that it would be desirable to extend the panels an additional 1-1/4 $\mathrm{m}$ down from the cone. 


\section{Conclusions}

Before investing in a 350,000 tpy demonstration plant, it will be necessary to close the gap between what can be claimed on the basis of pilot plant results and the process goals in terms of productivity and fuel rate. This gap is perceived to be in the forty percent range with the use of high volatile coal.

Based on the knowledge gained during the project and ongoing discussions with other smelting researchers around the world, AISI researchers are optimistic that this gap can be closed by an appropriate combination of the following devices:

1. Improved distribution of oxygen through the application of side-blown tuyeres. Initial work has shown encouraging results.

2. Better distribution of raw materials charged into the vessel. A major design change would be required to demonstrate and quantify the expected improvement, but there are strong reasons to believe that "dead zone charging" is a major cause of lost efficiency in the present configuration.

3. Use of newly developed sensors to measure foam height and to observe char distribution and behavior within the pressurized reaction vessel. A promising device, which has already been tested under basic oxygen furnace operating conditions, will be evaluated shortly.

4. Cooperative exchanges with other smelting programs are under consideration. Visits to pilot plants and technical exchange meetings are expected to take place throughout the summer and fall.

Interest in pursuing a demonstration project continues. The subject will be re-examined by AISI personnel and potential host companies as more data are available from the Waste oxide Recycling Program and from technical exchanges with other smelting research programs. 


\section{MANNESMANN DEKAG BASIC 8TODY OF AI8I DIRECT IRONLARING PROCE88}

To create the technical and economic basis for the next step in the development of a commercial-size plant, a comprehensive feasibility study was required for the industrial-scale application of the AISI direct ironmaking process. The objective was to install a demonstration plant with a capacity of approximately $350,000 \mathrm{t}$ per year on the site of a host company still to be identified.

\section{objectives of the study}

- A critical survey of the present stage of the ironmaking process technology by an independent and unbiased engineering and technology group examining the available process flowsheets, material and heat balances, and data collections based on the experimental results gained from the prereduction pilot plant operation at Hylsa in Monterrey, Mexico, and at the AISI ironmaking pilot plant in Universal, Pennsylvania.

- The determination of a preliminary plant concept and component configuration with elaboration of layout and section drawings and preliminary equipment specifications based on the AISI concept.

- Estimate of investment and operating costs.

- Considerations as to the need for a feasibility study.

The basic study was prepared by Mannesmann Demag (MD) and consists of a critical survey of the results gained from the pilot plant trials with the first vessel and theoretical computations of the process. It also includes the determination of a preliminary plant concept with rough estimated costs and rough feasibility evaluation. More specifically, the basic study includes:

- Evaluation of collected information and data of the theoretical background of the process received from AISI.

- Evaluation of the information and data of the experimental results gained from the pilot plant process, utilizing the Mannesmann-Demag-developed software for calculation of smelting reduction processes.

- Investigation of the plant concept and arrangement of plant components.

- Determination of preliminary plant flowsheet and outline of the proposed plant concept, utilizing the MannesmannDemag-developed software for calculation of smelting reduction processes. 
- Rough specification of the required equipment, including preliminary rough estimation of investment costs.

- Preliminary estimation of processing costs based on the preliminary plant flowsheet, utilizing the MannesmannDemag-developed software for calculation of smelting reduction processes.

- Preliminary comparison of costs of the AISI direct ironmaking process and the COREX process.

\section{Results of the study}

The bath smelting process is the heart of the process, and AISI demonstrated the technical success of this process for direct. ironmaking in the first year of pilot plant operation.

The critical survey, utilizing the MD-developed software for calculation of smelting reduction processes, shows that the bath smelting process can be equivalently described by both the AISI model and the MD model.

The postcombustion of about $40 \%$ of the process gas within the foaming slag in the BOF-type smelter leads to an autothermic and thermally well-balanced process.

Prereduction of the iron ore pellets for the smelter pilot plant at Universal would be performed by the very well-proven HYL gas-based direct reduction process. which technology has been specially modified to fulfill the ATSI process requirements, i.e. using the offgases from the smelter.

Based on extensive tests with iron ore pellets from Inland steel in the moving-bed pilot shaft in Monterrey, Hylsa concluded that the preheating and prereduction of hematite to wustite is viable when the specific gas flow and the temperature of the smelter offgas are above $1,025 \mathrm{Nm}^{3} / \mathrm{t} \mathrm{Fe}$ and between $900^{\circ} \mathrm{C}$ and $950^{\circ} \mathrm{C}$, respectively.

one main and difficult task of this basic study is to identify techno-economic assumptions to be expected in a demonstration plant with $50 \mathrm{t} / \mathrm{h}$ capacity, based on operational results with a vertical vessel in non-continuous operation and a production rate of $5 \mathrm{t} / \mathrm{h}$. Furthermore, the pilot plant at Universal is not equipped with a prereduction furnace to test the complete process plant concept.

Therefore, the scale-up critera to prepare the basic study were based on the experimental results at Universal and Monterrey and on the assumptions of AISI and Hylsa where proven data have not yet been gathered from pilot plant operation.

The following design specifications were established for the demonstration plant: 
The following design specifications were established for the demonstration plant:

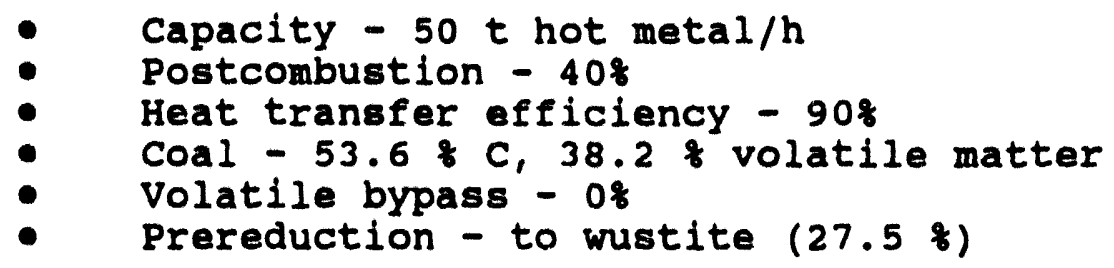

The design for the proposed plant was to include a BOF-type smelter and a soft blowing oxygen lance to secure a proper distribution of the oxygen over the entire cross section of the vessel.

Therefore, the following main design criteria were selected:

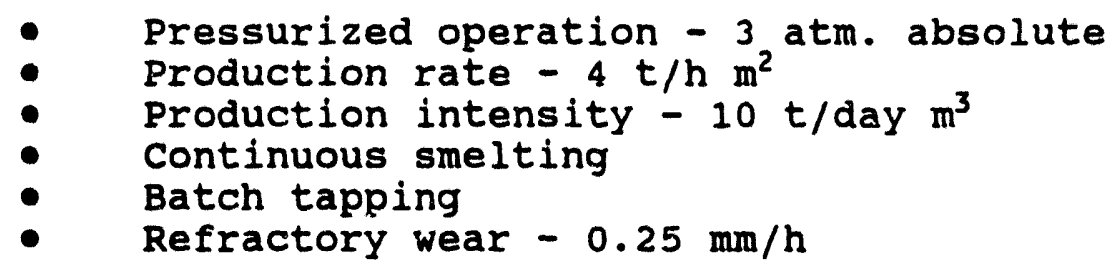

Due to the pressurized operation at 3 bar abs., the design proposal for the smelter is based on a doubling of the production rate per $\mathrm{m}^{2}$ bath surface, compared to the pilot plant operation at ambient pressure, which also results in a considerable reduction of the gas velocity in the vessel mouth area.

The bath surface is only $12.5 \mathrm{~m}^{2}$ (new lining) and allows the scaleup of the well-proven oxygen lance used at the pilot plant.

The upper part of the smelter has a larger diameter than in the bath area. Together with a large diameter of the vessel mouth

$(2 \mathrm{~m})$, this design allows proper foaming slag management within a pressurized vessel.

A separate tapping vessel is proposed to avoid high losses of iron and char and to allow batch tapping of metal and slag under pressure without interrupting the smelting process.

The proposed plant concept must be considered as a preliminary approach to the construction of a demonstration plant that will confirm the operability and economy of the in-bath smelting process during continuous and highly productive operation.

Accordingly, MD proposed a compact process plant concept with the following main features:

- Instead of a changeable vessel system, a single smelter unit was chosen as the core of the plant which will be shut down during relining. 
- The design of the shaft furnace as well as the material flow of the prereduced iron ore pellets from the shaft furnace to the smelter has been based on recommendations from Hylsa.

- The tapping of metal and slag from the non-tiltable smelter unit is carried out with proven BF technology into partially-filled torpedo car ladles and slag pots from a host company.

- The gas handling system is equipped with high efficiency hot dust cyclones and venturi scrubbers. About one-third of the smelter offgas behind the cyclones is cooled down and cleaned in order to be recycled in the water-cooled hood for additional cooling of the smelter offgas as well as to wash out alkalis.

- Latest test results indicate the necessity of installing a scrubber for sulfur removal between the hot cyclone and the prereducer.

- Extensive process control and automation will be applied to stabilize process conditions and control the combined operation of the prereducer and the smelter.

MD also investigated the use of a rotary kiln for prereduction as a replacement for the moving-bed shaft furnace but rejected it for technical and economic reasons.

Finally, MD investigated two alternatives for use of the export gas, namely for production of DRI in a shaft furnace or for utilization in an oxygen plant. They concluded that each was feasible and that local considerations would govern the choice.

The MD basic study confirms the considerable potential for technoeconomic advantages of the AISI direct ironmaking process in comparison to the COREX process. These advantages are lower consumptions of coal and oxygen, reduction in the generation of export gas, and a more compact plant concept. MD concluded that the basic study showed sufficient promise for a more comprehensive feasibility study to be clearly warranted. 


\section{MARTESMANI DEMAG PRE-ENGINEERING STODY FOR A 350,000 TPY DEYONSTRATION PLANT}

The Mannesmann Demag (MD) Pre-engineering study was for a demonstration plant having a capacity of $350,000 \mathrm{t} / \mathrm{y}$ of hot metal. Indigenous iron oxide pellets woul be processed, and indigenous coal would be used as reductant and energy source.

This study embodied the knowledge about the AISI direct ironmaking process provided in flow diagrams, material balances, and energy balances up to the summer of 1992. For the erection of the demonstration plant on a greenfield site, the battery limits were defined, starting from day bins for raw materials and ending with tapping of hot metal into torpedo ladle cars and slag into slag pot wagons. Cooling water circuits and make-up water facilities are part of the installation, whereas process gases, e.g. oxygen, nitrogen, and argon, are to be supplied "over the fence" by pipeline to the battery limits. Natural gas for heating process equipment is also taken over the fence from the host plant.

A plant layout, Figure 12.1, and sectional views, Figures 12.2 and 12.3, show the plant in sufficient detail to specify major equipment items and plant installations for assessing respective investment costs. Figure 12.4 is a typical energy balance flow diagram.

\section{Plant Description}

The plant is designed to produce $350,000 \mathrm{t} / \mathrm{y}$ of hot metal. The hourly production rate of $50 \mathrm{t}$ of hot metal is derived from:

$$
\begin{array}{lr}
\text { Operating time: } & 330 \text { days/y } \\
\text { Plant availability for production: } & 90 \% \text { of } 330 \text { days } \\
\text { Estimated capital cost with infrastructure } \\
\text { in place: }
\end{array}
$$

Raw Material Handling

Iron oxide pellets, coal, and fluxes are transported to the battery limits of the plant by payloaders or dump trucks which discharge them into ground hoppers. One ground hopper receives all materials except coal.

A second ground hopper receives coal which is first conveyed to a screening station to separate the minus $5 \mathrm{~mm}$ fraction before it reaches the day bin. Pellets and flux materials are directly conveyed to the respective day bins. From the day bins, coal and flux materials are discharged via vibrating feeders onto weigh feeders which allow discrete metering of each component. oxide 


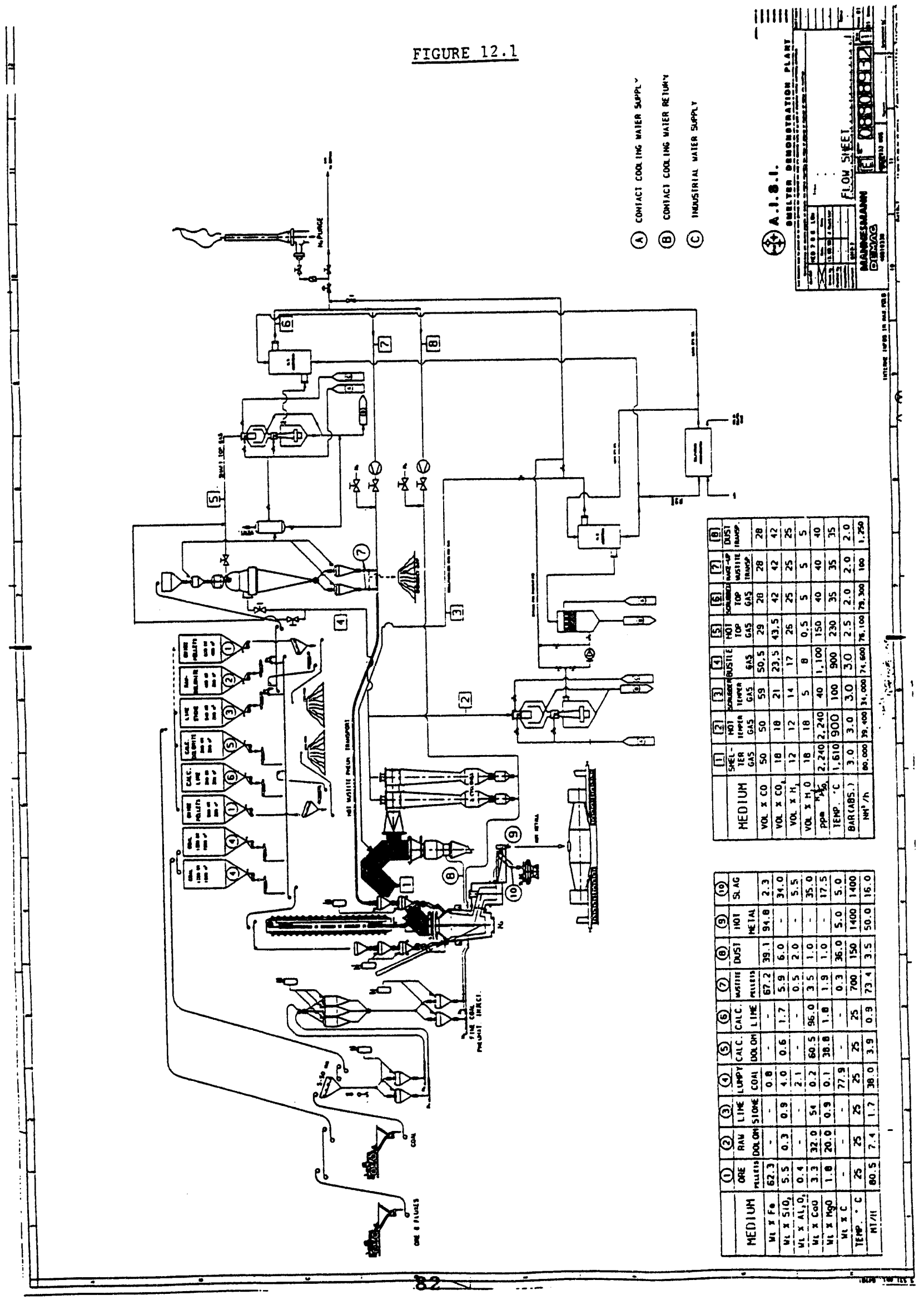




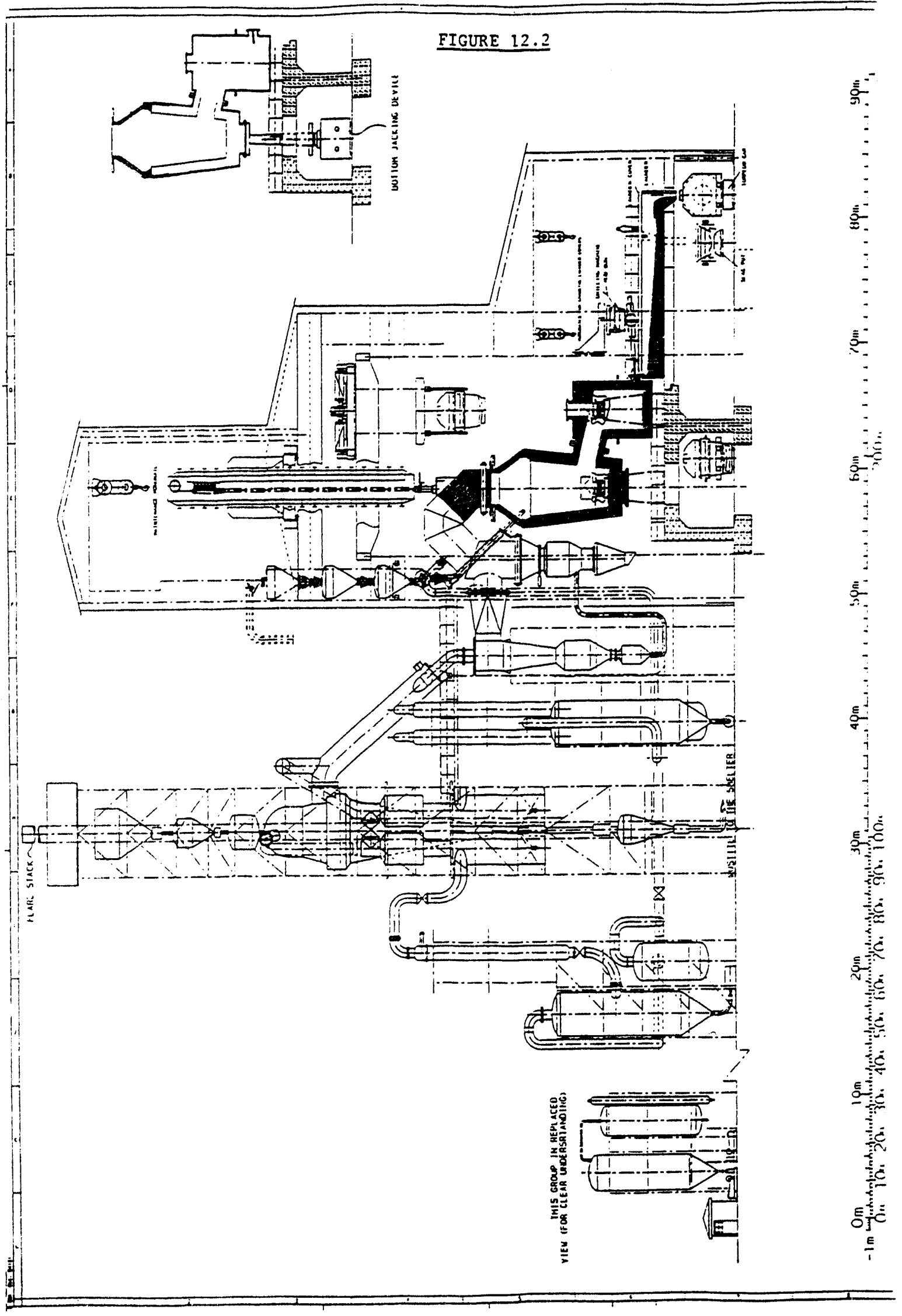




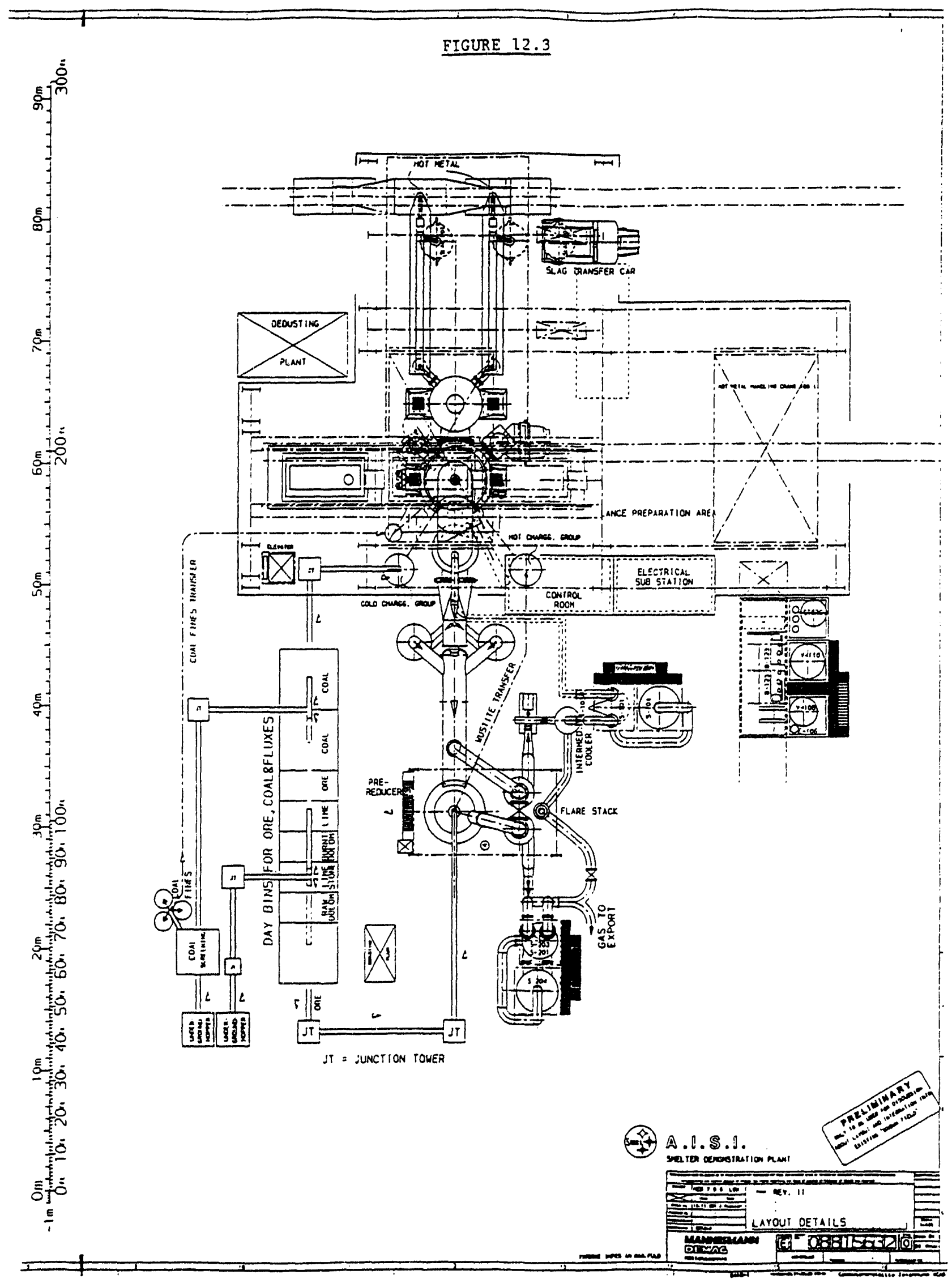




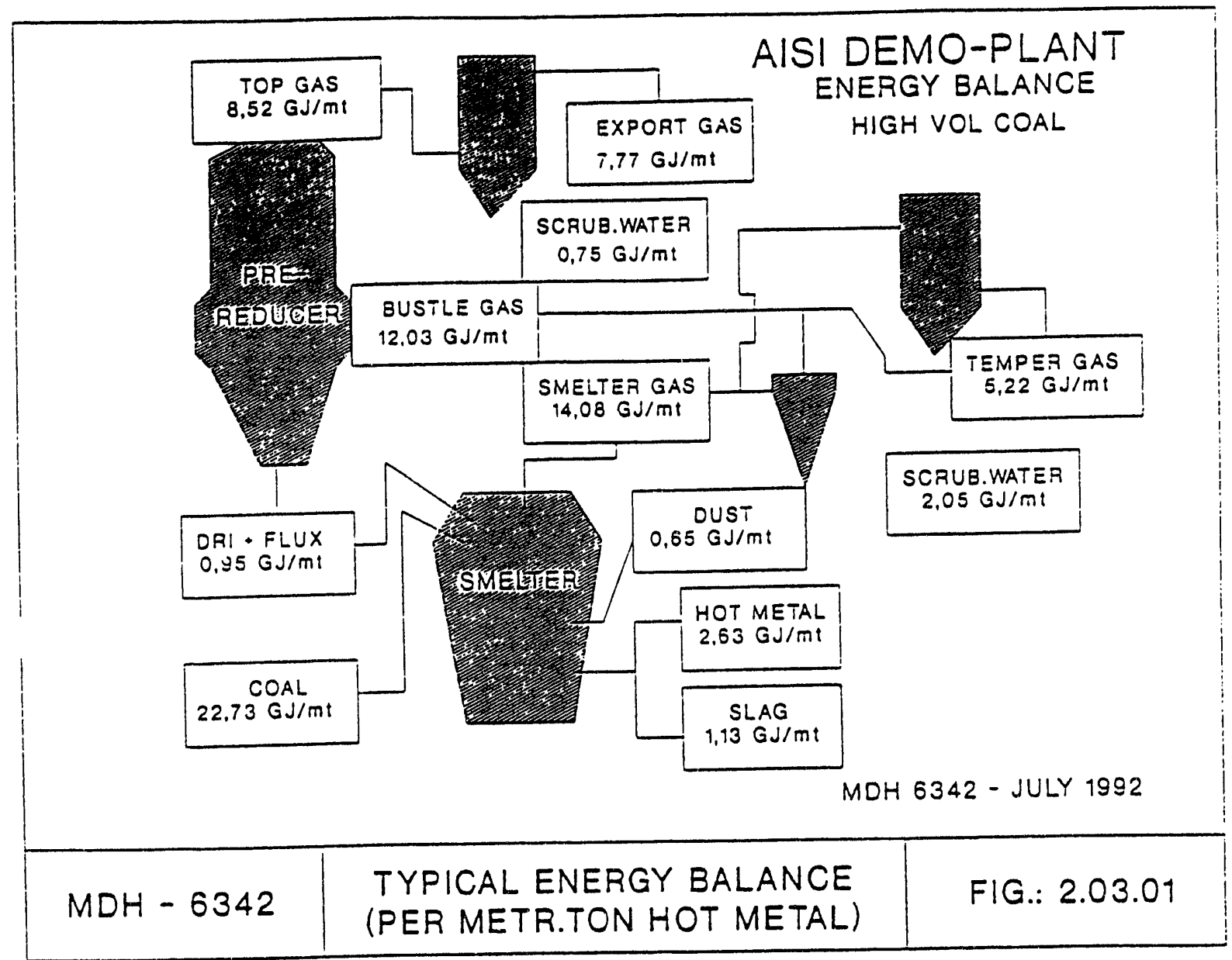


pellets are discharged from the day bins via vibro-feeders and a weigh feeder for controlling the material flow.

\section{Shaft Furnace and Ancillary systems}

Iron ore pellets and Iimestone and/or raw dolomite are continously fed to the prereducer. In order to guarantee a continuous masssolids flow inside the shaft furnace as needed for its proper operation and uniform product quality, there are specially-designed charge and discharge systems.

The charge system is designed to maintain a constant level of solids at the top of the prereducer. Iron ore pellets are transported by conveyor system to the top of the reduction tower. An automated system of bins and pressure locks allows the ore to be received at atmospheric pressure in an open loading hopper, pressurized in an intermediate bin, and discharged into an ore distributing bin which continuously discharges into the prereducer.

The chemical reactions which transform the oxide pellets into wustite (Feo) take place in the pressurized reactor vessel, made of carbon steel internally lined with refractory bricks with an upper cylindrical section and a conical discharge at the bottom adequately designed to ensure free mass flow of solids in the prereducer. The prereducer is divided into two zones: reduction zone and discharge zone. In the reduction zone, the iron ore is converted into wustite by action of hot reducing gas ( $\mathrm{rich}$ in $\mathrm{H}_{2}$ and $\mathrm{CO})$ generated in the combined smelter reactor. From this gas, coarse dust particles are separated in cyclones, and the gas temperature is adjusted in a gas tempering loop to meet the reducing gas entry temperature of approximately $900^{\circ} \mathrm{C}$. The reduction gas enters the reactor into the reduction zone through a plenum-and-tuyeres configuration which allows a good gas distribution in the reduction zone and makes contact with the descending burden in a counterflow manner.

While the burden is descending in the shaft furnace, the iron ore is increased in temperature and transformed into wustite. The counter-current reducing gas decreases in temperature and changes in chemical composition as it ascends through the burden.

The lowermost conical section of the reactor is where the wustite discharge takes place. This is an external water-jacketed section which is adequately designed to ensure uniform mass flow of the burden in this zone. The discharge system works under the double lock-hopper principle, switching from one to the other bin every 15 minutes (cycle time of 30 minutes). Filling of the bins is provided by a rotary valve which continuously discharges prereduced burden from the shaft furnace into one of the lock hoppers which is at the same pressure as the prereducer. Once the bin has been filled, the selector valve underneath the rotary valve switches to send the material to the second bin which, meanwhile, has been 
emptied and pressurized to match with the reactor inside pressure. At the same time, the full bin is isolated by its upper seal valve, and its pressure is readjusted by the lower seal valve as needed for the pneumatic transport system which conveys the wustite pellets to the smelter vessel.

The top gas leaving the shaft furnace is quenched and scrubbed to precipitate dust. A subsequent desulfurization unit lowers the $\mathrm{H}_{2} \mathrm{~S}$ content to a level of approximately 40 - $50 \mathrm{ppm}$. The gas with a calorific value of 7000 to $8000 \mathrm{~kJ} / \mathrm{Nm}$ is available for use outside battery limits.

\section{Startup and Shutdown Procedure for the Prereducer}

For startup, the prereducer is first filled with oxide pellets. Thereafter, tempered reducing gas generated in the smelter vessel from cold wustite or hematite pellets is introduced into the bustle pipe of the shaft furnace. Shortly thereafter, pellets from the prereducer are discharged to the ground, and a corresponding amount of oxide pellets is charged at the top to enable a discrete material flow inside the furnace. The flow rate is controlled in a manner to reach reduction temperature in the burden in the shortest possible time. Once the discharged pellets meet the desired degree of reduction, diversion to the ground is stopped, pneumatic conveyance to the reception tower for the smelter is started, and the pellet flow through the shaft furnace is increased stepwise to the desired production level.

For shutdown, the bustle gas is bypassed and diverted into the shaft furnace top gas quencher and scrubber for further cooling and lowering of the water content before this gas is either flared or used as export gas. The isolation valves stop any further gas entry, and the pellets will slowly cool down.

\section{Transport of Prereduced Pellets to smelter}

The HYL pneumatic transport system for hot wustit? pellets and, if applicable, dolomite being calcined in the shaft reactor is designed to link the prereducer unit with the smelter vessel by means of a pneumatic conveyor system. The material discharged from the prereducer is sent to the reception tower next to the smelter where it is temporarily held in an insulated and sealed storage bin. From there it is sent to a surge bin for continuous feeding to the smelter. All steps are taken to reduce temperature loss.

Salient design features of the system are:

1. The system is designed to transport the hot material at a low velocity in order to minimize product degradation. 
2. Handling of wustite is carried out in an enclosed system, thus the overall operation is cleaner, and the total metallic yield improved compared to mechanical handling.

3. There is a minimum of moving parts that could fail during operation.

4. To a large extent, the wustite thermal energy is preserved.

5. Maintenance for the transport system is reduced.

The transport gas used is either nitrogen or top gas from the shaft furnace that is cleaned and compressed. Because transport takes place at a pressure of 8 atmosphere absolute and the operating pressure of the smelter is about 3 atmosph re absolute, transport gas from the lock-hopper system is vented during the charging cycles of the smelter. The vented gas is cleaned in a scrubbing system. In the case of nitrogen being used as the transport gas, the vented gas after scrubbing is released to the atmosphere. In the case that the transport gas is top gas, the vented and scrubbed gas is recycled to the gas system.

The scope does not include a transport gas heater. This causes a temperature loss for wustite pellets of approximately $50^{\circ} \mathrm{C}$ for heating up the cold gas. Since an additional loss of $50^{\circ} \mathrm{C}$ will occur in the bins and the transport pipe system, the total temperature drop after discharging the pellets from the shaft furnace is approximately $100^{\circ} \mathrm{C}$.

\section{Smelter and Ancillary systems}

The smelter feeding system comprises two separately operating units, one for hot prereduced product from the shaft furnace and a second one for charging cold materials, i.e. coarse coal and flux additions, such as burnt lime and/or dolomite.

Both units operate according to the double lock-hopper concept which allows pressure equalization between the pneumatic transport system for hot pellets and the mechanical coarse coal transport system on one side and the pressurized smelter vessel on the other side. As with the shaft furnace charging and discharging system, vented gases are scrubbed and either released to the atmosphere (in the case of nitrogen) or recycled (in the case of process gases).

The smelter feeding system also comprises facilities to inject fine materials up to minus 5-mm grain size into the slag level of the smelter bath. The injection system is primarily used to recycle dust entrained in the smelter offgas which precipitates in the drop-out section of the water-jacketed gas duct and in the subsequent cyclones. Later in the project, the system might also 
be used to inject fine coal from coal screening facilities. However, this coal must be dried before it can be injected.

The working volume of the refractory-lined smelter vessel is $114.6 \mathrm{~m}^{3}$, which corresponds to a production intensity of $10.47 \mathrm{t} / \mathrm{m}^{3} /$ day and a production rate of $50 \mathrm{t} / \mathrm{hr}$ of hot metal. The average internal diameter of the vessel is about $4.6 \mathrm{~m}$. The height of the reactor is $6.88 \mathrm{~m}$ (excluding the cone section) with $1.8 \mathrm{~m}$ as freeboard space. The forehearth with its volume of $31 \mathrm{~m}^{3}$ can hold up to approximately $110 t$ of hot metal and $35 t$ of slag. During the operation, the average metal heel present in the main smelter vessel will be about $50 \mathrm{t}$. The total amount of foaming slag present in the reactor averages approximately $70 \mathrm{t}$. At design production level, every two hours $100 \mathrm{t}$ of metal and 30 to $35 \mathrm{t}$ of slag will be tapped from the forehearth through one tap hole. Hot metal and slag are separated by a slag skimmer in the launder trough. The metal is cast into torpedo cars, and slag runs into a slag pot and is transported either by rail or with rubber-tired vehicles.

oxygen with $95+\%$ purity is supplied for the smelting reactions through a water-cooled lance. To control the slag level in the vessel, the lance height is adjustable. The average oxygen flow rate depends on process parameters, i.e. production rate, coal chemistry, degree of prereduction, and degree of postcombustion.

Temporary adjustments can be made to alter char accumulation in the slag and to control the foam height of the slag.

Temperature and chemical composition of metal and slag can be determined intermittently through measurements and samples taken by a sublance.

Due to the pressurized operation of the smelter, both the oxygen lance and the sublance are installed in seperate housing boxes which are tightly sealed against atmospheric pressure to prevent process gas leaking from the pressurized smelter vessel. To change the oxygen lance, it is first retracted into the housing box. The vessel system is depressurized and the lance housing box deflanged from the gas off-take hood after purging with nitrogen. A dedicated trolley moves the box with the lance inside to the maintenance area where the lance can be lowered and taken out for servicing.

In the case of the sublance, the housing box is permanently fixed to the smelter vessel. For changing cartridges, the lance is retracted into the box, an isolation valve between the box and smelter vessel is closed, and the box is subsequently depressurized and purged with nitrogen. Thereafter, a sealed service door is opened to allow changing of cartridges. (The good performance of the seal on the oxygen lance in the third vessel trials indicates that these housing boxes may be unnecessary.) 
The smelter offgas leaves the vessel with a temperature between 1550 to $1650^{\circ} \mathrm{C}$. The entrained dust content ranges from approximately 40 to $60 \mathrm{~g} / \mathrm{Nm}^{3}$. The first part of the gas off-take system is designed as a water-cooled, jacketed duct where the gas temperature is lowered by approximately $400^{\circ} \mathrm{C}$. Before the gas may enter the cyclones to precipitate the major part of the entrained dust, the temperature must be further lowered to prevent build-up of fused dust in the cyclones. By quenching, scrubbing, and recycling a part of the cold smelter gas stream into the duct upstream of the cyclones, the gas temperature is reduced to approximately $900^{\circ} \mathrm{C}-950^{\circ} \mathrm{C}$, which is also the desired temperature for the reducing gas entering the shaft furnace.

\section{Startup and Shutdown Procedure for the smelter}

For starting up the smelter, e.g. after relining, the vessel is preheated by an auxiliary oil- or gas-fired burner under ambient pressure. The burner gases are sucked through the offtake duct by means of the booster fan of the temper gas loop and from there directed to the flare stack. After a lining temperature of about $1200^{\circ} \mathrm{C}$ is reached, the burner is retracted, the opening is sealed, and approximately $50 \mathrm{t}$ of hot metal from an outside source are poured into the vessel via a dedicated runner connected to a filling opening in the lower barrel section of the vessel. After sealing the filling openings, the system is purged with nitrogen, the oxygen lance is lowered, oxygen blowing is started, and the gas tempering loop is activated. A mixture of cold wustite or hematite pellets, coal, lime, and burnt dolomite is fed via the cold charging system into the smelter when the hot metal temperature has reached approximately $1450^{\circ} \mathrm{C}$. In the course of stabilizing the operation, the gas pressure control valve in the diversion line upstream of the booster fan is slowly closed. With the pressure building up in the vessel, an increasing amount of reducing gas is sent to the prereducer which then is started up. Feed rate of the cold material mixture sent to the smelter is increased stepwise until the smelter gas flow reaches the design level for the reducing gas needed to achieve the prereducer production rate of wustite. After the latter produces wustite pellets with the desired degree of reduction, these are fed to the smelter, and processing of cold hematite or wustite pellets in the smelter is stopped. The pressure control valve in the diversion line is completely closed and the system pressure is solely controlled by the valve after the top gas scrubber. 


\section{TECHNICAL ANALYSIS OF PILOT PLANT TRIALS}

\section{Rate of Reduction}

The rate of reduction of Feo in the slag in terms of moles of oxygen removed per second as a function of Feo content is shown in Figure 13.1 for a constant slag weight. More data are shown in Figure 13.2 where the rate is divided by the slag weight in accordance with the equation below:

$$
\mathrm{R}=\mathrm{W}_{\mathrm{s}} \mathrm{K}(\% \mathrm{FeO})
$$

The rate of reduction is determined from the feed rate minus the accumulation of $\mathrm{Feo}$ in slag. It does not include dust losses. The reduction rate is based on the rate of feed materials. The rate constant

$$
\left(\frac{k m o l e \mathrm{O}_{2}}{8 \mathrm{FeO}}\right)
$$

is shown as a function of slag weight in Figure 13.3. The data are reproduced in Figure 13.4 in terms of the rate per unit area and slag weight per unit area along with the results published by NSC $^{7}$ for their 5t and $100 t$ reactors. The NSC data fall in the region between the two lines.

The data for a constant slag weight are limited, since the slag weight is constantly changing. NSC data and the laboratory data support the conclusion that the rate is proportional to Feo. From the AISI data it is not possible, in general, to distinguish from the char-slag and the metal-droplet-slag reaction. When there were excessive amounts of char in the slag for the chosen reduction rate, the Feo content of the slag decreased. This indicates that the reaction of carbon in the char with Feo is faster than the reaction of carbon in the metal droplets with Feo. NSC also found that the rate constant increased with bottom stirring, presumably by ejecting more metal drops into the slag. In general, AISI used much lower stirring energies than NSC and did not vary it greatly. Consequently, AISI did not see a major effect of stirring on the reduction rate.

The AISI data in Figure 13.4 suggest that the rate approaches zero at zero slag weight. Analysis by Sarma et a ${ }^{8}$ indicates that the reaction on the planar slag-metal surface is less than $2 \%$ of the total rate and can be neglected. Within the scatter of the data are rates that are in agreement with those of NSC. The rate constant for NSC is most likely higher than that observed by AISI because they used much higher bottom gas stirring rates, increasing 


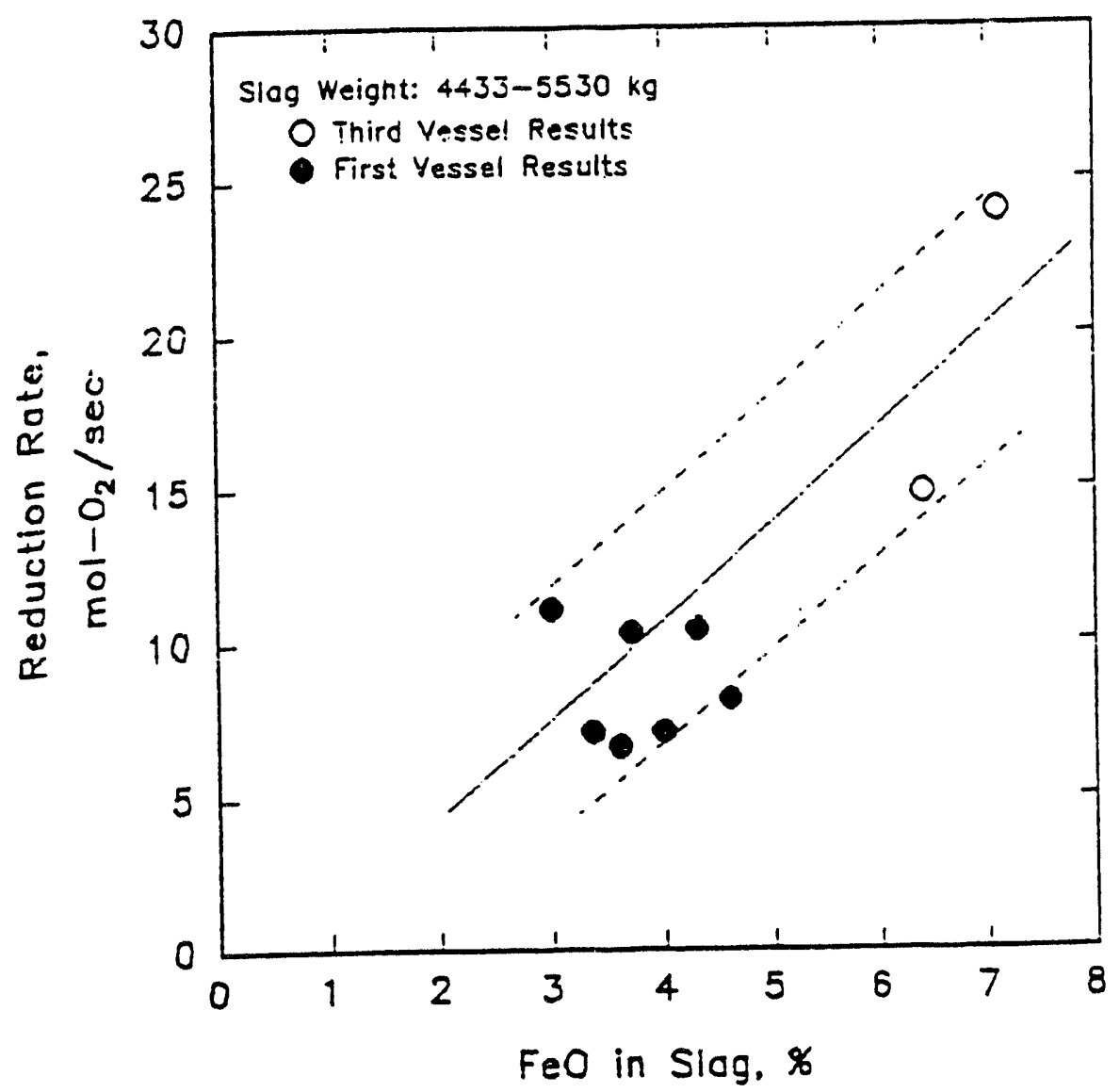

The rate of reduction as a function of $\mathrm{FeO}$ in the slag. 


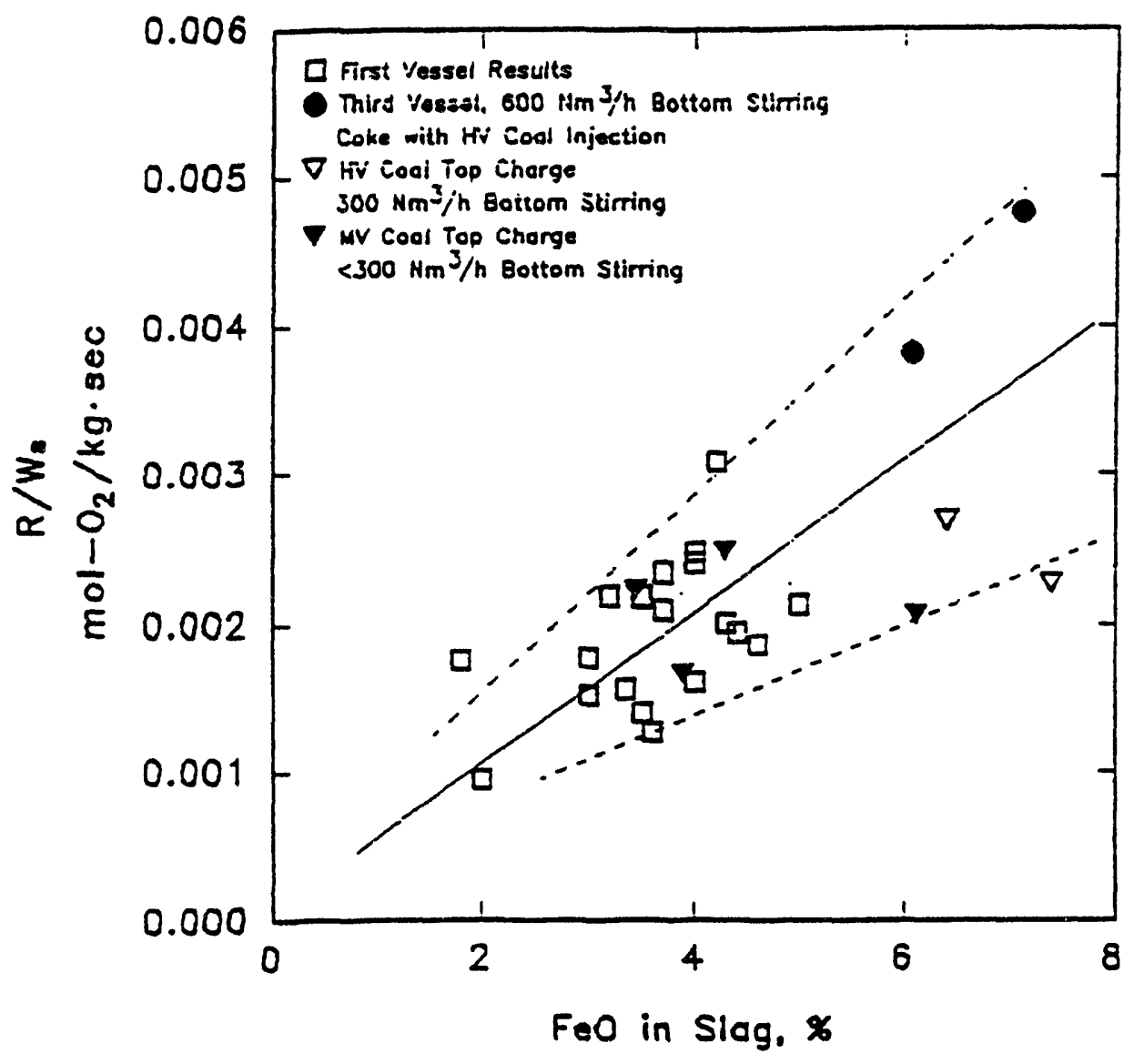

The rate divided by slag welght versus FeO in the stag. 


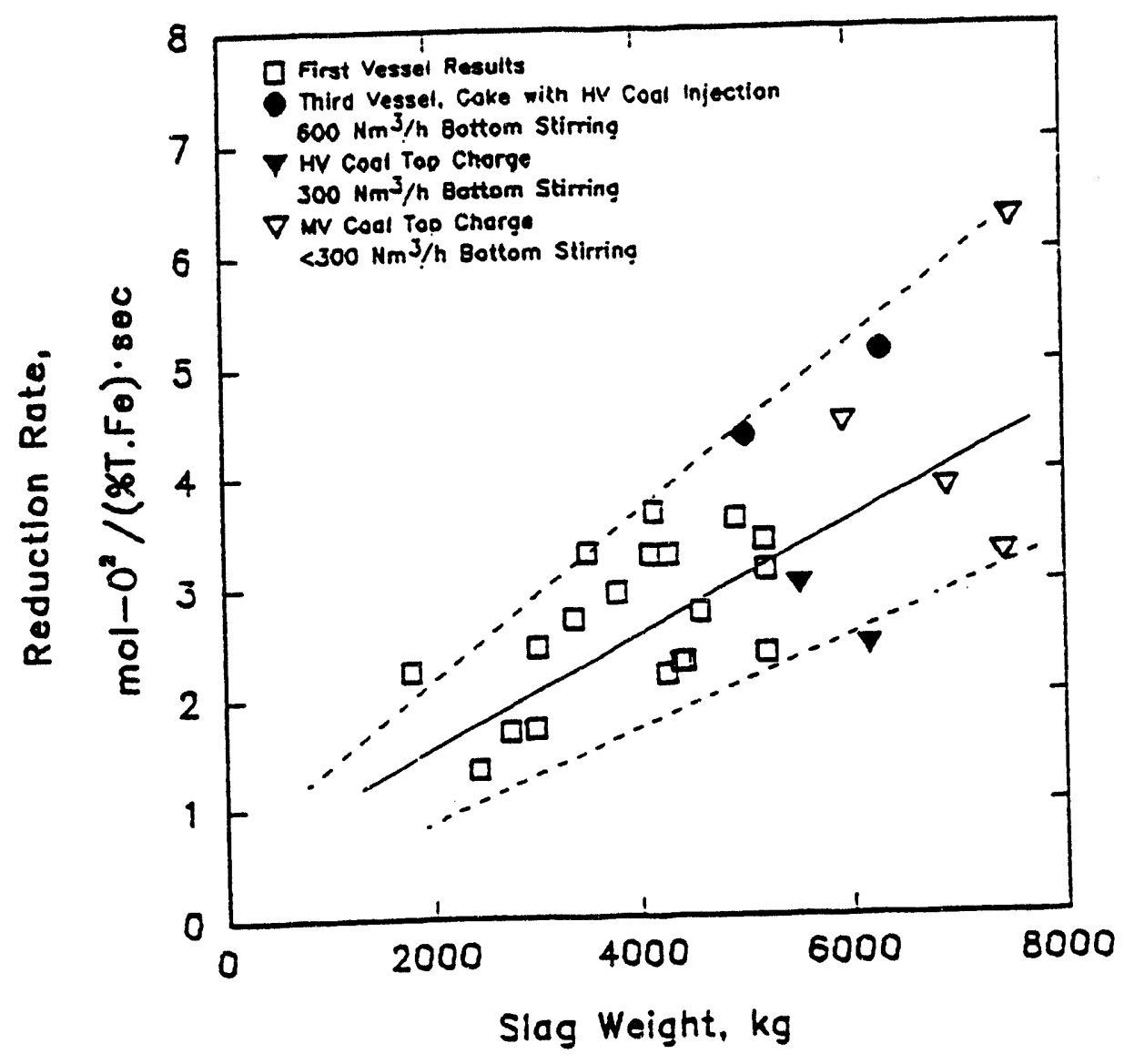

The rate constant as a tunction of slag wolght. 


$$
\stackrel{N}{\mathbf{O}}
$$


FIGURE 13.4

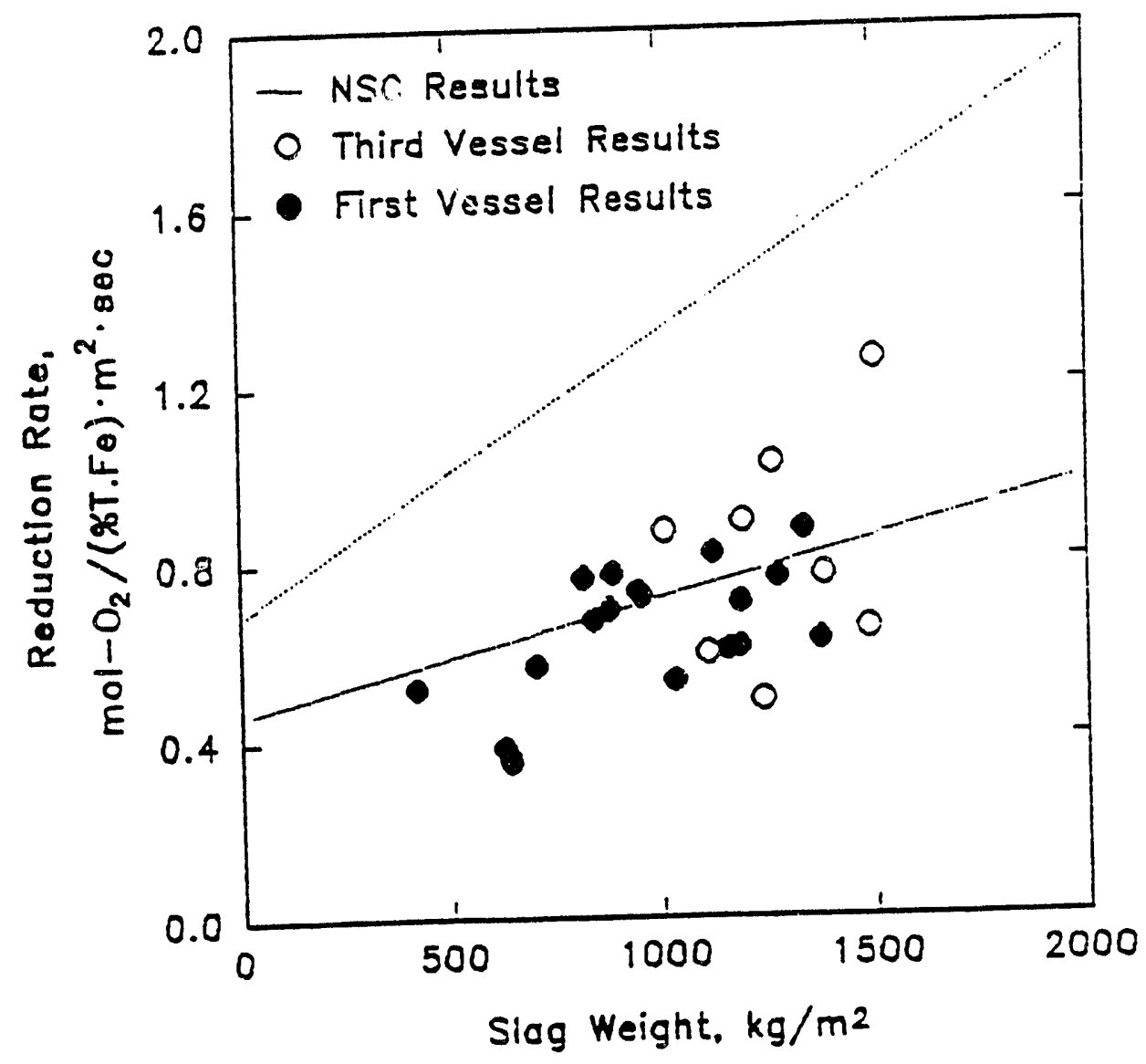

The rate constant per unit area and the results of NSC. 
the amount of metal drops in the slag and the rate of reaction of carbon in the droplets with the slag.

The reduction rate can be increased by allowing the Feo content to increase. For example, if the production rate is doubled by doubling the ore and coal rates, initially the rate of reduction is less than the rate of feeding and the Feo content of the slag increases. As the Feo increases, the rate of reduction increases until it reaches the rate of ore feeding and a steady state is achieved. However, the Feo content will have doubled, reducing yield and increasing the sulfur content of the metal. The effect of Feo content in the slag on the sulfur partition between the metal and the slag will be discussed later. The higher Feo may also increase refractory wear.

In actual operation, it is difficult to control the Feo content. For example, after tapping, the slag weight in the vessel decreases. Therefore, to maintain the same reduction or production rate, the Feo content of the slag will increase. Then as more slag is generated, the Feo content decreases. If the char in the slag is reduced, e.g. to increase postcombustion, the Feo content of the slag will increase. It is best to consider that the Feo responds to the other process variables, such as slag weight, production rate, and char in the slag, rather than being constant or controlled directly.

\section{slag Foaming}

Foaming in the smelter vessel is more complex than foaming in laboratory experiments as discussed in section 3. Some of the complicating factors are:

- Not all of the process gas actually goes through the slag. The $c 0$ from reduction passes through the slag, while the gas from combustion of volatiles may not.

- The bubbles formed from reduction are relatively small $(5 \mathrm{~mm}$, since the sulfur content in the hot metal is $0.1 \%$ ), while those from combustion are larger $(5-15 \mathrm{~mm})$.

- The gas velocities in the smelter are higher than can be achieved in the laboratory.

Nevertheless, the foaming in the smelter does behave similarly to that in the laboratory. In general, the foam volume or height is proportional to the gas velocity (Figure 13.5). The foam index observed is similar to those measured in the laboratory. The foam volume also decreases in the smelter with increasing pressure, as expected. 


\section{FIGURE 13.5}

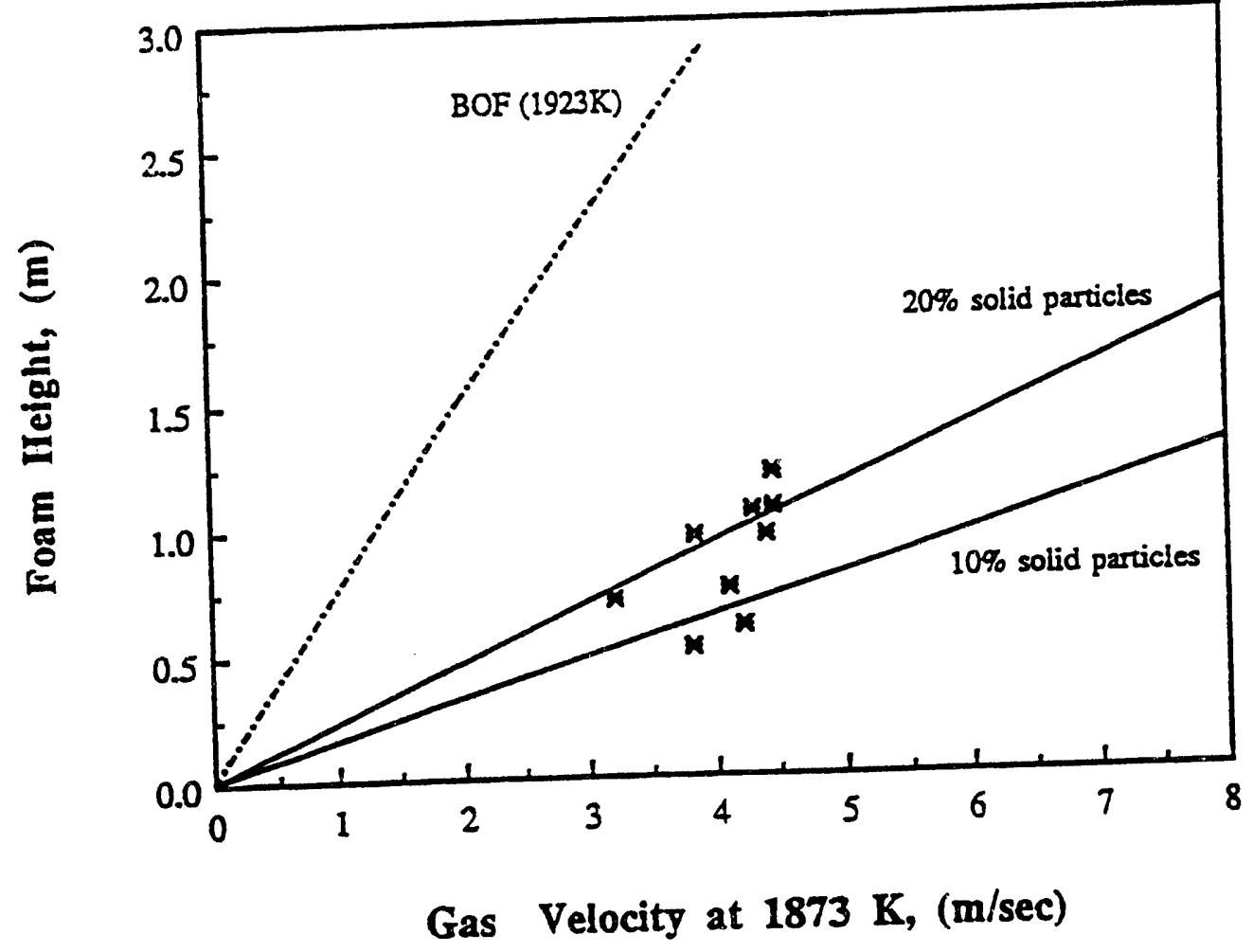

Calculated and observed foam helghts in bath smelting. 
The amount of char required to control foaming was studied in the pilot plant for $100 \%$ top feeding of coal. The results shown in Figure 13.6 indicate that, for 108 char in the slag by weight, foaming is controlled. When the char was reduced below $10 \%$, excess foaming occurred. NSC indicated that the critical amount was about 208. Within our ability to estimate the amount of char and the foam height, the critical char weight determined by AISI is in agreement with NSC results.

\section{Effect of oxygen Injection}

oxygen injection by tuyeres has been limited in the pilot plant. However, foam height has been studied as a function of lance gap (the distance between the lance tip and the foam). As shown in Figures 13.7 and 13.8 , the calculated foam index appears to increase as the lance approaches the foam, causing more gas to enter the slag and contribute to foaming. However, the foam index was computed using the total gas volume. As discussed above, if the lance is significantly above the foam, the gas from combustion does not pass through the slag. It is reasonable to conclude that the amount of gas going through the slag depends on the blowing conditions, as does the foam height or volume. oxygen injection into the slag would, therefore, be expected to increase foaming.

\section{Effect of Coal Injection}

Coal injection into the slag affects foaming in two ways:

- The volatiles released in the slag will increase the gas flow rate in the slag and, therefore, foaming.

- The injected coal is much smaller in size than for top feeding, resulting in smaller char particles. These small char particles may be of insufficient size to rupture the foam bubbles.

Following the reasoning of zhang et $a 1^{10}$ on the effect of char on foaming, the char particles should be larger than the foam bubble size. The foam bubbles are expected to be in the range of 3 - $10 \mathrm{~mm}$, depending on their source. Therefore, char from injected coal may not be effective in controlling foam.

In trial 17, with the third vessel, when coal injection reached $60 \%$ of the total fuel input, slopping occurred. Sarma's analysis indicates that the amount of char from top feeding alone was below 10\%, even though the total char was much higher. Therefore, it would appear that there is a minimum amount of top feeding of large coal required to control foaming. 
FIGURE 13.6

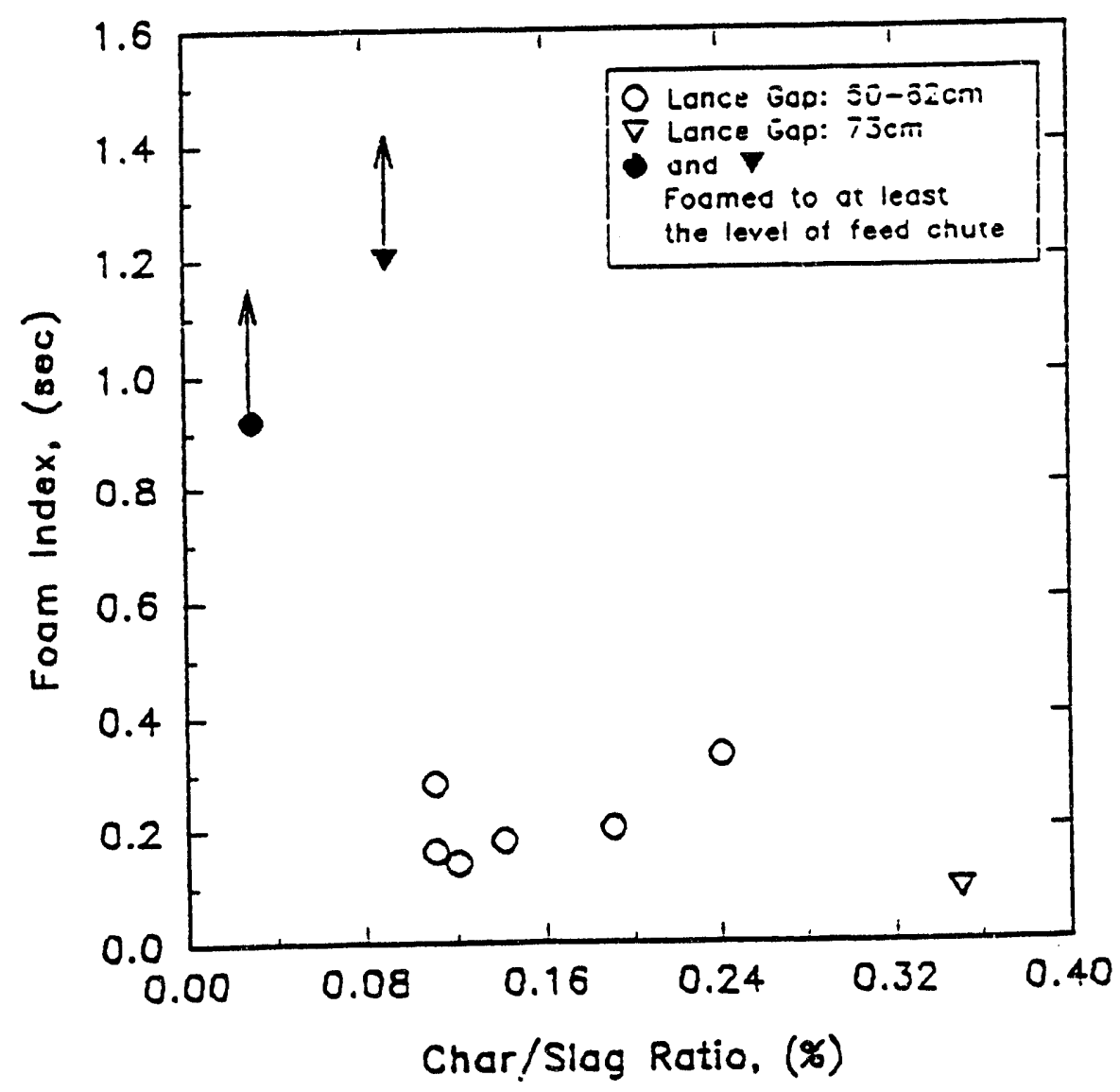

Effect of char on the foam index. 
FIGURE 13.7

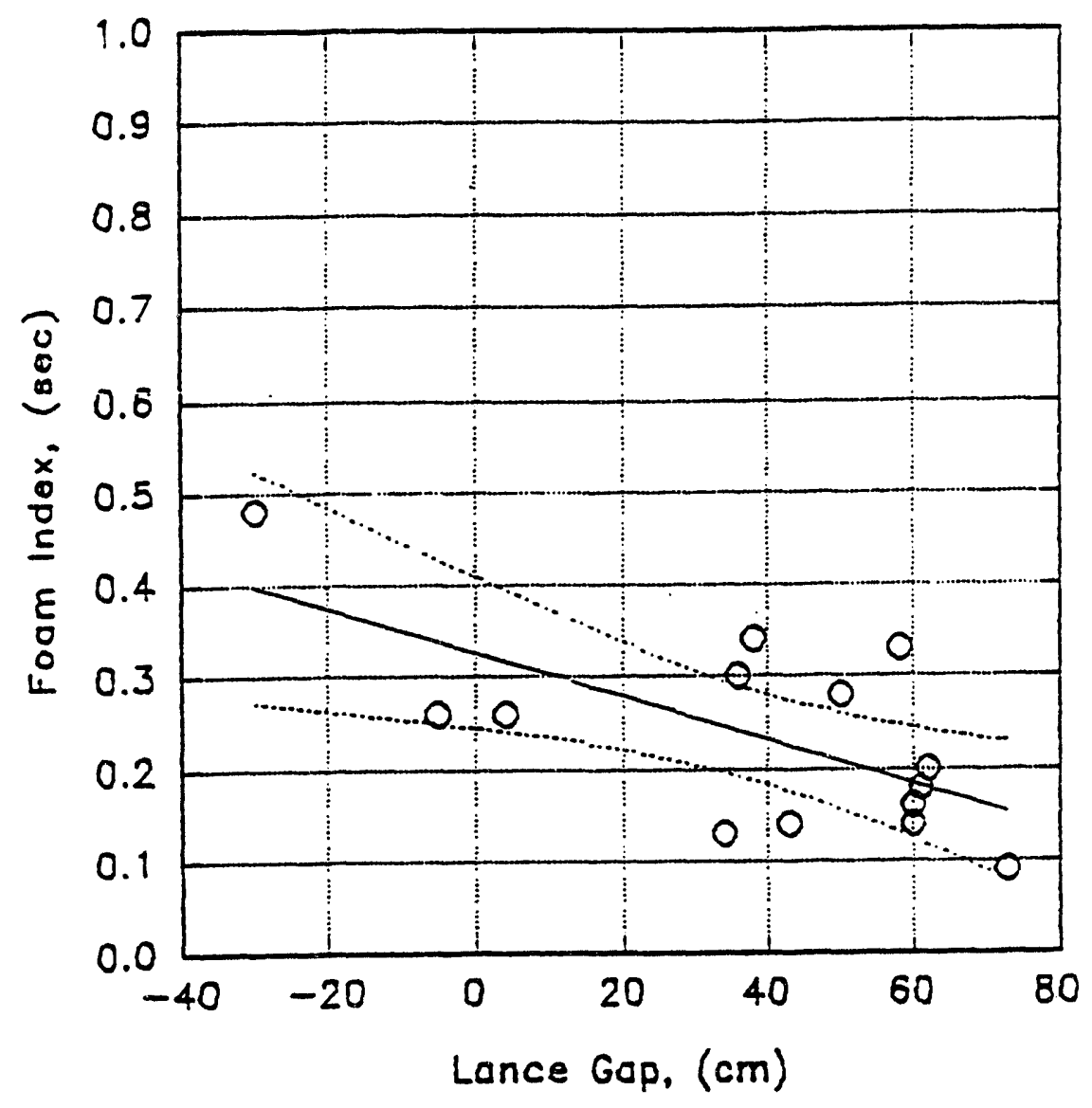

Effect of the lance gap on the foam Index in vessel 3. 
FIGURE 13.8

\section{Foam Index vs Lance Gap}

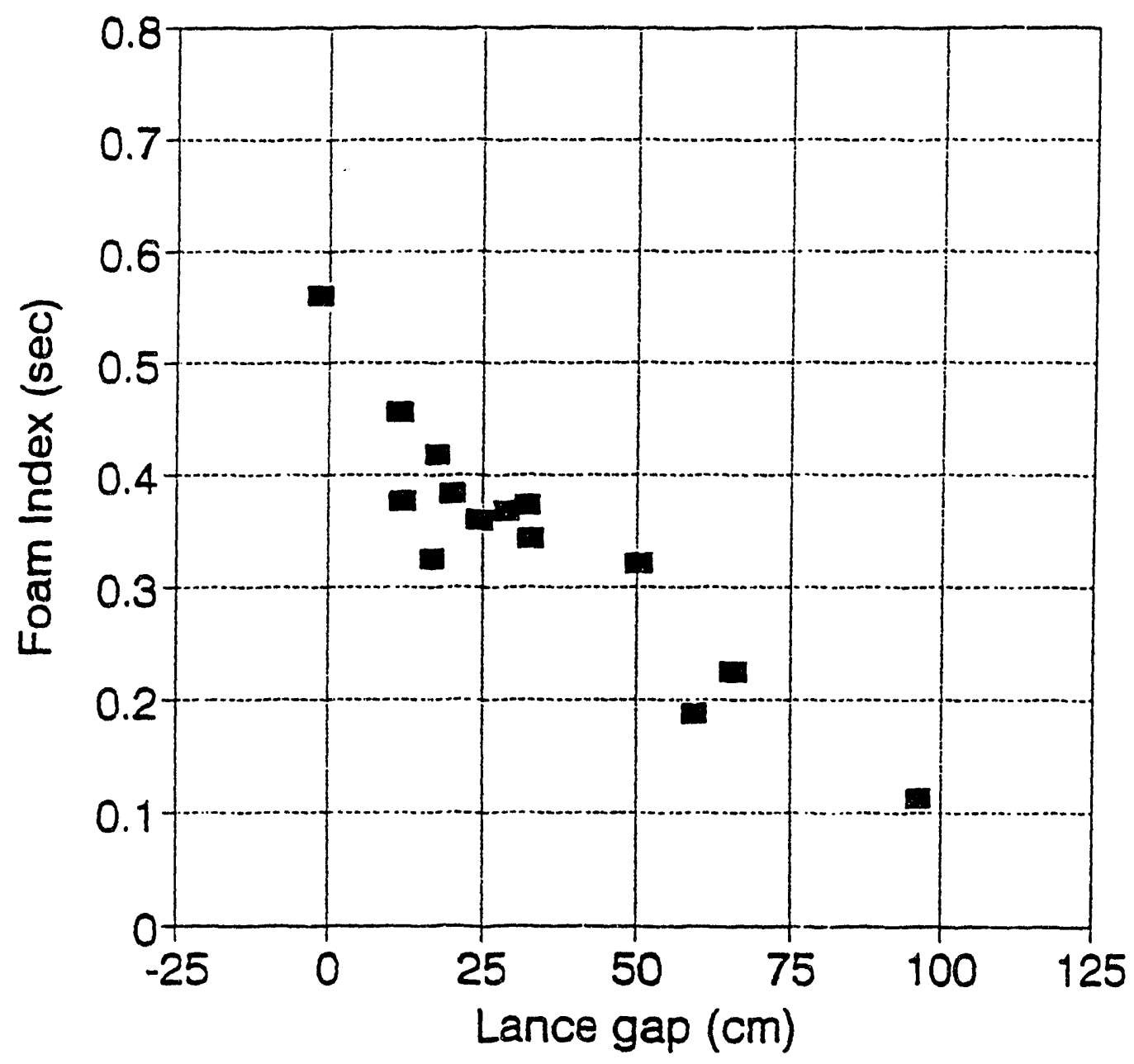

- Horizontal Vessel

Effect of lance on the foam index for the horizontal yessel. 


\section{Sulfur and Phosphorus}

\section{Sulfur Path}

Extensive work has been conducted to determine the behavior of sulfur in the process, including laboratory studies, special pilot plant trials, special prereduction trials at Hylsa, mathematical modeling, and a detailed mass balance. Based on this work, a clear understanding of the behavior of sulfur has been developed that can predict the sulfur content of the metal in a fully integrated production plant.

When coal is added, the sulfur associated with the volatiles (organic sulfur) primarily enters the gas phase as $\mathrm{H}_{2} \mathrm{~S}$. As the coal is combusted, some of the mineral sulfur (e.g. Fes) also enters the gas phase. This is because, during combustion, there is a gas phase insulating the char from the slag, allowing the sulfur to enter the gas phase. The remainder of the sulfur enters the metal, due to char dissolution into the metal, or into the slag. Sulfur also vaporizes from the slag as $\mathrm{H}_{2} \mathrm{~S}$ at a slow rate. The sulfur species in the offgas $\left(\mathrm{H}_{2} \mathrm{~S}\right.$, COS, etc.) react with $\mathrm{CaO}$ and $\mathrm{Fe}$ in the dust as it is cooled in the cyclone, reducing the sulfur species to about $200 \mathrm{ppm}$. Sarma conducted an extensive thermodynamic analysis of the reactions in the gas phase after smelting. His analysis indicates that most of the sulfur will react and form solid phases. The sulfur is further reduced by reaction with Feo or possibly CaO in the prereducer. The recycled sulfur as Cas and Fes primarily dissolves in the slag and metal. The sulfur distribution between slag and metal can be predicted from thermodynamic principles. At steady-state operation, over $90 \%$ of the sulfur will enter the slag and metal.

\section{Steady-state Model}

Fruehan, Sarma, and Cramb developed a model based on the above sulfur path to describe the sulfur content. It was shown that the sulfur content, in the metal at steady state, [\%S]s is given by:

$$
[z S]_{s}=\frac{100\left(\alpha F_{s}^{c}\right)+\beta F_{s}^{R}}{k+\frac{d W_{S}}{d t}+\frac{1}{L_{s}} \frac{d W_{M}}{d t}}
$$

\footnotetext{
$\alpha \quad=$ fraction of sulfur in coal entering slag and metal

$\mathrm{F}_{\mathrm{s}}^{\mathrm{c}}=$ rate of sulfur input from coal

$\beta^{s} \quad$ fraction of sulfur from recycle entering slag and metal

$F_{s}{ }^{R}=$ rate of sulfur input from recycle

$\mathrm{k}_{\mathrm{s}} \quad$ rate of removal of sulfur from slag

$\mathrm{I}_{\mathrm{s}} \quad$ = sulfur distribution ratio between slag and metal
} 
$W_{s} \quad=$ slag weight
$W_{u}=$ metal weight

Using this model, Myers developed a comprehensive mass balance for the process as a function of the various variables.

\section{Sulfur Distribution Between Metal and Slag}

The work above indicated that, for a fully integrated process, with recycle, over $90 \%$ of the sulfur will enter the slag or metal. The distribution between the slag and metal was documented and analyzed by Nassaralla and Myers and by Sarma and Cramb. As shown in Figure 13.9, the sulfur partition ratio increases with basicity. As with most steelmaking processes, the oxygen potential is controlled by Feo-Fe equilibrium, and the sulfur partition ratio can be predicted from the sulfide capacity and the Feo content of the slag (Figures 13.10 and 13.11). In the simplest form, the reaction for desulfurization is given by:

$$
(\mathrm{CaO})+\underline{\mathrm{s}}+\underline{\mathrm{Fe}}=(\mathrm{FeO})+(\mathrm{CaS})
$$

Consequently, $\mathrm{L}_{\mathrm{s}}$ decreases with Feo content.

The range of $I_{s}$ in the pilot plant data is 2 to 8 , depending on the Feo content and basicity of the slag. With vessel number three, the basicity was kept low in order to tap the slag effectively. For typical operation, the expected values of $L_{s}$ will be $2-5$. Since coal rather than coke is to be used, increasing the sulfur load, and $L_{s}$ is much lower due to the higher Feo in the smelter than in a blast furnace, the sulfur content of the metal will be significantly higher than for a blast furnace. Depending on the sulfur content of the coal and the slag chemistry, the sulfur content will be $0.15-0.30 \%$. The sulfur content in the slag and hot metal can be calculated from $L_{s}$, the coal sulfur content, and the rate, and slag weight as shown by Myers for the proposed demonstration plant operation (13.12) for coal with $0.7 \%$.

\section{Metal Desulfurization}

It is obvious that desulfurization will be more difficult and costly than for blast furnace metal. Two approaches are possible:

- In the smelting tapping ladle, provide stirring for further reduction of Feo from the slag, leading to more desulfurization of the hot metal, followed by slag removal and conventional desulfurization.

- Mannesmann Demag has explored a two-stage desulfurization process after removal of the smelting slag.

The first approach is currently being studied at CMU and was shown to be effective by DIOS. The reactions involved are, first, 
FIGURE 13.9

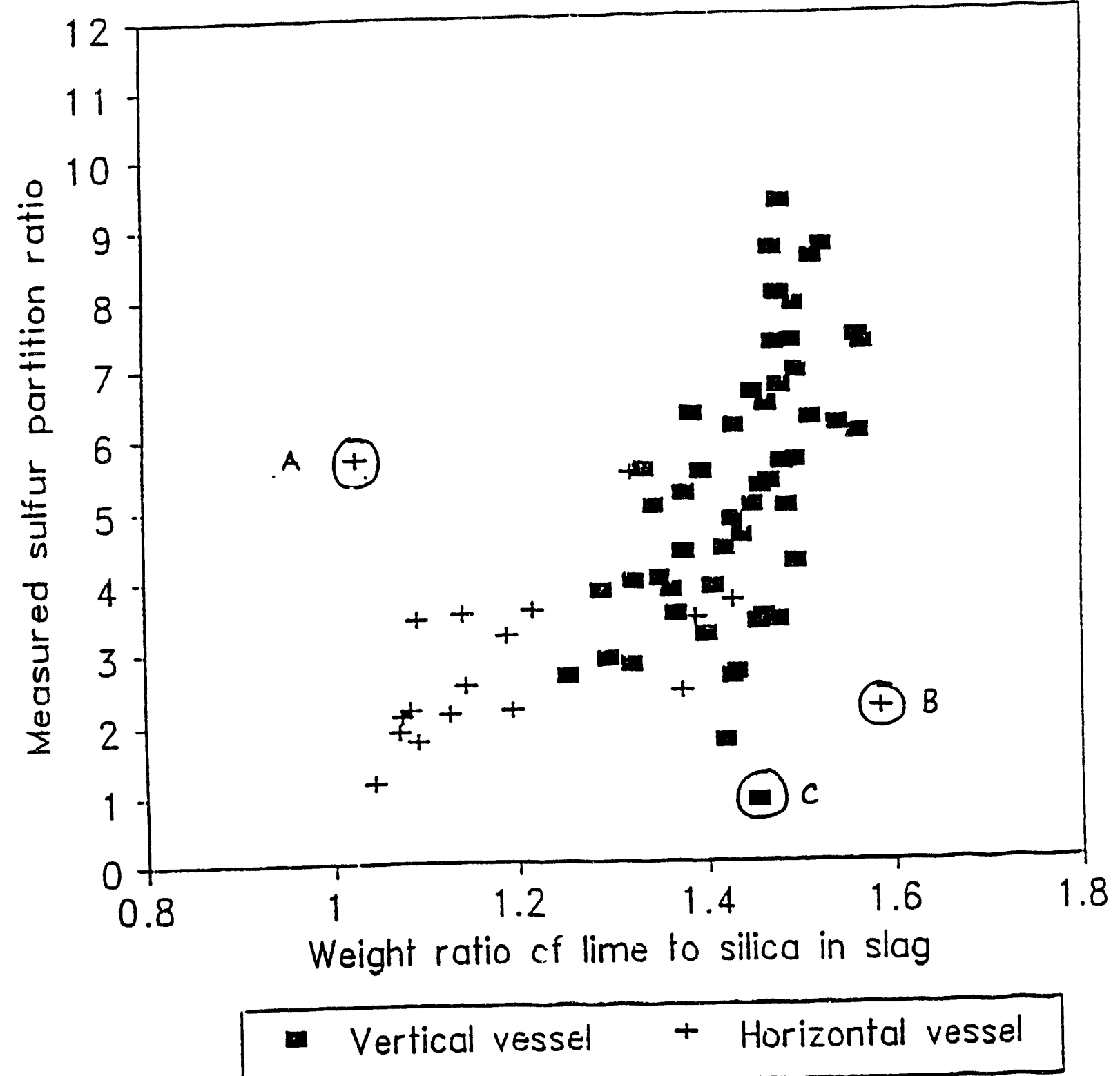

Effect of basictty on sulfur distribution ratio. 
FIGURE 13.10

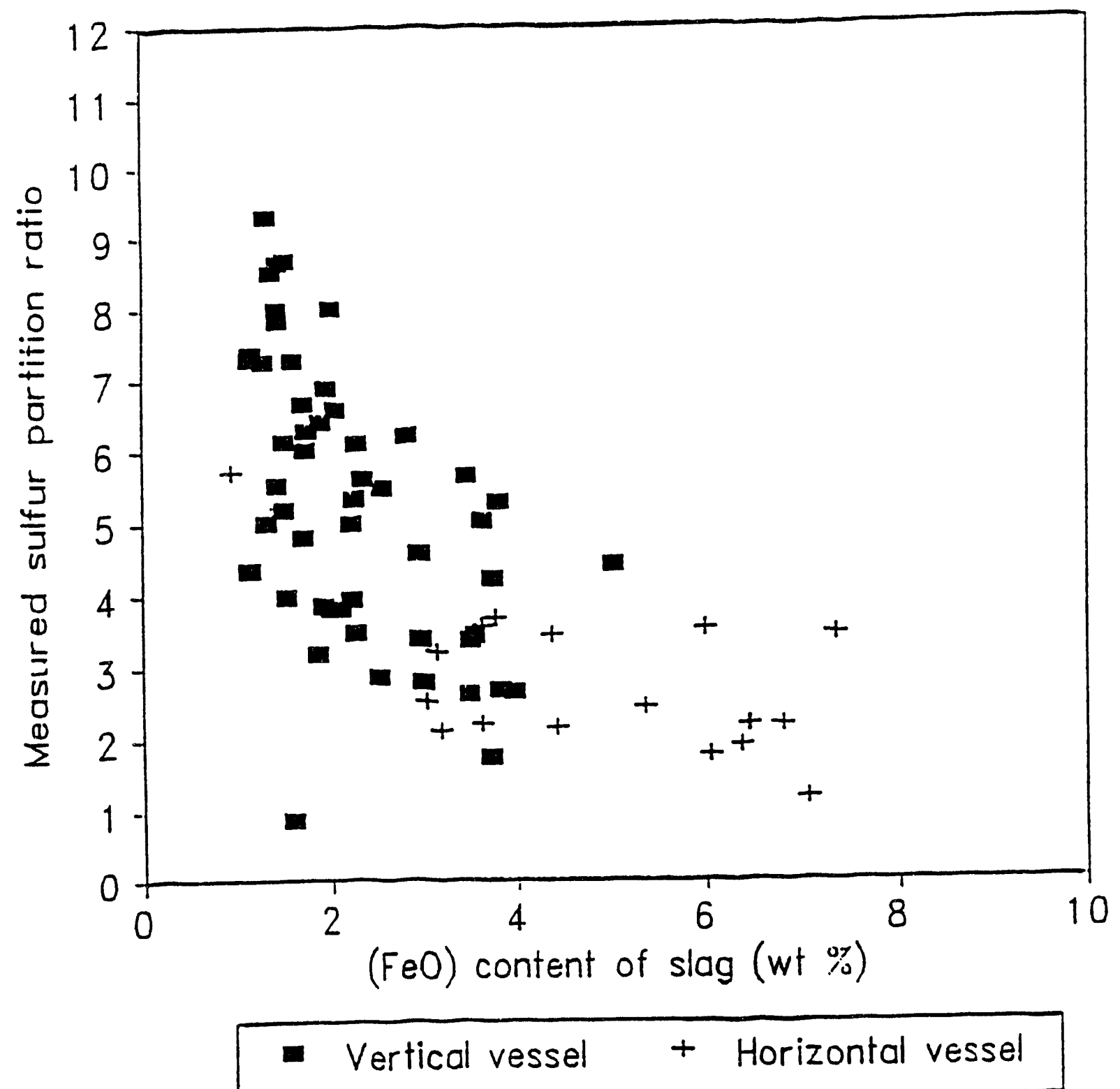

Effect of FeO on the sulfur partition ratio. 
FIGURE 13.11

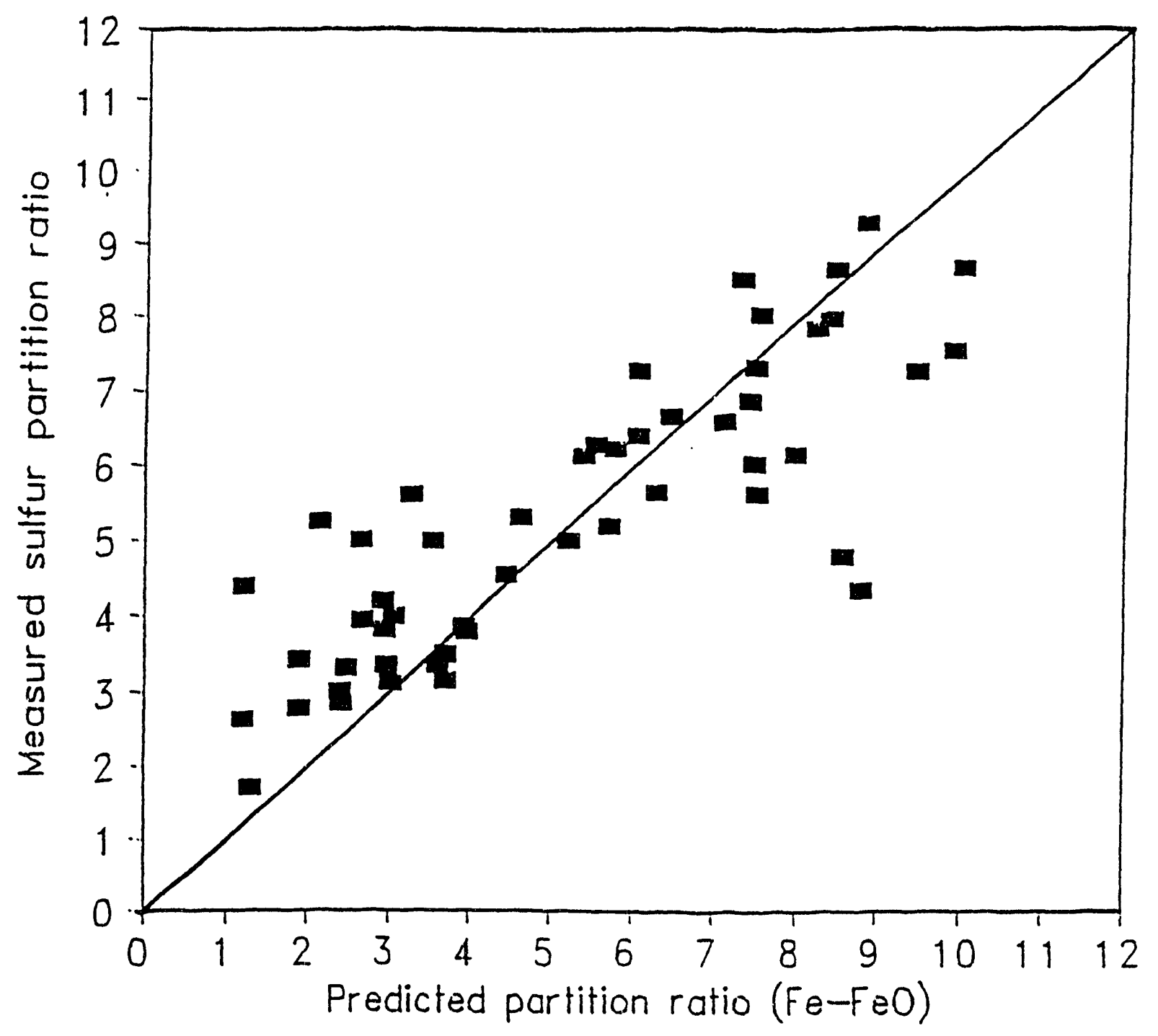

- Vertical vessel

Comparison of computed and measured sulfur partition assuming the oxygen potential is controlled by Fe-FeO. 


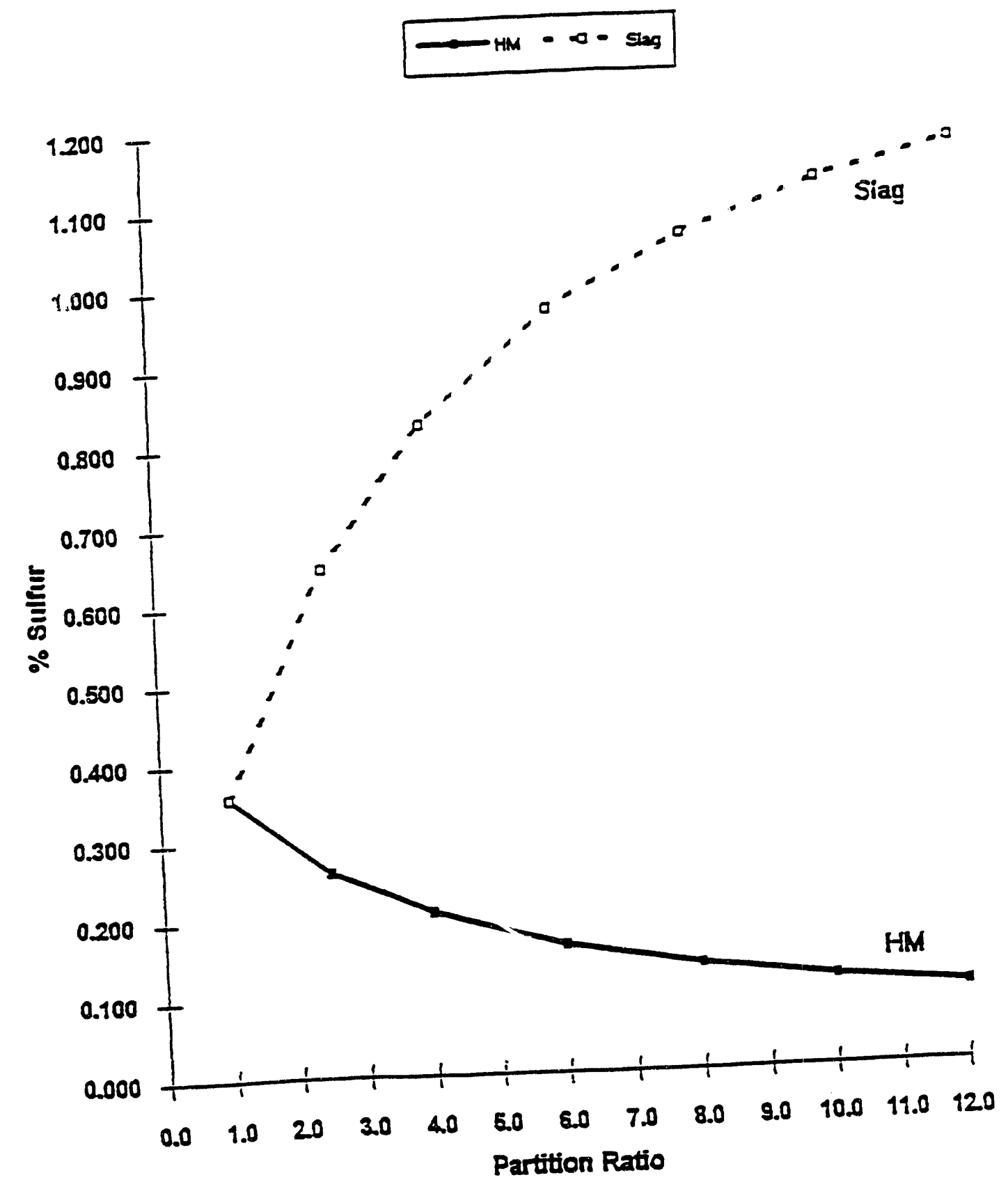

Effeci of sulfur partition ratio on sulfur content for the demonstration plant for coal containing $0.7 \% \mathrm{~S}$. 
reduction of Feo by the carbon in the metal or char, if it still exists in the slag.

$$
F e O+C=F e+C O
$$

Since the oxygen potential for sulfur is controlled by Fe-Feo, the transfer of sulfur to the smelting slag will follow reduction. For example, if the Feo is reduced from $5 \%$ to $2.5 \%$, the sulfur partition ratio will double, and the sulfur content of the metal will be reduced by about a factor of two. In addition, for typical slag volumes, the yield of iron can increase by up to 18 .

It may be possible to add ferrosilicon or aluminum to increase the rate of reduction of FeO and add heat to the process. Silicon would also improve the subsequent rate of desulfurization. The process is unproven and requires more study and evaluation. At CMU, work is underway to examine the rates of the reactions, and water modeling is planned to see the effect of the large slag volume on the process.

For the final step in the two approaches, the smelting slag must be completely removed. Recent work at CMU by Iwamasa and Fruehan shows the effect of Feo on desulfurization. Also, work by McFeaters anc Fruehar ${ }^{17}$ showed that, for effective desulfurization, there must be a critical amount of silicon in the metal of about $0.1 \%$ (Figure 13.13).

\section{Phosphorus}

The behavior " phosphorus is much less complex than sulfur and was analyzed by Nassaralla and Myers. They found that dephosphorization could be adequately described by the reaction:

$$
2 P+5 \mathrm{FeO}=\left(P_{2} \mathrm{O}_{5}\right)+\mathrm{Fe}
$$

From the pilot plant data, they determined the phosphate capacities and developed the following equation for phosphorus:

$$
\begin{aligned}
\log \frac{\left(P_{2} O_{5}\right)}{[P]^{2}}= & \frac{20,929}{T}+0.826 \log \left(F e_{T}\right)-0.417(\mathrm{CaO})-1.078(\mathrm{MgO}) \\
& +0.529\left(\mathrm{SiO}_{2}\right)+0.385\left(\mathrm{Al}_{2} \mathrm{O}_{3}\right)-0.9245
\end{aligned}
$$




\section{FIGURE 13.13}

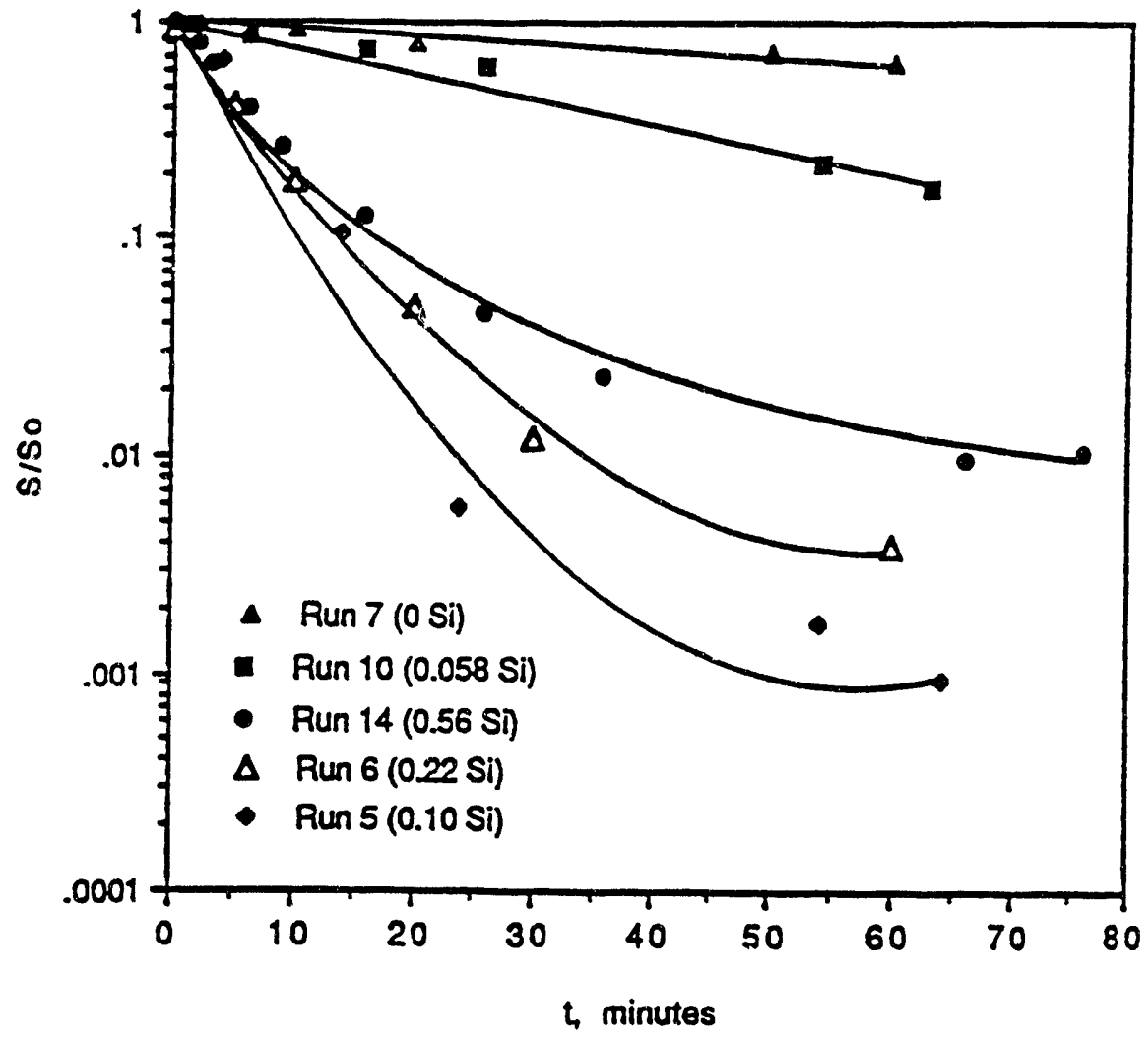

The effect of SI content on the rate of desulfurization of carbon saturated iron at $1450^{\circ} \mathrm{C}$ using $\mathrm{CaO}-10 \% \mathrm{CaF}_{2}$. 
The comparison of the observed and calculated partition ratios is shown in Figure 13.14. The phosphorus cuntent of the metal will depend on the Feo content and basicity of the slag and the phosphorus in the ore. In general, the phosphorus will be $10-20 \%$ less than for a blast furnace.

\section{Dust Formation}

Dust leaving the smelter with the offgas is captured in the hot cyclone and recycled and does not affect iron yield, provided the cyclone efficiency is high. However, it does affect energy consumption and productivity, and excessive recycling adds complexity and cost to the process. Very roughly, 150 to $350 \mathrm{~kg}$ of dust per tonne of hot metal are generated, which represents about 8\% to $15 \%$ of the feed materials. A considerable amount of data from the pilot plant concerning smelter dust exists. However, there are large variations in the amount and composition of the dust, and no fundamental work has been carried out to help understand the mechanisms of dust formation.

Despite the large variations in composition and amounts of dust, some general trends have been observed from which reasonable speculation on dust formation mechanisms can be made.

1. The amount of dust increases significantly with the VM content of the fuel as indicated below:

$\begin{array}{lcc}\text { Fuel } & \text { VM } & \begin{array}{c}\text { Total Dust } \\ \mathrm{kg} / \mathrm{t}\end{array} \\ \text { Coke } & & \\ \text { MV } & -- & 60-80 \\ \text { HV } & 25 & 160-200 \\ & 36 & 290-350\end{array}$

2. As the VM increases, the carbon content of the dust increases (Figures 13.15 and 13.16).

3. As the offgas volume flow rate increases, the amount of dust increases as expected (Figures 13.17 and 13.18). However, this observation cannot simply be explained by entrainment of the added fines. As shown by Du, the amount of fines which could be carried out ( $<3 \mathrm{~mm}$ or $1 / 8$ inch) is much less than the total (Figure 13.19).

4. The cyclone dust contains roughly $10 \%-50 \%$ iron, with about half being metallic iron. The remainder of the cyclone dust is primarily carbon. The sludge is $20 \%$ $70 \%$ iron, but it is impossible to estimate how much was metallic when it left the smelter, since it could have been oxidized by the water. 


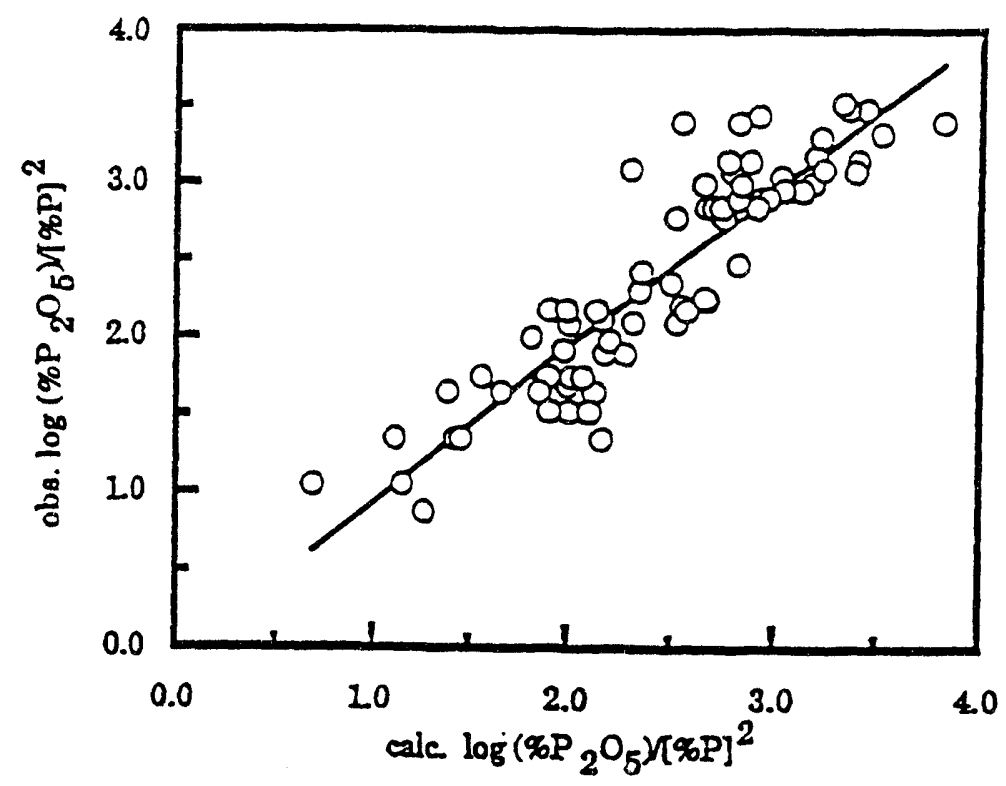

Statistical correlation between $\left(\% \mathrm{P}_{2} \mathrm{O}_{5}\right) /[\% \mathrm{P}]^{2}$ observed and $\left(\% \mathrm{P}_{2} \mathrm{O}_{5}\right) /[\% \mathrm{P}]^{2}$ calculated as a function of slag composition and temperature. log $\left.\left(\% \mathrm{P}_{2} \mathrm{O}_{5}\right) \pi \% \mathrm{P}\right]^{2}=20,929 \pi \mathrm{T}+0.826 \log (\% \mathrm{~F} . \mathrm{Fe})-0.417(\% \mathrm{CaO})-1.078(\% \mathrm{MgO})+$ $0.529\left(\% \mathrm{SIO}_{2}\right)+0.385\left(\% \mathrm{Al}_{2} \mathrm{O}_{3}\right)-9.245, \mathrm{r}^{2}=0.815$. 
Carbon Losses vs. Volatile Matter

(Trial Averages)

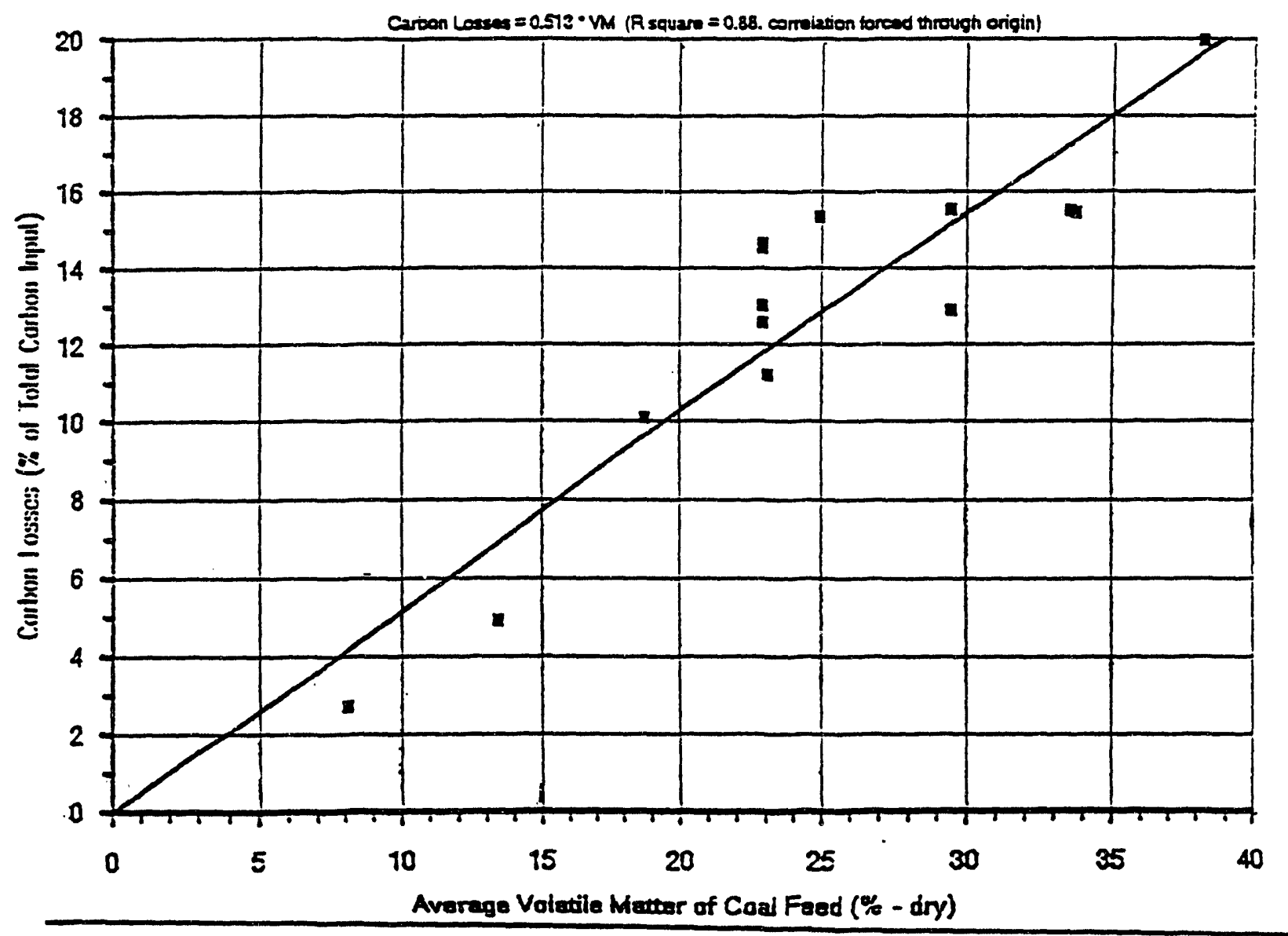

The increase of carbon content of the dust from the horizontal smeiter. 


\section{FIGURE 13.16}

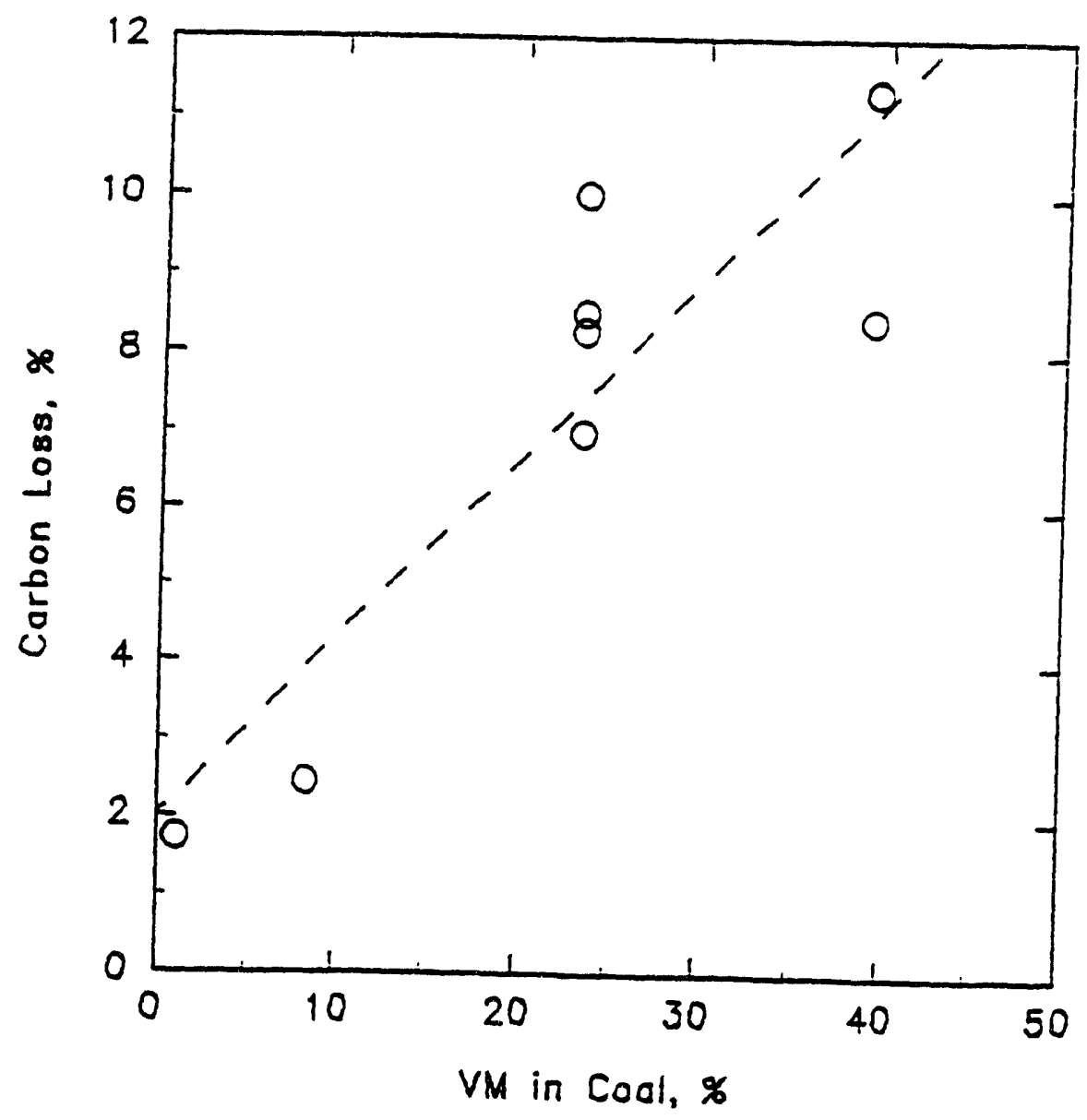

The increase in carbon loss as dust with VM for the 3rd smelter. 


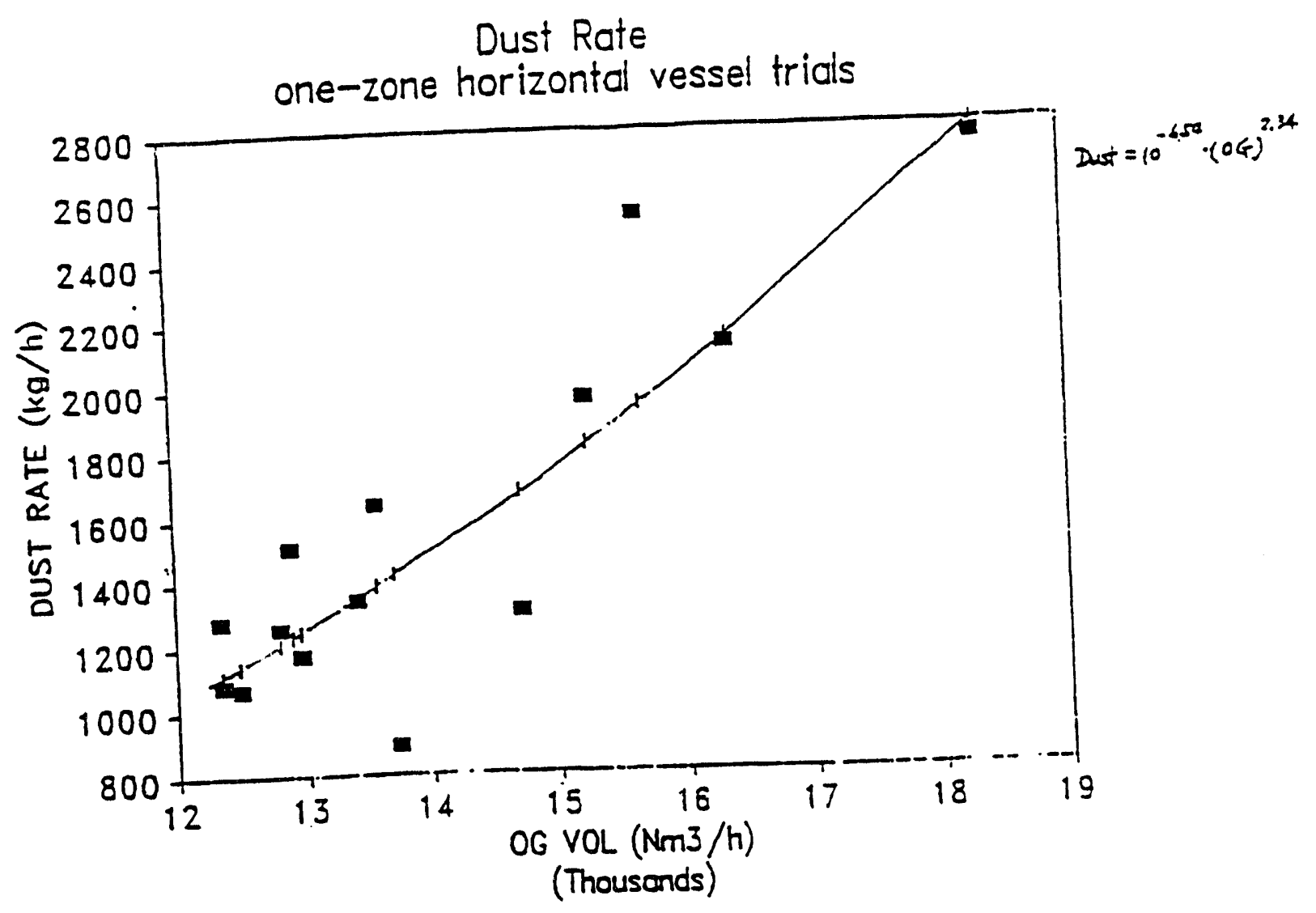

Effect of off gas volume on dust in the horizontal smelter. 
FIGURE 13.18

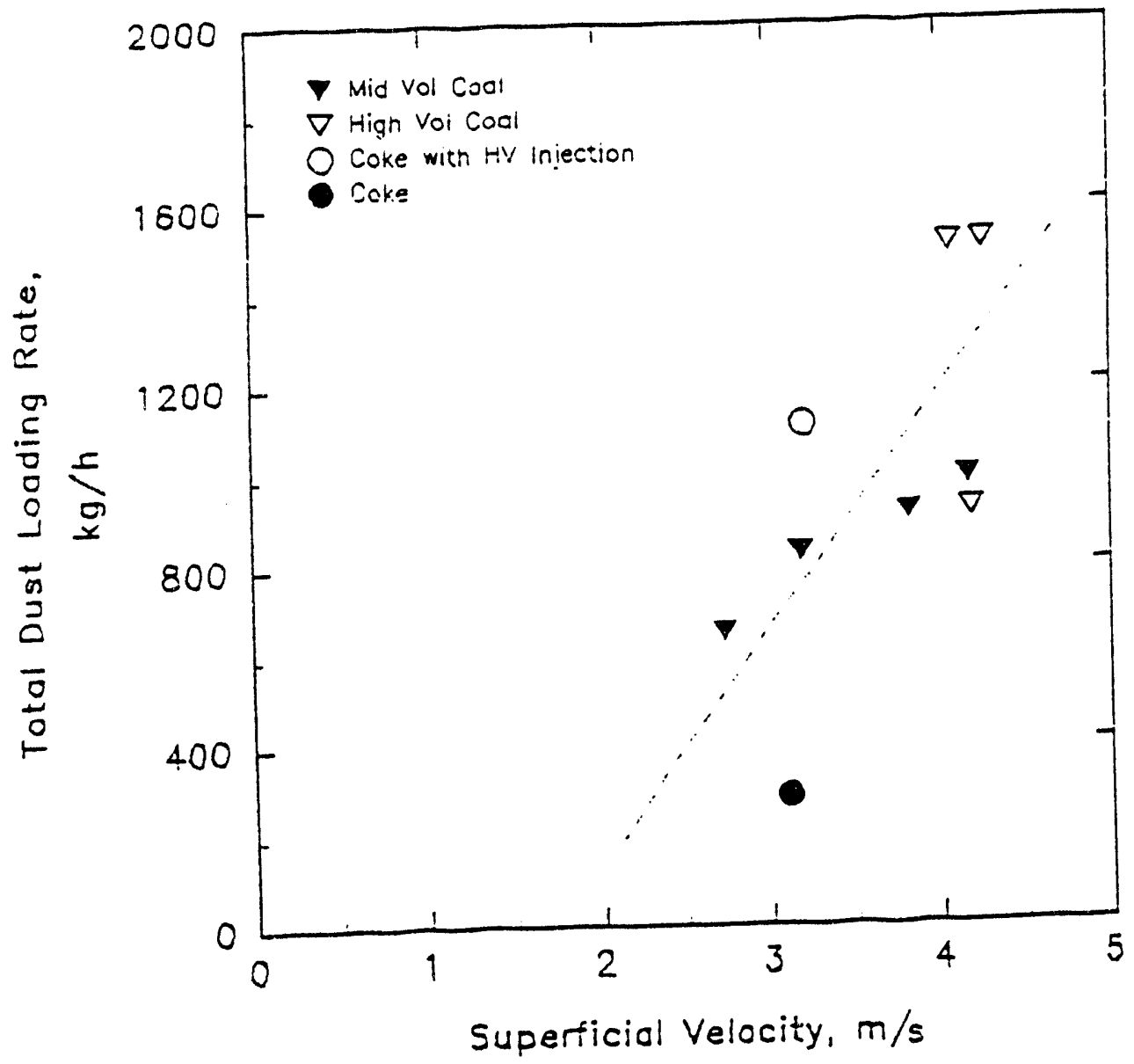

Effect of superticial gas velocity on dust in the 3rd smetter. 


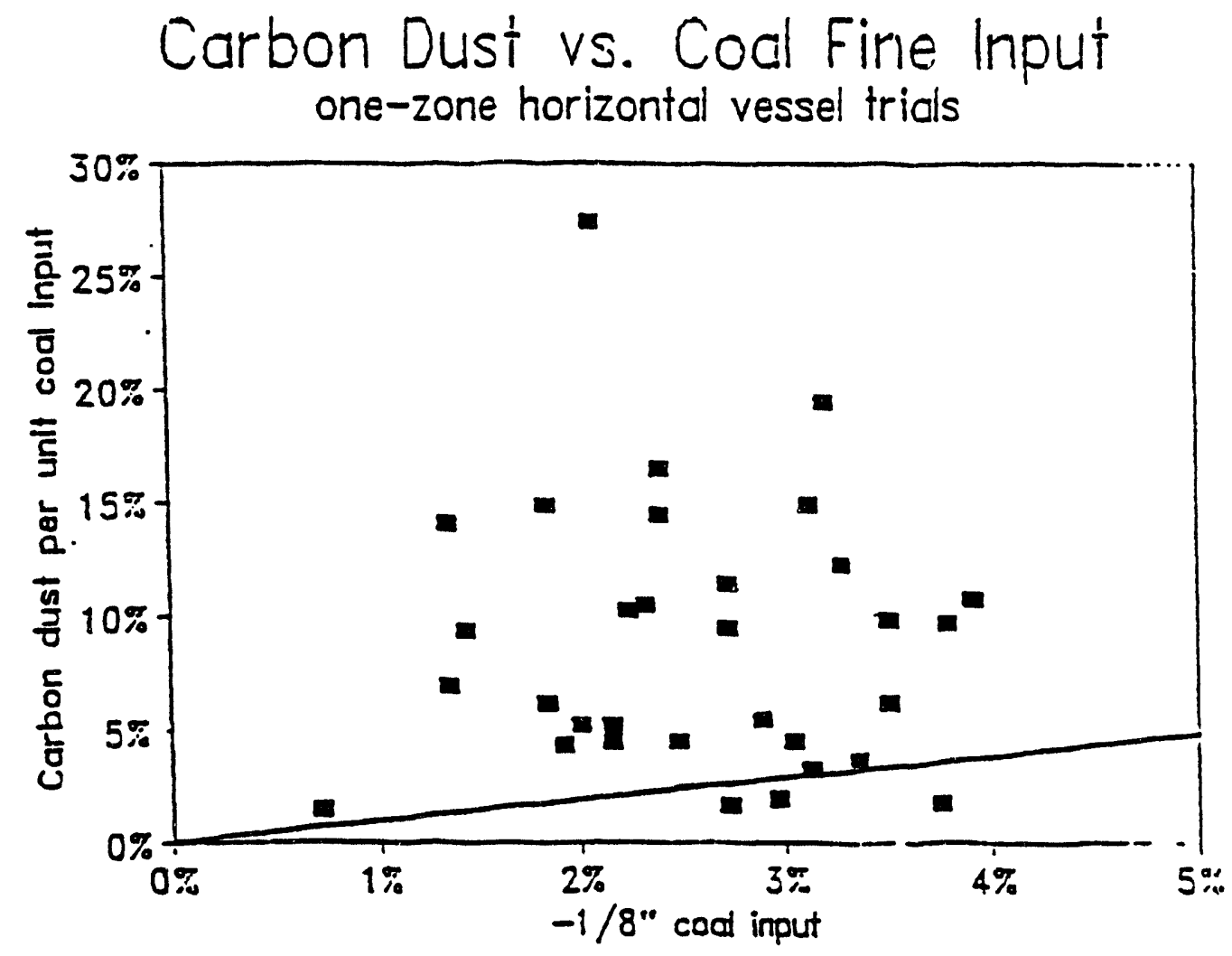

Carbon loss versus percent fines and that calculated for simple entrainment. 
5. The CaO to $\mathrm{SiO}_{2}$ ratio in the sludge is $0.3-0.4$ and slightly higher in the cyclone.

6. Dust rates increase as slag volume decreases. In Figure 13.20, the oxygen, coal, and dust rates are given along with the slag weight. In particular, the iron content of the dust increased after slag tapping at $14: 10$.

7. There are insufficient data at this time to determine if coal injection significantly reduced the amount of dust.

These observations allow us to postulate the following mechanisms of dust formation:

1. Coal fragmentation during devolatilization causes formation of carbon fines. Some of this carbon is large enough to be removed in the cyclone.

2. A significant portion of the carbon from the VM which is formed by the cracking of the hydrocarbons is soot and is carried out of the vessel, most likely into the sludge.

3. The majority of the $\mathrm{CaO}$ and $\mathrm{SiO}_{2}$ does not come from slag but, rather, from the fragmented coal. This is based on the fact that the basicity ratio is that of the coal, not of the slag.

4. Iron primarily comes from vaporization and fuming of iron. The large amount of metallic iron can only come from vaporization. Even some of the vaporized iron would be expected to be oxidized. Some large iron particles found in the dust may be from metal ejected from the bath. This is expected to be low, due to the large amount of slag cover.

5. A small percentage of the dust $(<20 \%)$ is due to fines being entrained in the offgas.

Based on these mechanisms, some methods for reducing dust may be possible:

- Increasing pressure to reduce gas velocities and reduce fines being carried out and to increase residence time of $V M$ for cracking and combustion.

- Maintain a reasonable slag cover at all times, and avoid excessive temperatures to reduce iron vaporization.

- Distribute the coal feed throughout the vessel to increase the probability of combustion of the coal volatiles released. 
FIGURE 13.20
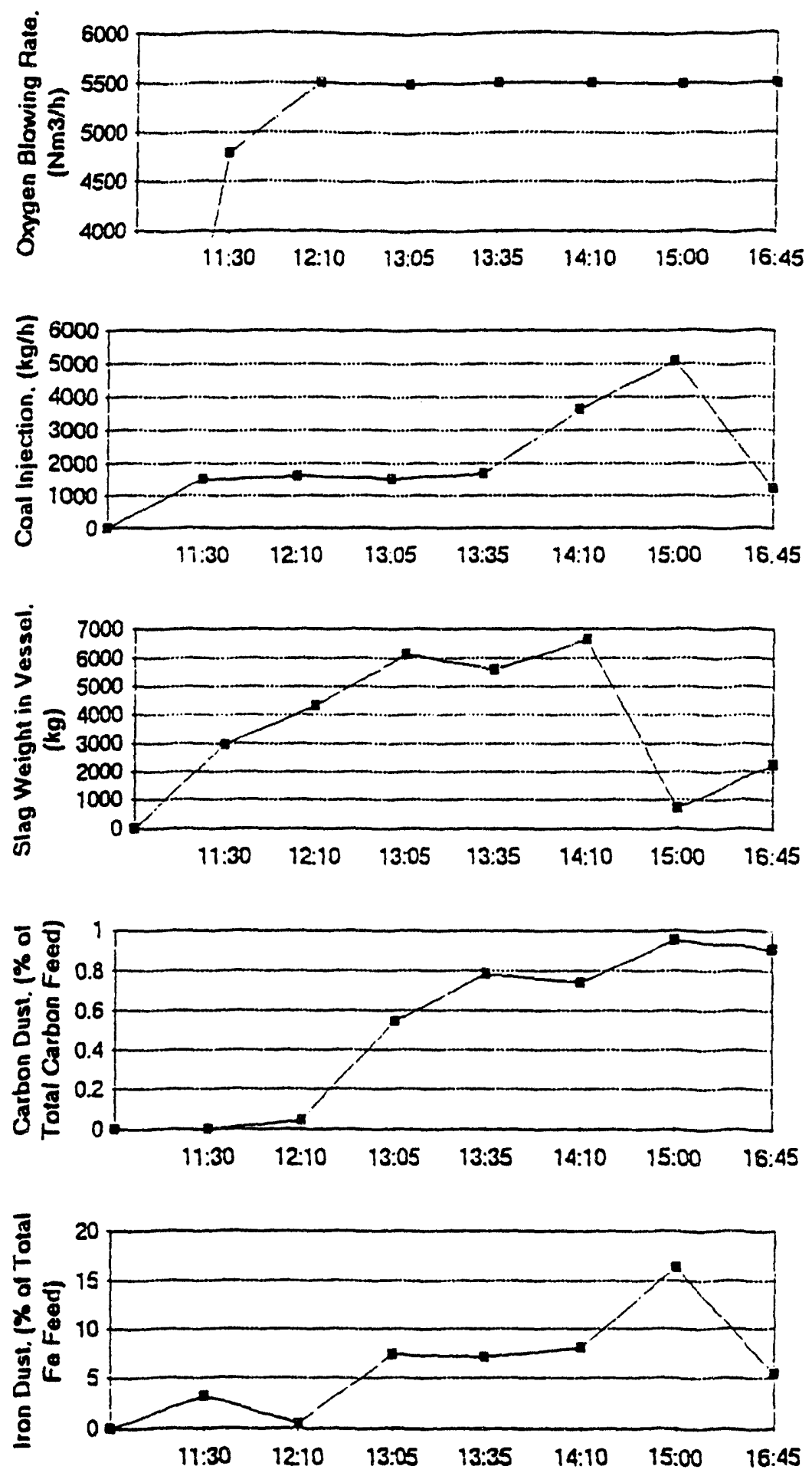

Effect of process variables on carbon and iron in dust. 


\section{Energy Consumption}

Energy consumption in the smelting process is a very complex issue. It depends on the amount of postcombustion, coal volatile matter content, heat transfer from postcombustion, heat losses, dust recycling rate, and other factors. The key to successful smelting is to obtain sufficient postcombustion and heat transfer.

\section{Energy and Materials Balance}

The energy and materials balances for AISI smelting were developed at CMU and later refined by AISI for analysis, control, and predictions. The energy and materials balances are essentially exact for the assumed operating conditions. The smelting parameters are set, and the coal consumption is calculated. The most critical parameters are:

- Postcombustion degree (PCD)

- Heat transfer efficiency from PC (HTE)

- Feed materials compositions

- Heat losses

- Dust losses

The key to energy efficiency is obtaining the desired PCD and HTE. However, PCD is not controlled but is dictated by the other process variables in a complex manner.

\section{Volatiles}

Based on published NSC and NKK work, it was recognized early in the AISI program that it was difficult to obtain high PC and HTE for high volatile coals. It was believed that the volatiles came off before they could be combusted. Extensive work was done by Sampaio and Fruehan ${ }^{18}$ on devolatilization of coals for smelting conditions in the gas phase and the slag. The major results of these studies are:

1. The rate of devolatilization in terms of percentage of volatiles released is independent of coal type (Figure 13.21).

2. The rate is a strong function of particle size (Figure 13.21), with the time to achieve a given degree of devolatilization being proportional to the particle diameter to about the second power. 


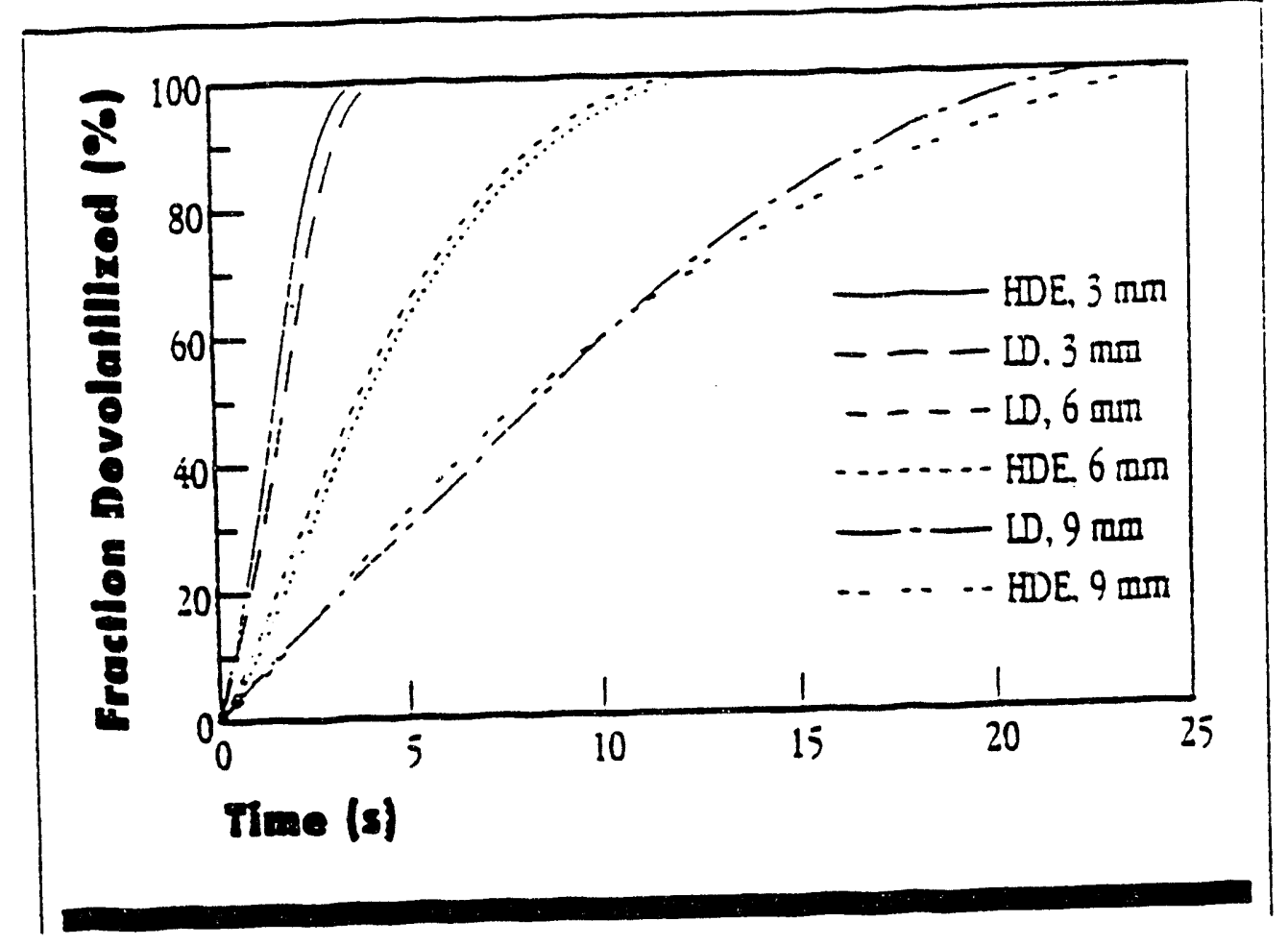

Rate of devolattization of coal as a function of size and type. 
3. The rate of devolatilization in a gas phase with high heating rates was the same as for coal submerged in slag.

4. The rate of devolatilization is primarily controlled by heat transfer within the particle for top-charged larger particles.

Sampaio and Fruehan ${ }^{12}$ also developed a two-zone energy and material balance, one for the smelting system and one for the offgas. The model demonstrated that some of the VM would simply dilute the smelting gas, reducing the net $\mathrm{PCD}$.

Zhang analyzed what could be happening with the volatiles in the top-charged coal. His conclusions are:

1. The largest particle which could be blown cut is less than $1 \mathrm{~mm}$ diameter.

2. The time for the particles to fall through the hot gases ranged from about $1-2$ seconds for small particles to 0.6 seconds for those greater than $3 \mathrm{~mm}$.

3. For the majority of the coal which is in excess of $6 \mathrm{~mm}$, less than $5 \%$ of the volatiles come off during their residence time in the top space.

4. The majority of the volatile matter comes off from coal on top of the slag over a period of about 10 30 seconds.

\section{Postcombustion}

The following trends regarding degree of postcombustion were observed in pilot plant trials:

1. PCD increases with the distance between the lance and the slag as shown in Figure 13.22. This has also been found by DIOS.

2. For relatively constant operating conditions, PCD decreases with increasing VM (Figures 13.23 and 13.24).

3. Fixed carbon consumed by oxidation per cubic meter of oxygen decreases with VM, indicating some VM is combusted and supplies energy (Figure 13.25) to the system. The fixed carbon combusted is calculated from the gross fixed carbon consumption minus the carbon for reduction, solution, and in the dust, assuming all of the dust is fixed carbon. Whereas this assumption concerning the dust may be oversimplified, it would not change the conclusion. 
FIGURE 13.22

\section{PCD vs Lance Gap}

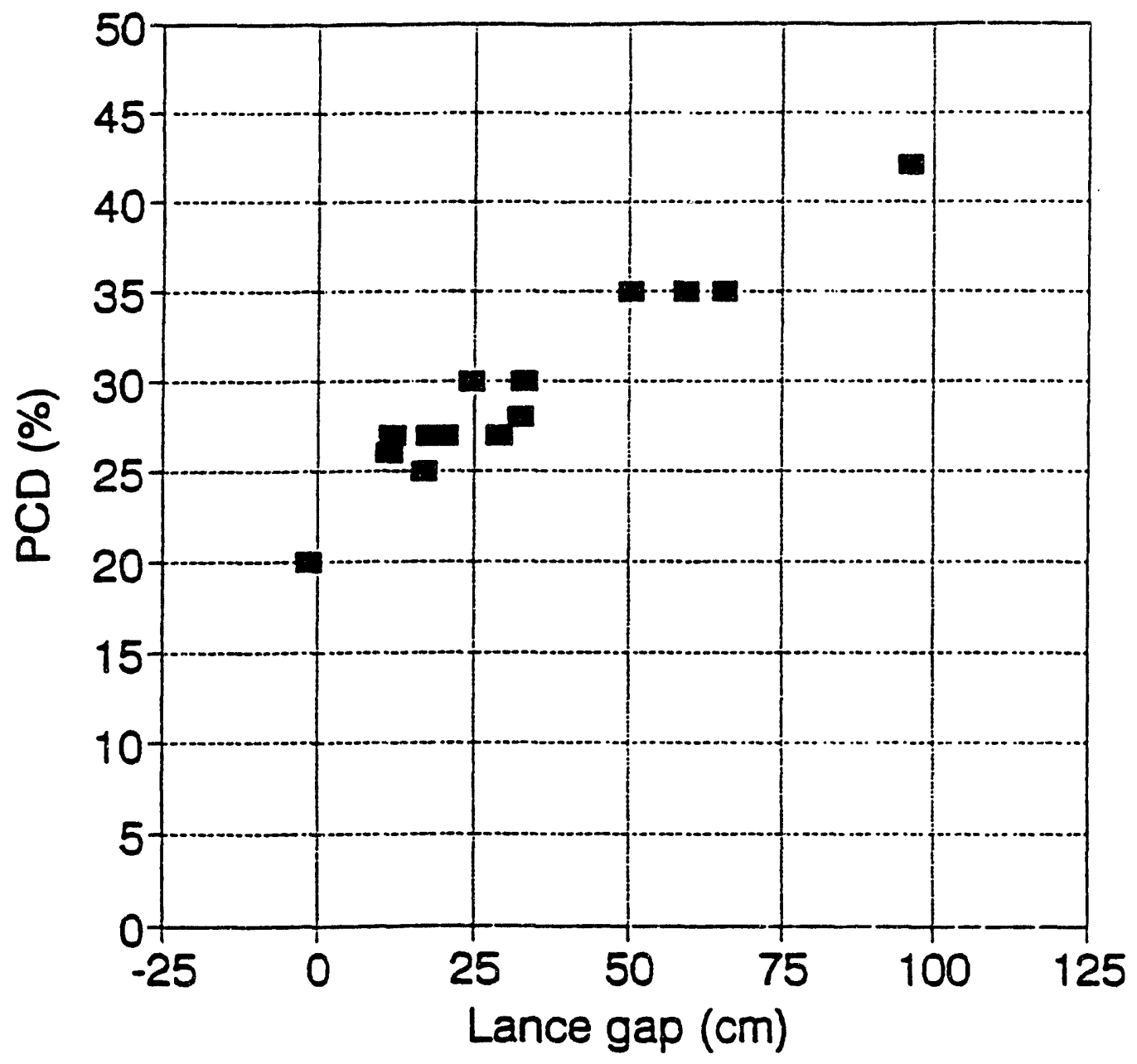

- Horizontal Vessel

The effect of lance gas on PCD. 
Post-combustion degree vs volatile matter input as percent of fuel feed

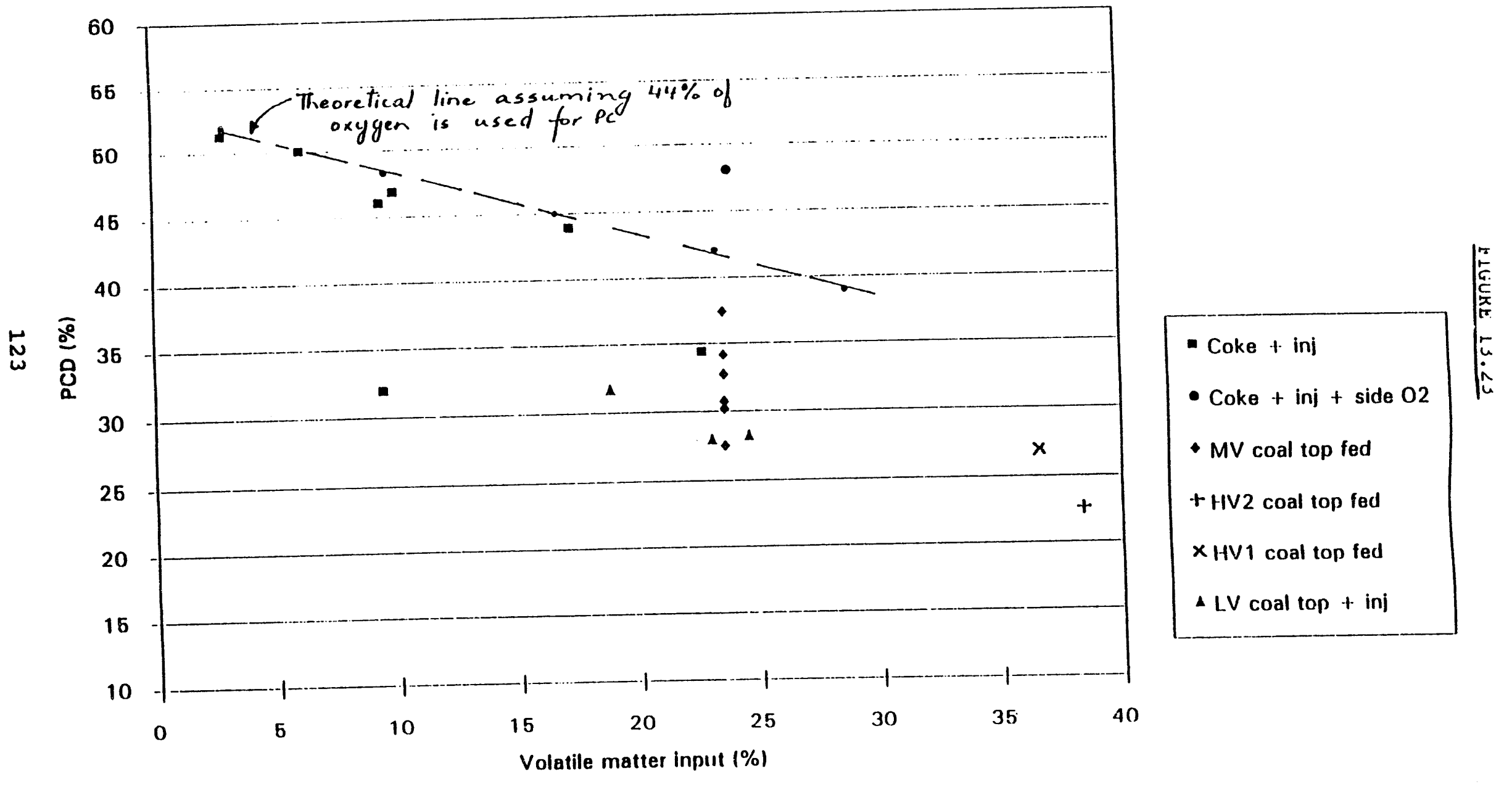

Decrease in PCD with amount of VM (\%) (3rd smelter). 
Post-combustion degree vs volatile matter input per unit oxygen

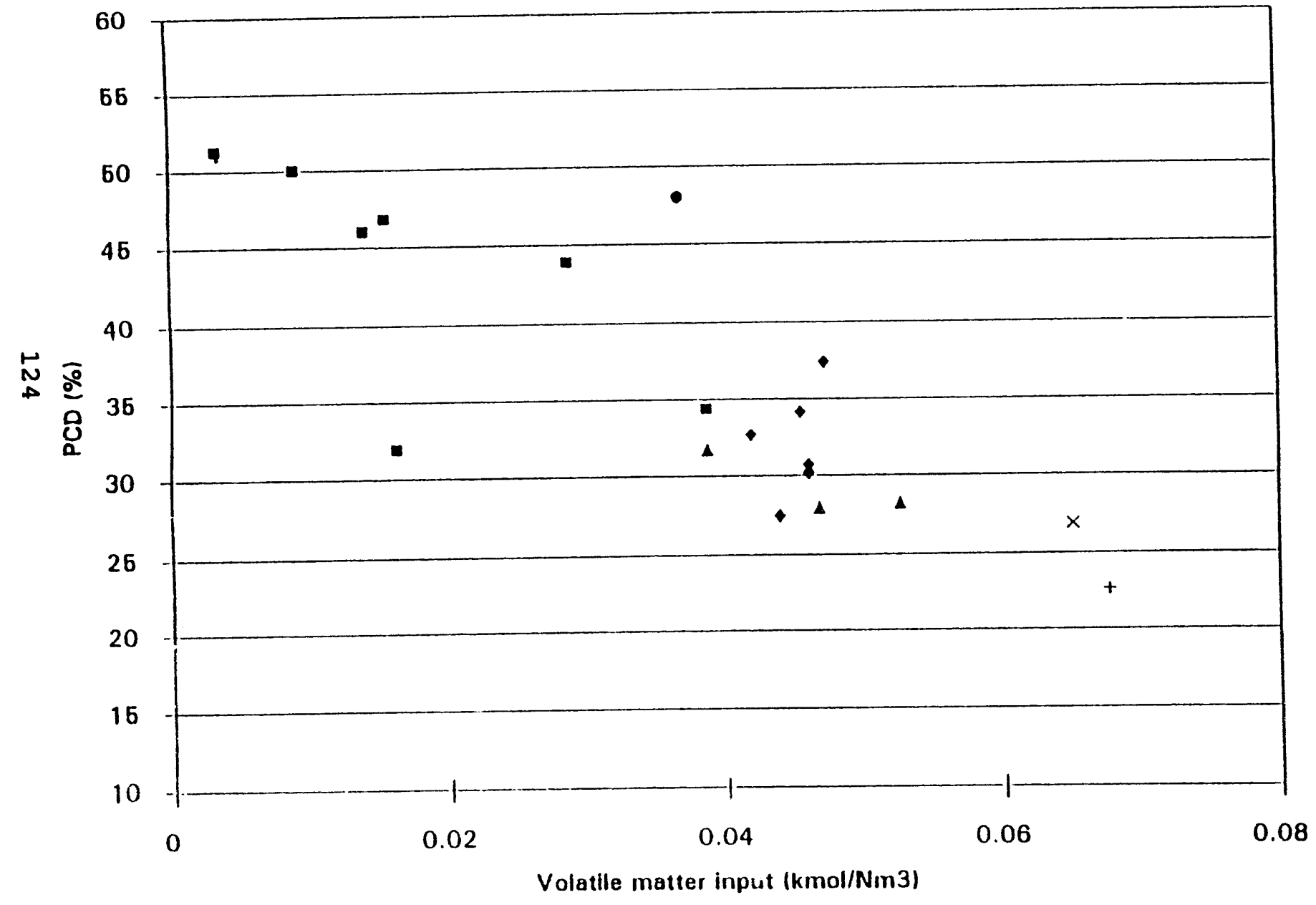

- Coke + inj

- Coke + inj + side 02

- MV coal top fed

+ HV2 coal top fed

$\times$ HV1 coal top fed

$\Delta$ LV coal top + inj 
Fixed carbon used for combustion vs volatile matter input per hour

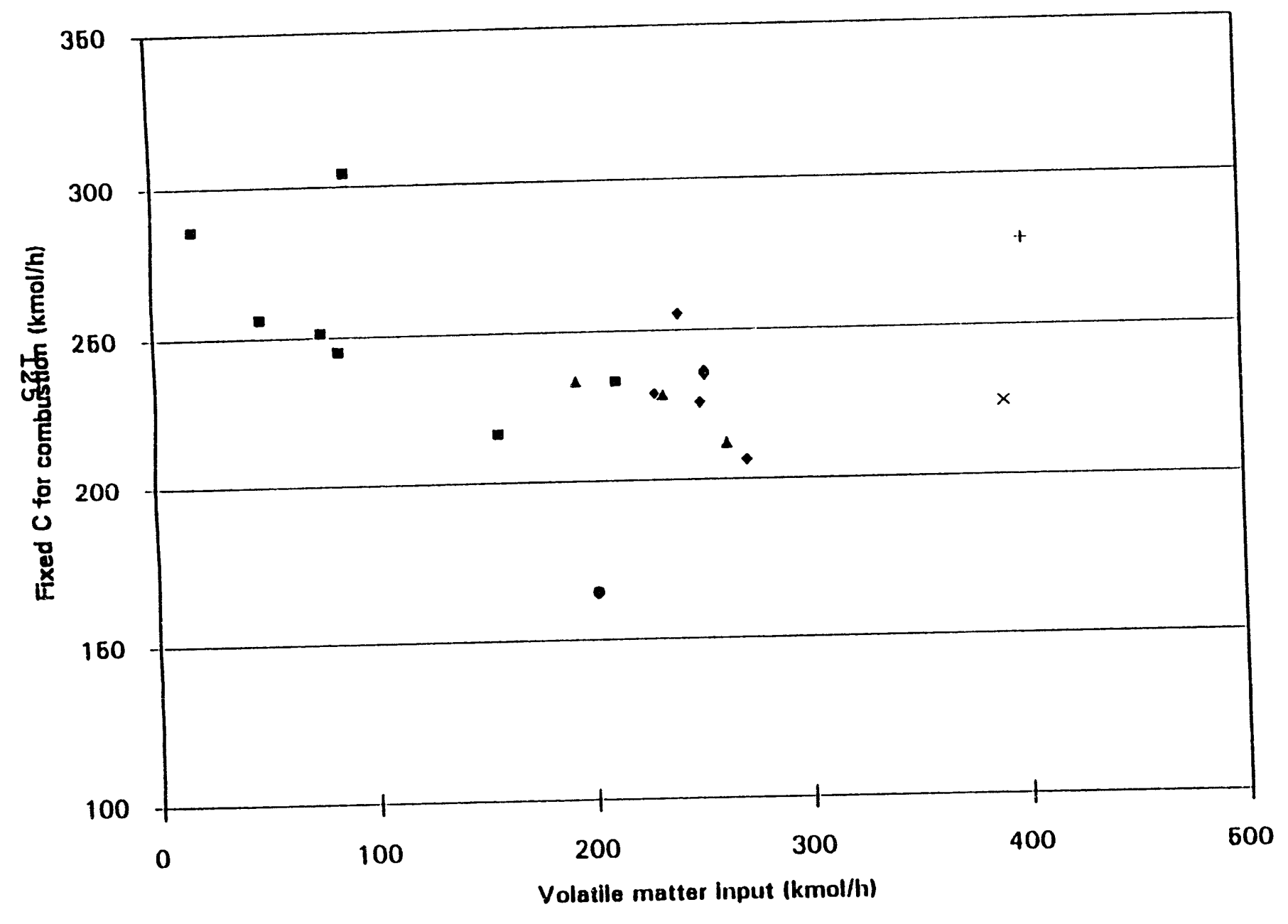

- Coke + inl

- Coke + inj + side $\mathrm{O2}$

- MV coal top fed

+ HV2 coal top fed

$\times$ HV1 coal top fed

L L coal top + inj

Decrease In flxed carbon consumption. 
4. Coal injection improves the use of volatiles and postcombustion as indicated in Figures 13.23 to 13.25 .

5. If there is excessive char in the slag (greater than 20\%), postcombustion decreases. As shown in Figure 13.26, as the char decreases, PCD increases.

\section{Limits to Postcombustion}

From the previous discussion, to achieve high levels of postcombustion, the following must be achieved:

1. Entrainment of $\mathrm{CO}$ and $\mathrm{H}_{2}$ into the oxygen jet. This is related to the jet characterization.

2. Limiting the reactions of $\mathrm{H}_{2} \mathrm{O}$ and $\mathrm{CO}_{2}$ with the char or iron droplets.

To achieve (1), obviously the oxygen must be distributed across the vessel. Equally important, the gases to be postcombusted must be distributed in the vessel. The $c 0$ from char combustion and reduction is equally distributed. However, with the present coal feeding system, most of the coal is devolatilized in one section of the smelter, literally flooding that area with $\mathrm{CO}, \mathrm{H}_{2}$, soot, and hydrocarbons. In that area, an insufficient quantity of these species are entrained and combusted.

This can be illustrated by the following simple example. Consider 5 tonnes per hour of coal with $40 \% \mathrm{VM}$. The result is 3 tonnes or $250 \mathrm{k}$ moles/hr of $\mathrm{co}$ from fixed carbon being equally distributed throughout the vessel and about 350 - $400 \mathrm{k}$ moles/hr of volatiles in the section where the coal is added. If the coal volatile matter comes off in one-fourth of the area, the amount of gas for postcombustion in this area is six times that in the rest of the vessel. Much of this may not be postcombusted due to lack of oxygen in this area.

with coke, there are no volatiles, and the $c 0$ is evenly distributed. With coal injection, more of the gas released during devolatilization is evenly distributed than with top feeding only. It therefore can be concluded that the coal should be added, such that the volatiles are released uniformly across the vessel for more efficient postcombustion.

Another problem with volatiles is simply that the more gas that must be postcombusted, the higher the VM content. Shown in Figure 13.27 is the percentage of oxygen used for postcombustion as a function of volatile matter input. For the best cases, the percentage of oxygen used for postcombustion is about $42 \%$ to $44 \%$. Based on this number, the PCD expected as a function of VM is shown in Figure 13.23. Even under the best conditions, PCD is expected to decrease with VM. However, if a constant percentage of oxygen 


\section{PCD vs time in Trial $H-12$.}

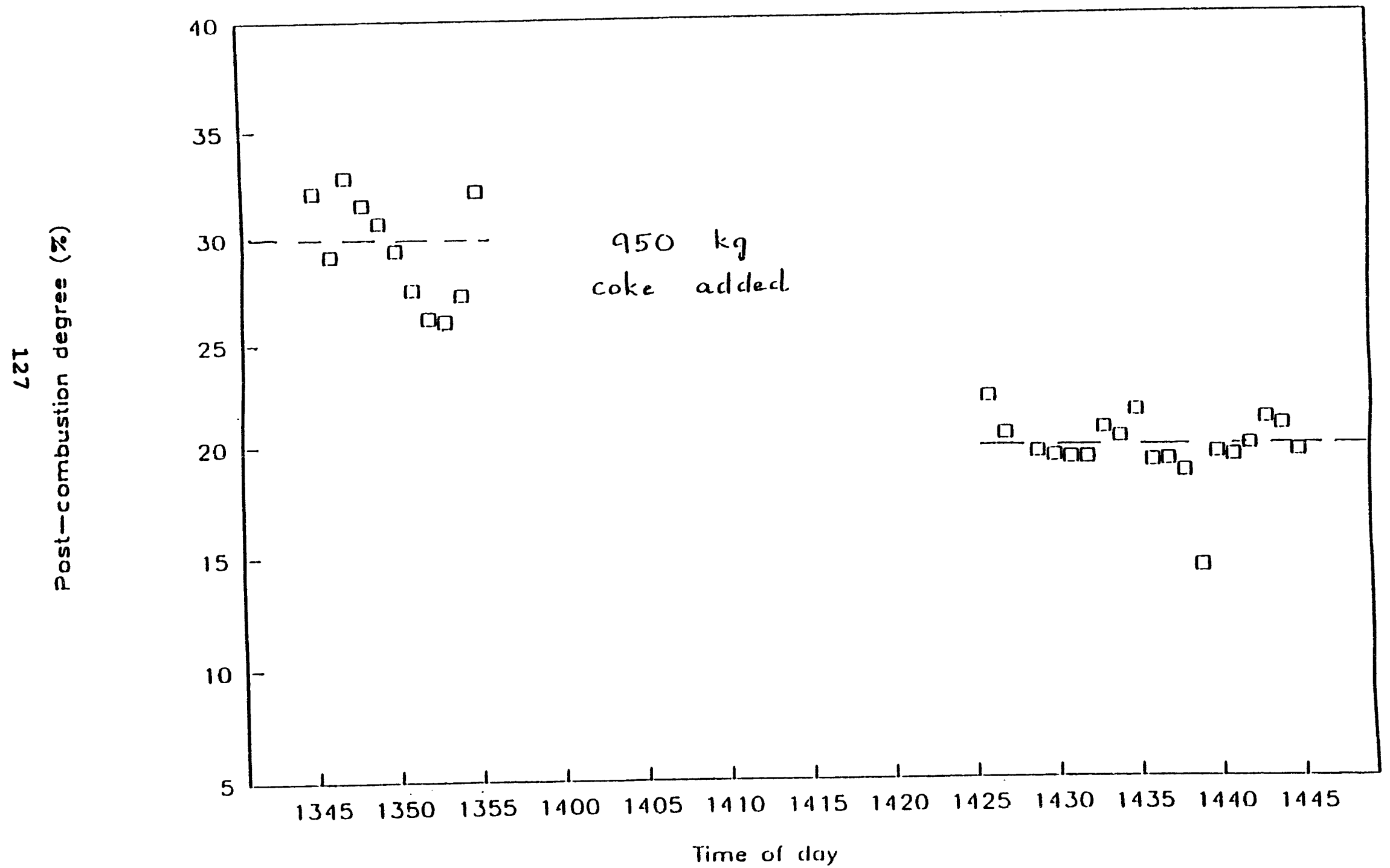


Fraction of lance oxygen used for PC vs volatile matter input as percent of fuel feed

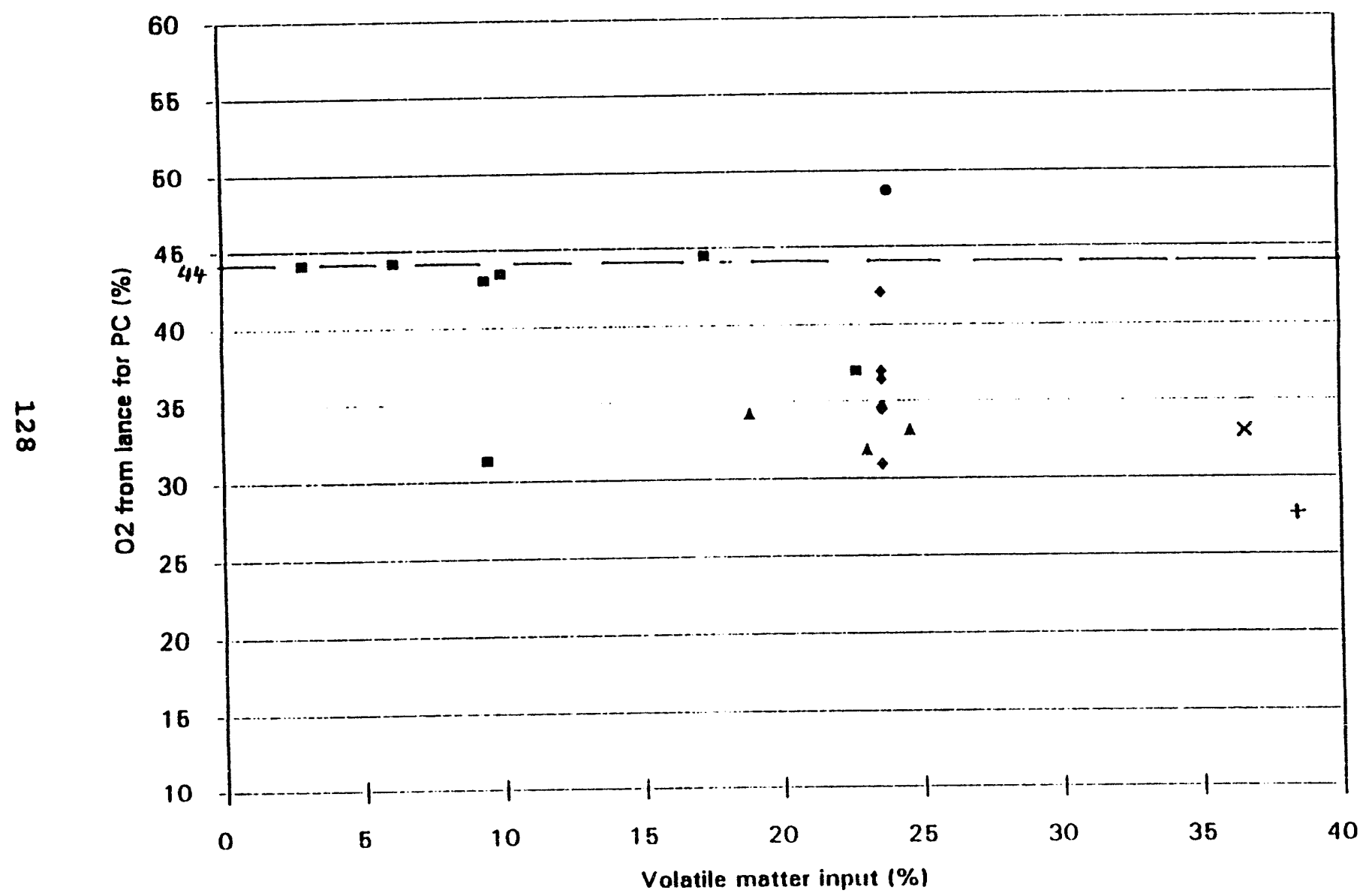

- Coke + inj

- Coke + inj + side 02

- MV coal top fed

+ HV2 coal top fed

X HV 1 coal top fed

I.V coal top + inj

The percentage of oxygen used for post combustlon as a funclion of VM. 
can be used for postcombustion, 358 PCD should be attainable with adequate distribution of the coal feed and oxygen.

\section{Char in the slag}

Char in the slag is important for foam control, reduction, maintaining carbon in the metal, and its effect on postcombustion. with $20 \%$ char, there is adequate char for foam control, reduction, and for carbon in the metal. Above this amount, postcombustion decreases. Therefore, the char should be controlled to about $20 \%$ by weight in the slag.

\section{Heat Efficiency}

Heat utilization or efficiency depends on normal heat losses through the refractories and water cooling and heat transfer from postcombustion. In vessel \#1, and in DIOS trials, the heat transfer efficiency (HTE) from postcombustion was measured by measuring the temperature of the postcombusted gases. This is a useful indication of HTE, but measuring the temperature accurately is difficult and does not indicate the total efficiency. Therefore, for our purposes, the gross energy efficiency will be considered, i.e. the percentage of total heat generated from primary combustion of char and from postcombustion that is utilized in the process. The remainder is the total heat losses, including those in the super-heated offgases.

The total heat efficiency is shown in Figure 13.28. Typically, about $90 \%$ of the heat is utilized. Variations are due to the amount of insulation used in the hood, the location of postcombustion, etc.

Heat transfer mechanism and extrapolation -- The heat transfer mechanisms are complex and not completely understood. The mechanisms include:

- Radiation

- Transfer of postcombustion heat to the foamed slag and unfoamed slag.

- Transfer to "splatter or splash" of slag and metal in the top space.

- Transfer by circulation of the slag and char in the slag.

In smelting, over 50 of the energy comes from postcombustion. Furthermore, heat transfer from postcombustion is most likely more difficult than from primary combustion. one very important distinction must be made between heat transfer from postcombustion in smelting and in BOF steelmaking. In the BOF, the postcombustion heat must be transferred to the metal to be effective. In 


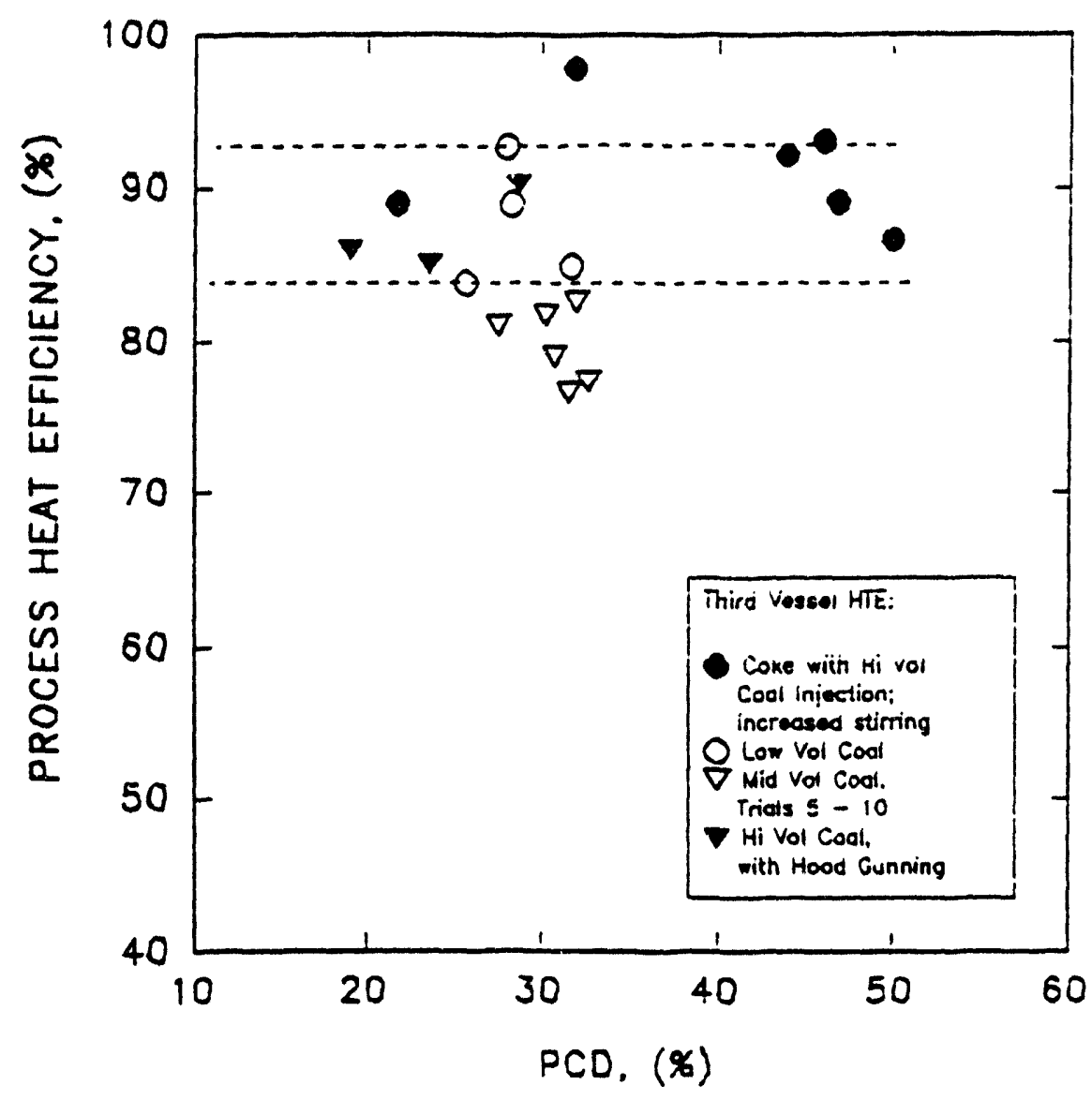

Total heat etficiency versus PCD. 
smelting, the energy is utilized in the slag and, therefore, transfer is easier and more effective.

An important consideration for extrapolation of heat transfer is whether it is related to the cross-sectional area of the vessel or some volumetric measurement. Most of the heat transfer mechanisms are related to the smelting rate (ie., offgas rate) or volume. The total heat utilized per unit area is given as a function of PCD in Figure 13.29 and for postcombustion heat in Figure 13.30 for the first and third AISI vessels and for NSC. It must be emphasized that this represents the heat utilized in the process and is about $90 \%$ of that generated. It is, therefore, the minimum heat which could be transferred, since this is what was achieved. It may have been possible to generate and utilize more heat by adding more coal and oxygen, but in all three cases, this was not possible due to other process limitations, such as oxygen capacity, offgas capacity, or foaming.

It is apparent from Figure 13.29 that the minimum heat utilization is not related to the cross-sectional area. In Figures 13.30 and 13.31, the heat generated per unit weight of slag for the three vessels is in good agreement. Also, shown in Figure 13.28 is the heat utilization requirement of the proposed demonstration plant at $10 \mathrm{t} / \mathrm{m}^{3} \mathrm{~d}$.

The exact heat transfer mechanisms are not known, and the method of extrapolation is not based on fundamental considerations. However, there is strong evidence to indicate that heat transfer increases with volume and can be achieved in the proposed demonstration plant.

\section{Smelting Intensity}

There are three major possible limiting processes with regard to smelting rate or intensity:

$$
\begin{aligned}
& \text { - } \quad \text { Reduction of Feo } \\
& \text { - } \quad \text { Slag Foaming } \\
& \text { - Heat Transfer }
\end{aligned}
$$

Projected intensity -- The restrictions for reduction and foaming can be combined, since they both depend on slag volume. Fruehan previously estimated the smelting rate based on this principle. A more detailed and conservative analysis is given below.

The available volume $\left(V_{A}\right)$ of the process for foaming is given by: $v_{A}=v_{T}-v_{M}-v_{S}-v_{C}$ 
FIGURE 13.29

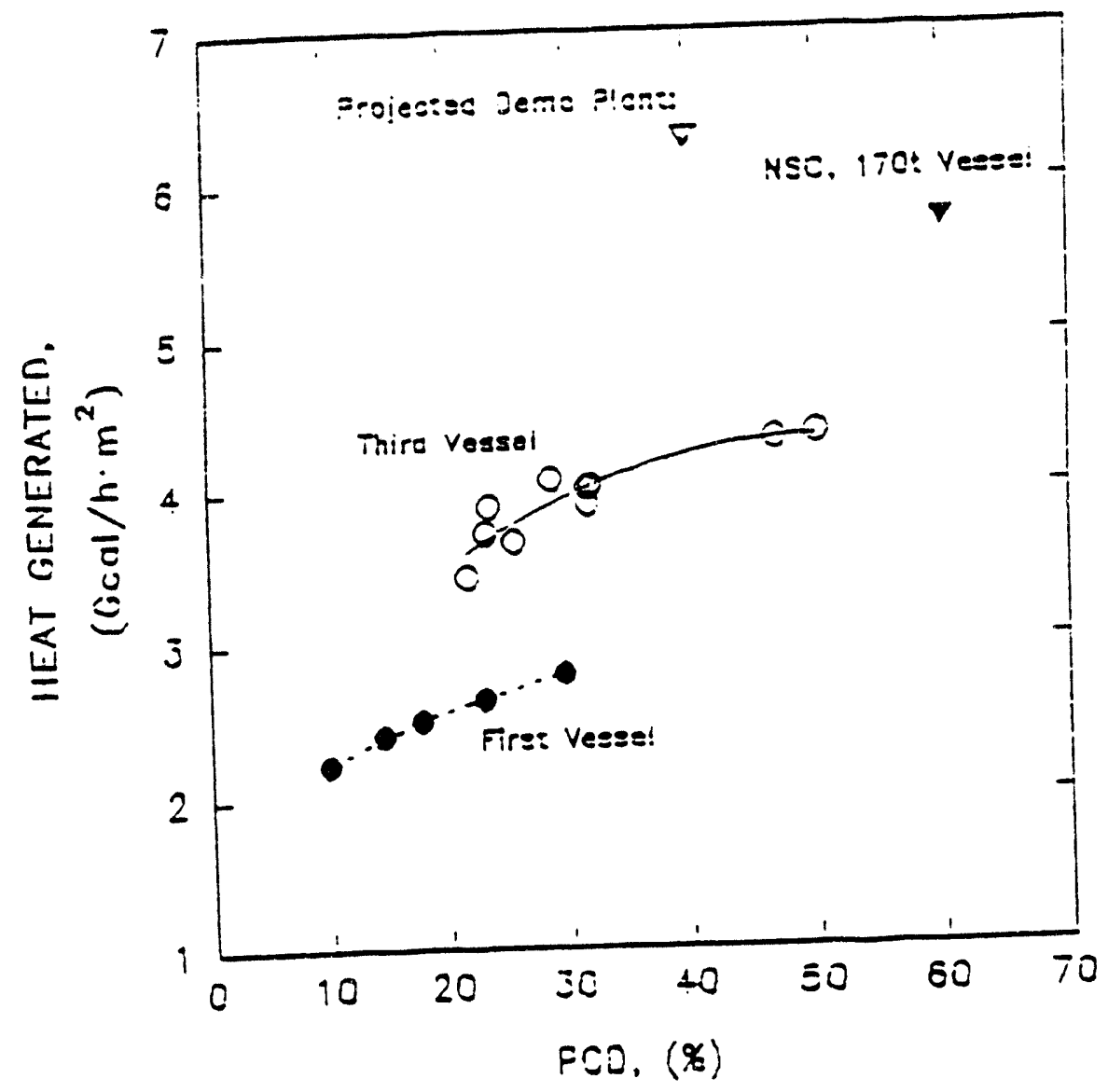

Tota heat utilized per unit area versus FCD. 


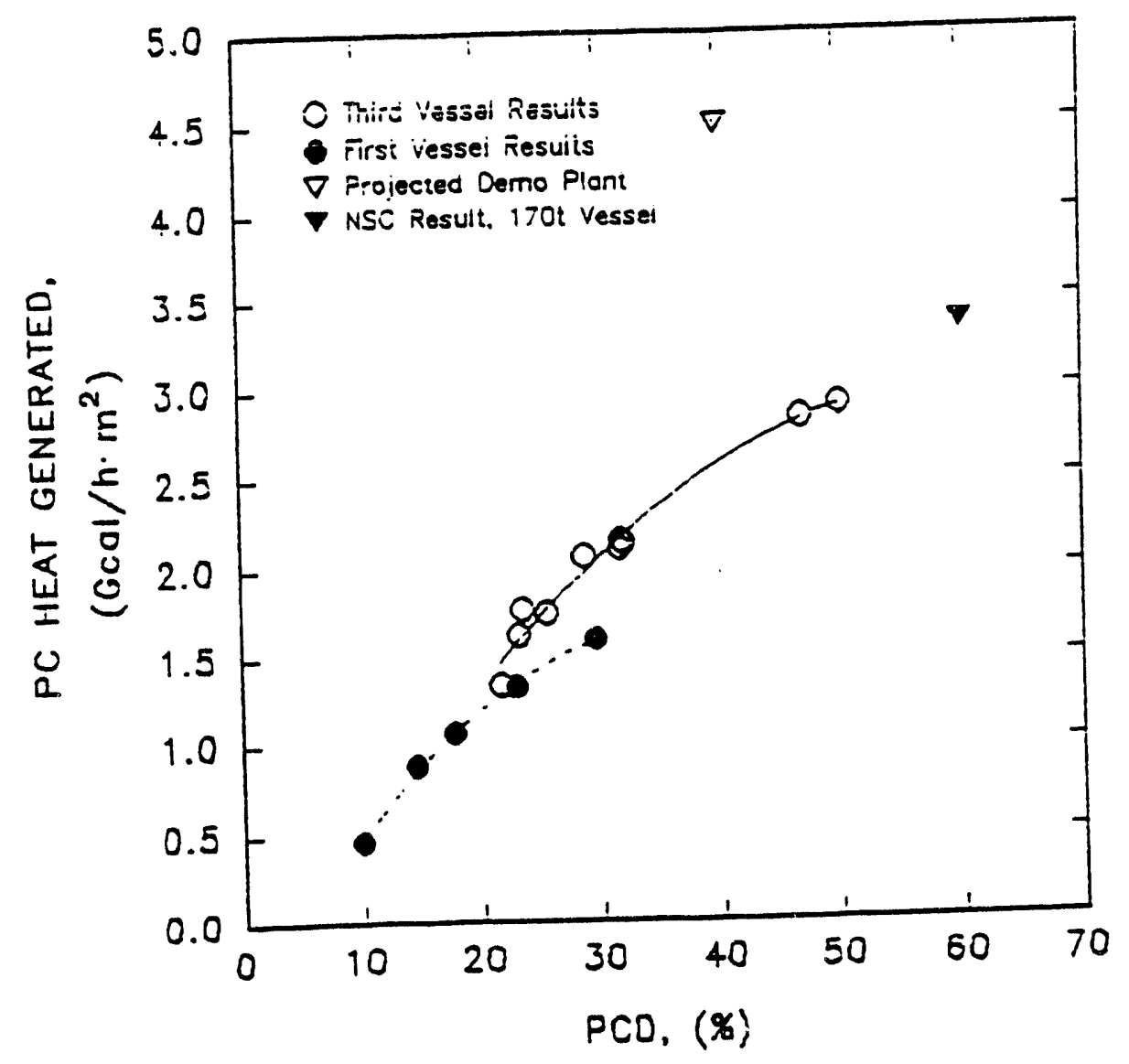

Post combustion heat utilized per unit area versus PCD: 


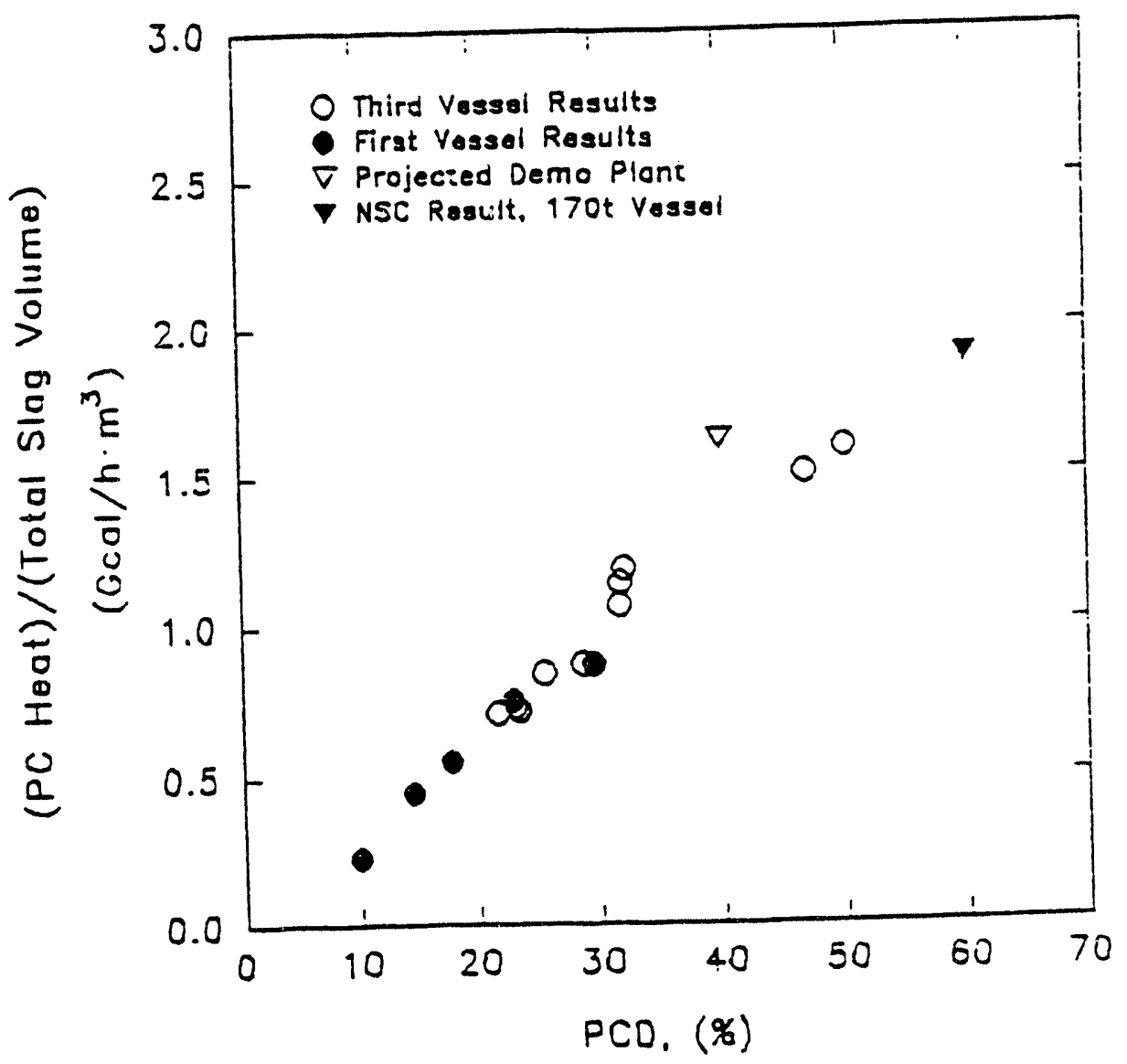

Total heat utilized per volume of slag versus PCD. 
where the subscripts indicate the total, metal, static slag, and char volumes, respectively. The char volume is calculated on the requirement that $20 \%$ of the slag weight should be char. The minimum was found to be $10 \%$; therefore, a value of $20 \%$ is conservative. $V_{M}$ is calculated from the assumed metal weight (100 tonne) and its density. The volume of static slag is computed from the required reduction rate as a function of slag weight using the data in Figures 13.2 and 13.3 . The production rate is computed from the reduction rate minus the iron being recycled from the dust. The amount of slag required for reduction decreases with Feo or $\mathrm{Fe}_{\mathrm{T}}$ content. Two cases were considered: 2.5 and $5.0 \% \mathrm{Fe}_{\mathrm{T}}$. The calculation of the volume of slag required for reduction assumes that the presine data can be scaled up to larger slag weights. More specifically, the slag will behave similarly with regard to reduction. This assumption is supported by the agreement with Vessels \#1 and \#3 and the agreement with the DIOS results.

The volume of foam is computed from the observed foam index and the offgas volume. Note that the foam index was determined from pilot plant results from the total gas generation and foam height measurement. The foam volume can be more accurately described as the expansion of the slag due to the gas generation. The gas generation rate is computed from the energy and material balance and the production rate. Two values of PCD were used: the aim of $40 \%$ and a more conservative figure of $35 \%$. In all cases, a high volatile coal was assumed. The gas volume and, consequently, foam volumes decrease with pressure.

The results are shown in Figures 13.32 and 13.33 for a generic $100 \mathrm{~m}^{3}$ vessel, of which only $65 \mathrm{~m}^{3}$ is used for smelting. The maximum production rate is when the available volume equals the foam volume. The remaining $35 \mathrm{~m}^{3}$ is used for the cone and splashing, etc. Using $35 \mathrm{~m}^{3}$ for this purpose is conservative in predicting smelting intensity.

The resulits in Figures 13.32 and 13.33 are for $40 \%$ PCD and a foam index of $0.2 \mathrm{~s}$ and $0.4 \mathrm{~s}$, respectively. For a pressure of $3 \mathrm{~atm}$, the production rate is $44 \mathrm{t} / \mathrm{h}$, or $12.7 \mathrm{t} / \mathrm{m}^{3} \mathrm{~d}$ for $5 \% \mathrm{Fe}$ in the slag.

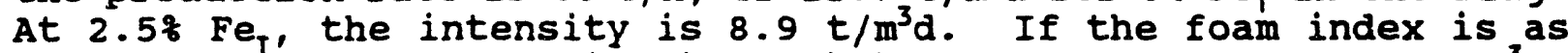
high as $0.4 \mathrm{~s}$, the smelting intensities drop to 6.6 and $5.3 \mathrm{t} / \mathrm{m}^{3} \mathrm{~d}$, respectively. The results with $35 \%$ PCD were nearly indentical. If a medium volatile coal is used, the intensities increase by about 20\%. Therefore, at 3 atm pressure, allowing $\mathrm{Fe}_{\mathrm{h}}$ in the slag to be 3 - 48 gives smelting intensities of $7-11 \mathrm{t} / \mathrm{m}^{3} \mathrm{~d}$.

The other possible limiting process for smelting intensity is heat transfer. As discussed previously, heat transfer is more closely related to the slag volume than the simple cross section area. In Figures 13.30 and 13.31 , the required heat utilization for a production rate of $10 / \mathrm{m}^{3} \mathrm{~d}$ for the proposed demonstration plant is shown. Based on AISI and NSC results, heat utilization will be adequate to produce $10 \mathrm{t} / \mathrm{m}^{3} \mathrm{~d}$. It should be remembered that the heat 
Foom Index: 0.2 seconds.

HV Cocl, 40\% PCD

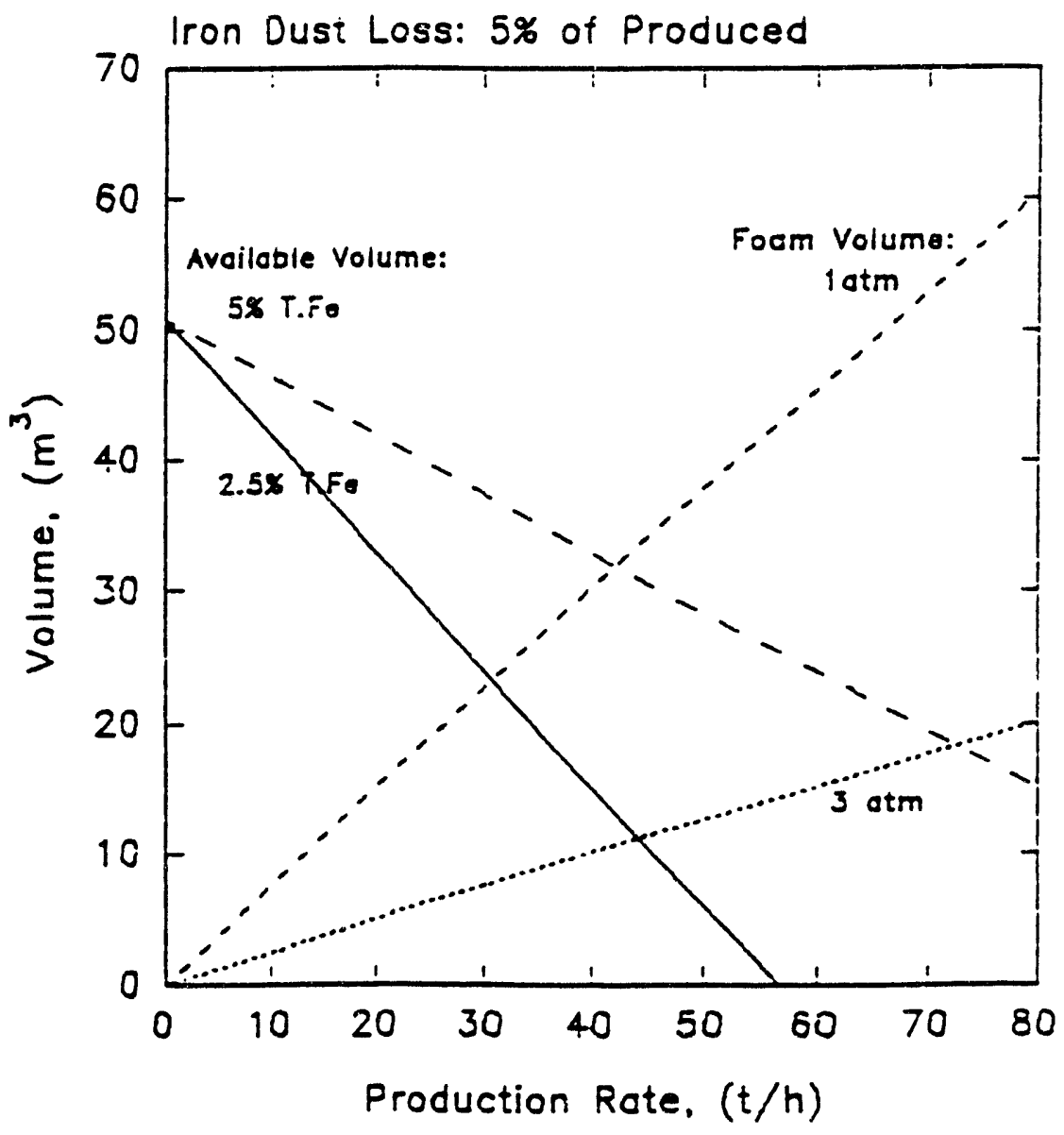

Plot of available and foam volume as a function of production rate $\left(40 \%\right.$ PCD, $\left.\Sigma=0.2 \mathrm{~s}^{-1}\right)$. 
FIGURE 13.33

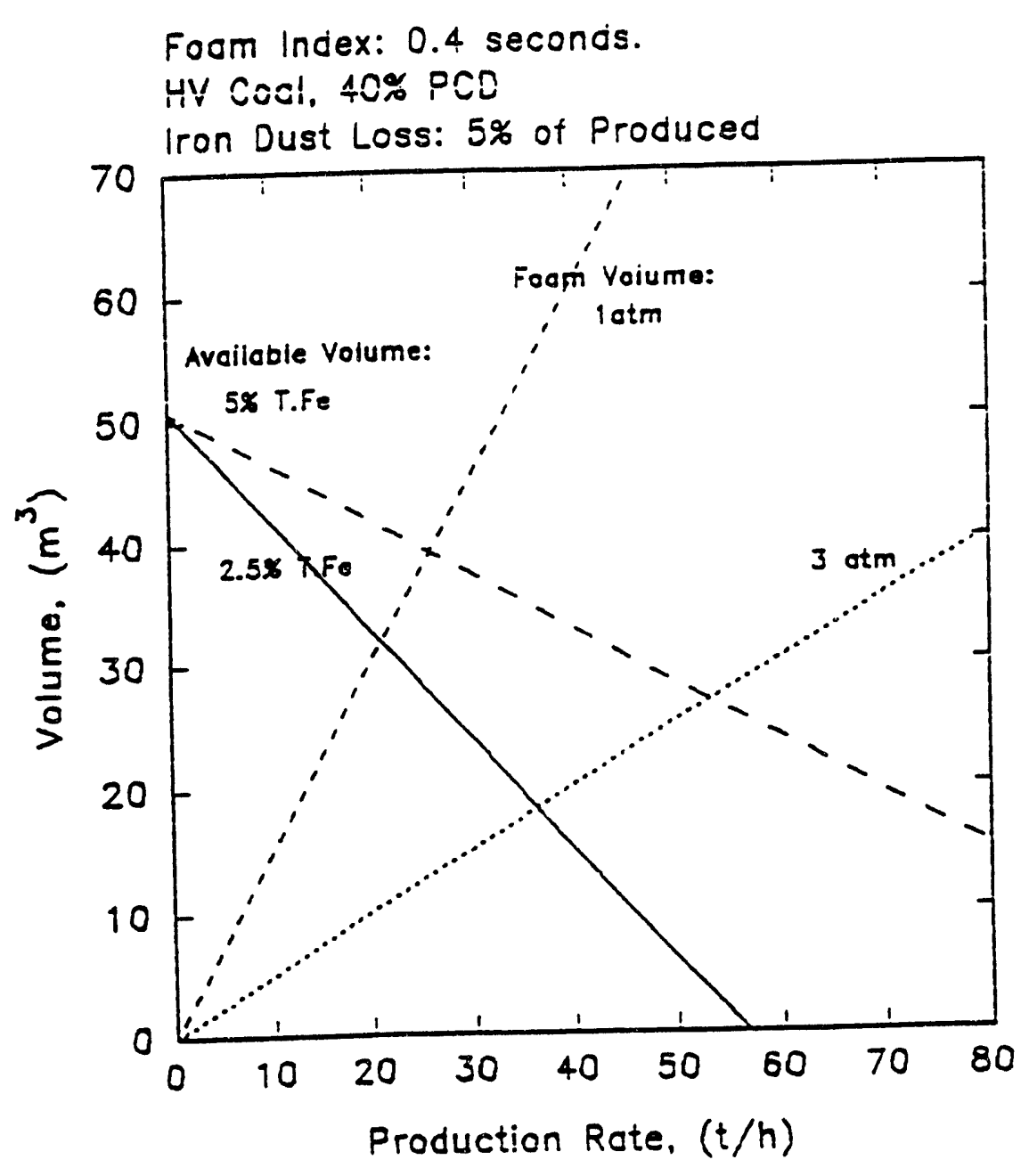

Plot of available and foam volume as a function of production rate (40\% PCD, $\Sigma=0.4 \mathrm{~s}^{-1}$ ). 
utilization shown in Figures 13.30 and 13.31 is the heat actually transferred and represents about $90 \%$ of that produced. Possibly even more heat could be utilized if more were generated.

Pilot plant results -- In some of the trials, with vessel 3, the foam height and, therefore, process volume, was measured accurately. In trial 15, the productivity was $6.1 \mathrm{t} / \mathrm{h}$ with hematite ore after subtracting dust losses, and the process volume was $15.1 \mathrm{~m}^{3}$; this corresponds to $9.7 \mathrm{t} / \mathrm{m}^{3} \mathrm{~d}$. In another trial the measured intensity was $8.5 \mathrm{t} / \mathrm{m}^{3} \mathrm{~d}$. These trials were run at 1.5 atm and with hematite and represent just the process volume with no free space for the lance, etc. At 3 atm and with wustite, the intensity would be in excess of $14 \mathrm{t} / \mathrm{m}^{3} \mathrm{~d}$, and with a $35 \%$ excess volume, it would still be in excess of $9 t / \mathrm{m}^{3} \mathrm{~d}$.

Conclusion -- Based on the available information, the smelting intensity in the proposed demonstration plant will be a minimum of $8 t / \mathrm{m}^{3} \mathrm{~d}$, with $10 \mathrm{t} / \mathrm{m}^{3} \mathrm{~d}$ most likely possible. This analysis indicates that, at 3 atmosphere pressure, there is sufficient volume for reduction and foaming. Based on extrapolation of AISI results and those of NSC, the system is capable of effectively utilizing the heat generated. 


\section{ECONOMIC NMTY8I8}

Critical to justification of the AISI demonstration plant is a comparison of the projected costs of the process with the cost of the coke oven-blast furnace system.

\section{Capital Costs}

A comparison of capital costs for the coke oven-blast furnace and AISI processes are shown in Table 14.1. They are costs per annual tonne of hot metal based on plants with hot metal capacity of one million metric tons per year.

TABLE 14.1

CAPITAL COST COMPARISON

( $\$$ per annual metric ton)

COKE OVEN/BLAST FURNACE

243
AISI

160

The cost for the coke oven-blast furnace is for rebuilding both units (blast furnace $\$ 165$, coke oven $\$ 155$ ). The costs can vary from site to site, depending on the condition and age of the facilities being rebuilt. For greenfield construction, the costs would double. The significant cost advantage of the AISI process derives in part from its much greater process intensity, as shown in Table 14.2. The measure is shown as metric tons of hot metal produced per cubic meter. These data reflect the much smaller size of the AISI smelter compared to the other units of similar production capacity, which substantially reduces construction costs. (The production intensity for the AISI process is less than the $10 t / \mathrm{m}^{3} \mathrm{~d}$ reported in section 10 because the volume of the shaft furnace is included.)

TABLE 14.2

PRODUCTION INTENSITY

(Metric tons per day per cubic meter)

COKE OVEN/BLAST FURNACE AISI
1.0
4.6

Operating costs

Table 14.3 provides variable operating cost estimates for the coke oven/blast furnace and the AISI processes operating at 1 million metric tons per year. 
TABLE 14.3

(Per metric ton at 1 million tpy)
$\begin{array}{cc}\text { COKE OVEN/BLAST FURNACE } & \text { AISI } \\ \$ 131 & \$ 120\end{array}$

Certain cost factors could decrease the AISI cost by up to $\$ 5$ per metric ton through scale-up or maturation:

- The estimated costs include stirring the bath with nitrogen. It is expected that nitrogen will eventually be replaced with air, at a savings of $\$ 1.40$ per ton.

- In the current flowsheet, some of the sensible heat energy in the smelter offgas is dissipated in the gas cooling loop. In a 1 million metric ton per year plant, about one million BTU per ton should be recoverable for an energy credit and a cost saving of $\$ 3.85$ per ton.

other items, including better hot metal desulfurization and the substitution of fluxes, could result in additional savings.

\section{Coal Utilization}

Coal properties including heating value, fixed carbon, and ash and moisture contents have an impact on smelter operation. For example, coals with high heating values and high fixed carbon contents (low volatile matter) result in lower fuel rates. Conversely, coals with high ash and moisture contents result in higher fuel rates. In general, higher postcombustion levels are also achieved with coals lower in volatile matter. However, because the process operates with high postcombustion, the detrimental effects of moisture and ash tend to be offset. Therefore, high postcombustion, which is a characteristic of the smelting process, permits the use of a larger range of coals than is possible with other coal-based processes that operate with very little postcombustion. 


\section{COMAERCIALIZATION}

A wholly-owned subsidiary of AISI, steel Technology Corporation, pursuant to an agreement between it and DOE, will be responsible for commercialization. It is clearly understood by AISI that DOE has a strong interest in the aeployment of the technology that has been developed through the pil.ot plant phase. The next step is to demonstrate that a 350,000 tpy plant is viable on a commercial scale.

All aspects of any demonstration plant program will be planned and executed so as to enhance the widespread deployment of the direct ironmaking technology on a commercial basis at the earliest possible date.

Before investing in a 350,000 tpy demonstration plant, it will be necessary to close the gap between what can be claimed on the basis of pilot plant results and the process goals in terms of productivity and fuel rate. This gap is perceived to be in the forty percent range with the use of high volatile coals.

Based on the knowledge gained during the project and ongoing discussions with other bath smelting researchers around the world, AISI researchers are optimistic that this gap can be closed by an appropriate combination of the following devices:

- Improved distribution of oxygen through the application of side-blown tuyeres. Initial work has shown encouraging results.

- Better distribution of raw materials charged into the vessel. A major design change would be required to demonstrate and quantify the expected improvement, but there are strong reasons to believe that "dead zone charging" is a major cause of lost efficiency in the present configuration.

- Use of newly developed sensors to measure foam height and to observe char distribution and behavior within the pressurized reaction vessel. A promising device, which has already been tested under BOF (basic oxygen furnace) operating conditions, will be evaluated shortly.

- Cooperative exchanges with other smelting programs are under consideration. Visits to pilot plants and technical exchange meetings are expected to take place throughout the summer and fall. (Recent information indicates that the expected production rates and fuel rates can be achieved with better ore and coal feeds and with an operating pressure of three atmospheres absolute.) 
Interest in pursuing a demonstration project continues. An extensive series of additional trials could be undertaken if equipment modifications are made in the pilot plant. 


\section{REFERENCES}

1. B. Ozturk and R. J. Fruehan, Transactions ISIJ (1992), pg. 538 - 544 .

2. MIT Report in AISI Direct steelmaking Program Annual Technical Report for 1990, pg. 19, and for 1991, pg. 11.

3. D. -J. Min and R. J. Fruehan, Metalluraical Transactions B, Vol. 23B (1992), pg. $29-37$.

4. F. J. Manion and R. J. Fruehan, Metallurgical Transactions B, Vol. 20B (1989), pg. 853 .

5. B. Sarma, A. W. Cramb, and R. J. Fruehan, to be published in Metallurgical Transactions B.

6. R. J. Fruehan, "Reaction Rates and Rate Limiting Factors in Iron Bath Smelting," Proceedings of the savard/Lee International symposium on Bath smelting, The Minerals, Metals, and Materials Society (1992), pg. 233.

7. . Ibaraki et al, "Development of Smelting Reduction of Iron ore - An Approach to Commercial Ironmaking," 49th Ironmaking Conference Proceedings, March, 1990.

8. B. Sarma, A. W. Cramb, and R. J. Fruehan, to be published in Metallurgical Transactions B.

9. K. Ito and R. J. Fruehan, Metallurgical Transactions B, Vol. 20B (1989), pg. $509-521$.

10. Y. Zhang and R. J. Fruehan, to be published in Metallurgical Transactions $B$.

11. B. Ozturk and R. J. Fruehan, CISR Report, May, 1993.

12. R. Sampaio and R. J. Fruehan, "Rate of Coal Devolatilization in Iron and Steelmaking Processes, Part II," ISS Transactions, Vol. 14 (1993), pg. 69.

13. B. I. Farrand, J. E. Wood, and F. J. Goetz, "Postcombustion Trials at DOFASCO's KOBM Furnace," steelmaking Proceedings 75 (1992), pg. $173-180$.

14. Z. Du and H. Kobayashi, "Characterization of oxygen Jets for Postcombustion," steelmaking Proceedings 75 (1992), pg. 853 859. 
15. H. Gou, G. A. Irons, and W-K. Lu, "Mathematical Modeling of Postcombustion in DOFASCO's KOBM," steelmaking Proceedings 75 (1992), pg. $181-186$.

16. P. Mathur and G. Daughtridge, "oxygen Injection for Effective Postcombustion in the EAF," Iron and steel Engineer, May, 1994, pg. $53-57$.

17. I. B. MCFeaters and R. J. Fruehan, Metallurgical Transactions B. Vol. 24B (1993), pg. 441.

18. R. Sampaio and R. J. Fruehan, "Rate of Coal Devolatilization in Iron and Steelmaking Processes, Part I," ISS Transactions, Vol. 14 (1993), pg. 59 . 
17. II8T OF PUBLIBHED REPORTS, TALKB, AND TECENICAL PAPERE

\section{Reports}

1. E. Aukrust, AISI Direct Steelmaking Proaram Annual Technical Report for Year Ending November 30 , 1990, DOE/ID/12847-1 (DE91007163), January 9, 1991.

2. E. Aukrust, AISI Direct Steelmaking Proaram Annual Technical Report for Year Ending November 30 , 1991, DOE/ID/12847-3 (DE92008640), January, 1992.

3. E. Aukrust, AISI Direct steelmaking Program Annual Technical Report for Year Ending November 30, 1992, DOE/ID/12847-4 (DE93008687), 1993 .

4. R. J. Fruehan, Evaluation of Steelmaking Processes Topical Report, DOE/ID/12847-5 (DE94005368), January, 1994.

5. AISI-DOE Direct Steelmaking Program Annual Report for the Year Ending November 30, 1993, DOE/ID/12847-6 (DE94006738), February, 1994 .

Talks

1. G. G. Krishna Murthy and J. F. Elliott, "Observations of the Reaction of Oxide Pellets with Liquid Fe-C Melts, 1200 $1650^{\circ} \mathrm{C}$," TMS Annual Meeting, New Orleans, Louisiana, February 16 - 21, 1991.

2. J. M. Farley, "AISI/DOE Direct steelmaking Program Update," AISE Iron and steel Exposition, Pittsburgh, Pennsylvania, September 23 - 16, 1991.

3. E. Aukrust, "AISI Direct Steelmaking Project," Capital Metals and Materials Forum, Washington, DC, March 26, 1992.

\section{Technical Papers}

1. R. J. Fruehan, "Iron Bath Smelting - current status and Understanding," Proceedings of the Elliott symposium on Chemical Process Metallurgy, June 10-13,1990, issued 1991.

2. E. Aukrust and K. B. Downing, "The AISI Direct steelmaking Program," 1991 Ironmaking Conference Proceedings, pg. 659 663 .

3. B. Ozturk and R. J. Fruehan, "Dissolution of $\mathrm{Fe}_{2} \mathrm{O}_{3}$ and FeO Pellets in Bath Smelting slags," ISIJ International, volume 32, No. 4, 1992, pg. 538 - 544 . 
4. A. Hasham, U. B. Pal, and G. G. Krishna Murthy, "Investigation of Reduction Rates of Iron Oxides Dissolved in CaO- $\mathrm{SiO}_{2} \mathrm{Al}_{2} \mathrm{O}_{3}$ Slags by Fe-C Melts and Determination of Rate Mechanisms," EPD Conaress, TMS, March, 1992, pg. 847 - 860 .

5. G. G. Krishna Murthy and J. F. Elliott, "Reduction of $\mathrm{Fe}_{x} \mathrm{O}_{y}$ Pellets with Iiquid Fe-C Melts and Determination of Rate Mechanisms," EPD Congress, TMS, March, 1992, pg. 867 - 884 .

6. M. B. Mourao, G. G. Krishna Murthy, and J. F. Elliott, "Interaction of Carbonaceous Materials with Liquid Iron-Carbon Alloys," EPD Congress, TMS, March, 1992, pg. 807 - 820 .

7. Y. Sawada, G. G. Krishna Murthy, and J. F. Elliott, "Reduction of FeO Dissolved in $\mathrm{CaO}-\mathrm{SiO}_{2}-\mathrm{Al}_{2} \mathrm{O}_{3}$ Slags by Iron-Carbon Droplets," EPD Congress, TMS, March, 1992, pg. 915 - 930.

8. J. M. Farley and P. J. Koros, "AISI-DOE Direct steelmaking Program," Steel Times International, March, 1992, pg. $22-25$.

9. Z. Du and H. Kobayashi, "Characterization of Oxygen Jets for Postcombustion," steelmaking Proceedings 75, April, 1992, pg. $853-859$.

10. B. L. Farrand, J. E. Wood, and F. J. Goetz, "Postcombustion Trials at Dofasco's KOBM Furnace," Steelmaking Proceedings 75 , April, 1992, pg. $173-180$.

11. H. Gou, G. A. Irons, and $W-K$. Lu, "Mathematical Modeling of Postcombustion in Dofasco's KOBM," Steelmaking Proceedings 75 , April, 1992, pg. $181-186$.

12. R. Jiang and R. J. Fruehan, "Slag Foaming in Bath Smelting," Metallurgical Transactions B, Volume 22B, August, 1992, pg. $481-489$.

13. R. S. Sampaio, R. J. Fruehan, and B. Ozturk, "Rate of coal Devolatilization in Iron and Steelmaking Processes - Part I Experimental Results," Iransactions of ISS, August, 1992, pg. $49-57$.

14. R. S. Sampaio, R. J. Fruehan, and B. Ozturk, "Rate of Coal Devolatilization in Iron and steelmaking Processes - Part II Effect of Coal Devolatilization on Energy Efficiency in Bath Smelting," Iransactions of ISS, August, 1992, pg. $59-66$.

15. E. Aukrust, "Results of the AISI/DOE Direct steelmaking Program," Proceedings of the savard/Lee International symposium on Bath Smelting, TMS, October, 1992, pg. $591-610$. 
16. R. J. Fruehan, "Reaction Rate and Rate Limiting Factors in Iron Bath Smelting," Proceedings of the Savard/Lee International Symposium on Bath Smelting, TMS, October, 1992, pg. $233-248$.

17. J. M. Farley and P. J. Koros, "The AISI-DOE Direct steelmaking Process - Raw Materials Requirements," KINExpo International 192 Session Papers, October, 1992, pg. $203-224$.

18. G. G. Krishna Murthy, A. Hasham, and U. B. Pal, "Means for Rapid and Complete Reduction of Feo in Slags by Fe-C Droplets (Melts)," Bath Smelting Proceedings of Ironmaking Conference, ISI, 1993.

19. G. G. Krishna Murthy, Y. Sawada, and J. F. Elliott, "Reduction of $\mathrm{FeO}$ in CaO-SiO $\mathrm{S}_{2} \mathrm{Al}_{2} \mathrm{O}_{3}$ slags by Fe-C Droplets," Ironmaking and Steelmaking, volume 20, 1993, pg. $179-190$.

20. G. G. Krishna Murthy, U. B. Pal, and A. Hasham, "Reduction Rates of $\mathrm{FeO}$ in $\mathrm{CaO}-\mathrm{SiO}_{2}-\mathrm{Al}_{2} \mathrm{O}_{3}$ Slags by $\mathrm{Fe}-\mathrm{C}$ Melts, "Ironmaking and Steelmaking, Volume 20,1993, pg. $191-200$.

21. H. Gou, G. A. Irons, and $w-K$. Lu, "Mathematical Modeling of Postcombustion in a KOBM Converter," Metallurgical Transactions B, Volume 24B, 1993, pg. $179-188$.

22. M. B. Mourao, G. G. Krishna Murthy, and J. F. Elliott, "Dissolution Rates of Coals and Coal Chars in Fe-C Alloys," Metallurgical Transactions B, Volume 24B, 1993, pg. $629-637$.

23. G. G. Krishna Murthy, "Investigation of Heat Transfer Characteristics of Molten Slags," EPD Congress, TMS, February, 1993, pg. $547-550$.

24. G. G. Krishna Murthy and J. F. Elliott, "Experimental Investigation of Interaction of Rates of Iron oxide Particles with Molten Iron-Carbon-slag systems," EPD Congress, TMS, February, 1993, pg. 583 - 590 .

25. E. Aukrust, "Planning for the 400,000 Tons/Year AISI Ironmaking Demonstration Plant," 1993 Ironmaking Conference proceedings, Volume 76, March, 1993, pg. $341-346$.

26. L. B. McFeaters and R. J. Fruehan, "Desulfurization of Bath Smelter Metal," 1993 steelmaking Conference Proceedings, Volume 76, March, 1993, pg. 671 - 677.

27. T. Nagasaka and R. J. Fruehan, "Kinetics of the Reaction of $\mathrm{H}_{2} \mathrm{O}$ Gas with Liquid Iron," 1993 Steelmaking Conference proceedings, Volume 76, March, 1993, pg. 713 - 721. 
28. E. Aukrust, "Planning for the 400,000 tpy AISI Ironmaking Demonstration Plant," Iron and Steelimaker, June, 1993, pg. 14 $-16$.

29. G. G. Krishna Murthy, A. Hasham, and U. B. Pal, "Study of Interactions Between Low Carbon-Iron Baths and Iron Oxide Containing CaO-SiO $\mathrm{C}_{2}-\mathrm{Al}_{2} \mathrm{O}_{3}$ Slags at $1723 \mathrm{~K}, "$ ISIJ International, Volume 34, 1994, pg. 408 - 413 .

30. G. G. Krishna Murthy and J. F. Elliott, "Fundamental Processes During Bath Smelting - Reactions of Iron Oxide Pellets with Iron-Carbon Melts," Ironmaking and Steelmaking, Volume 21, 1994 (in press). 

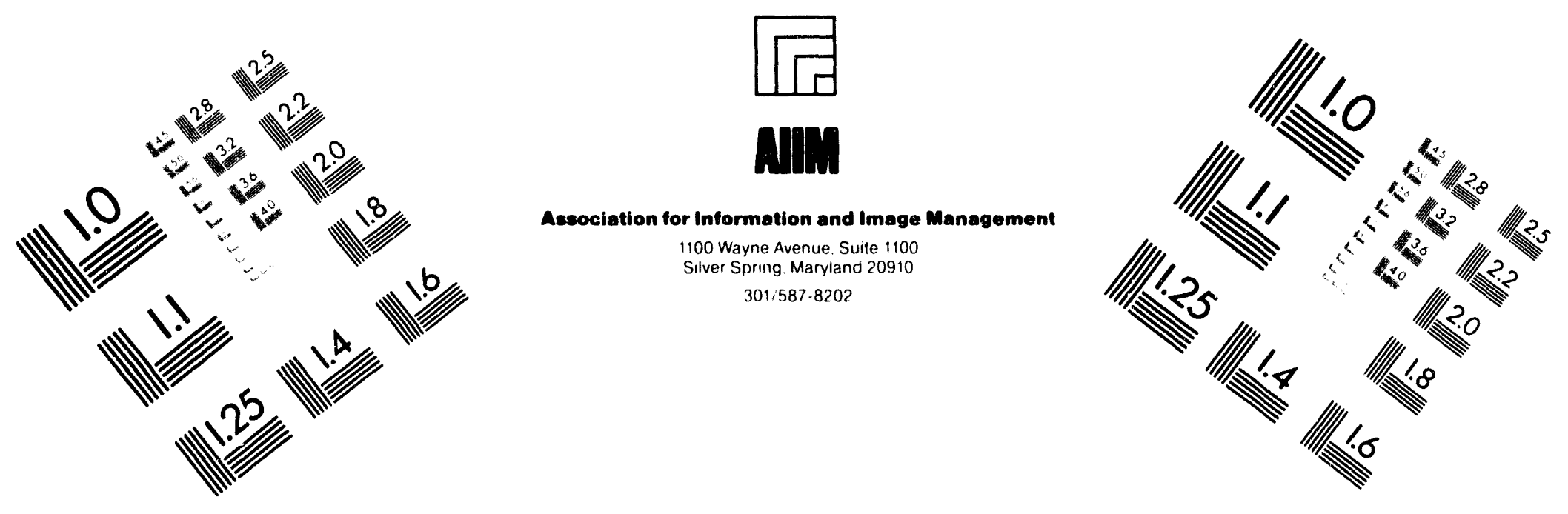

Centimeter

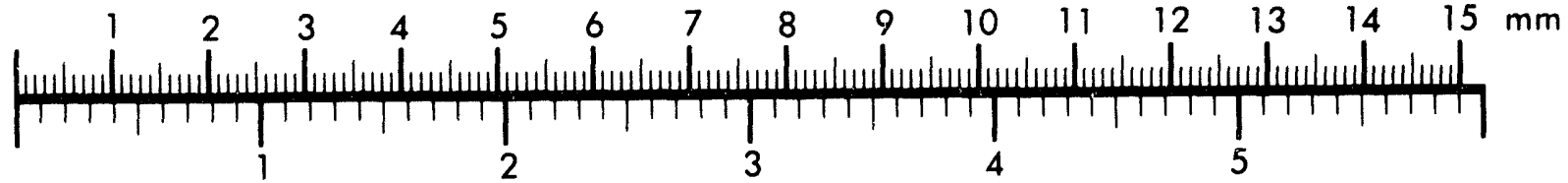
Inches
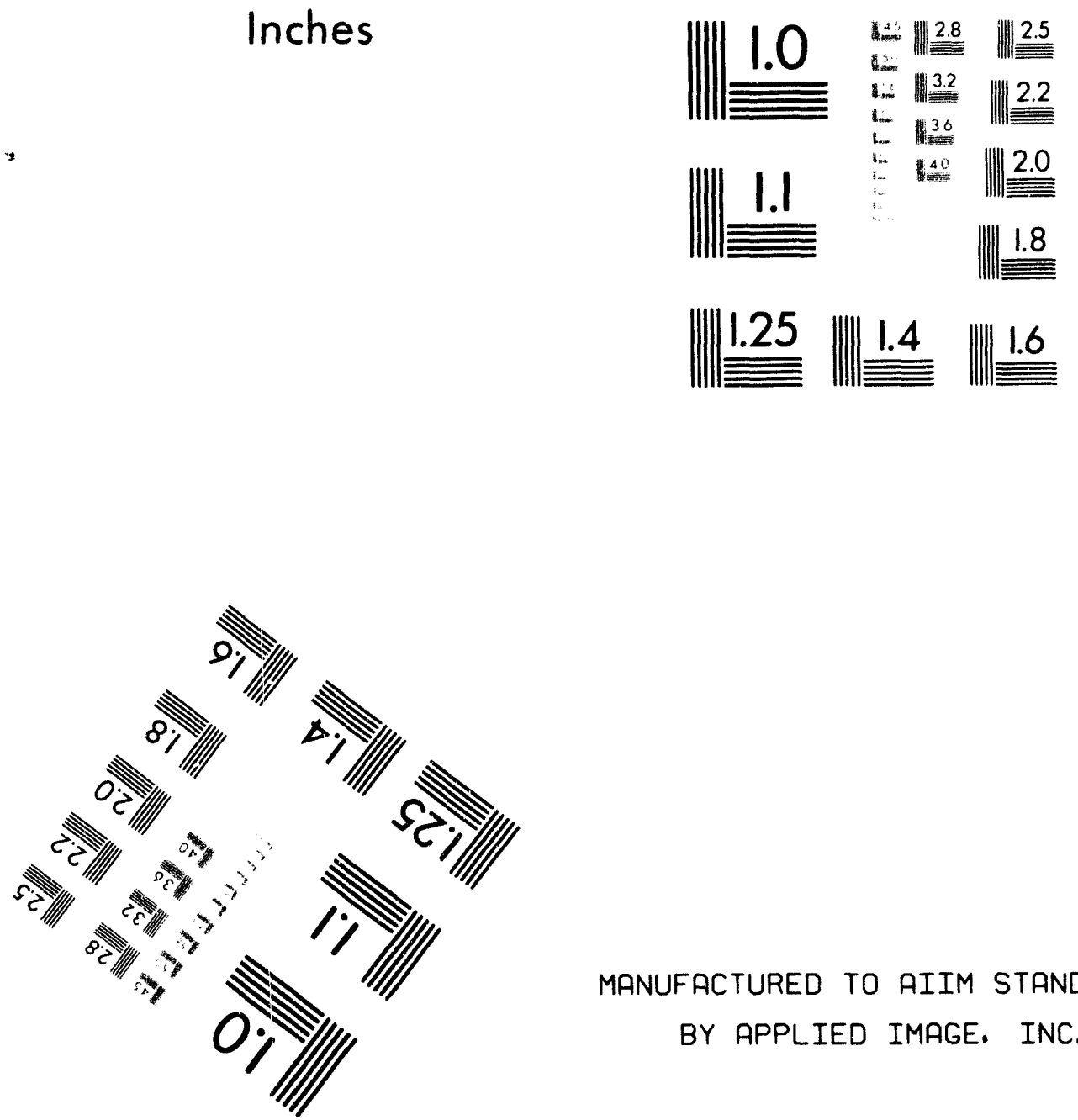

MANUFACTURED TO AIIM STANDARDS

BY APPLIED IMAGE. INC.

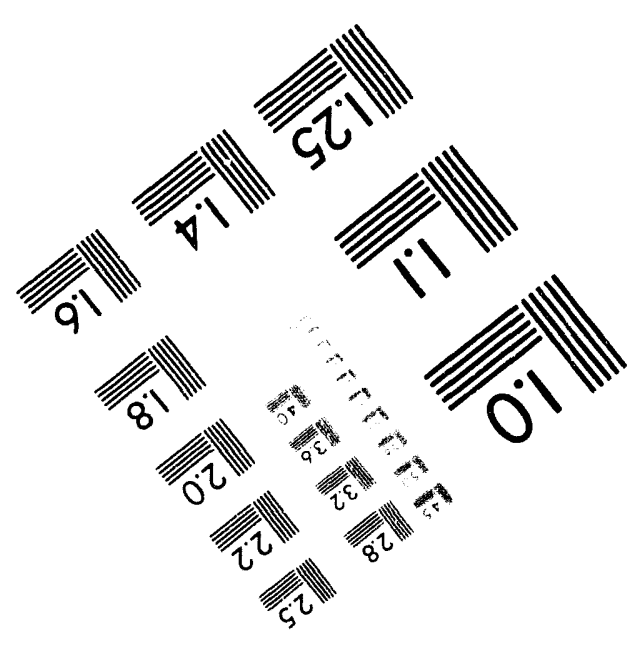



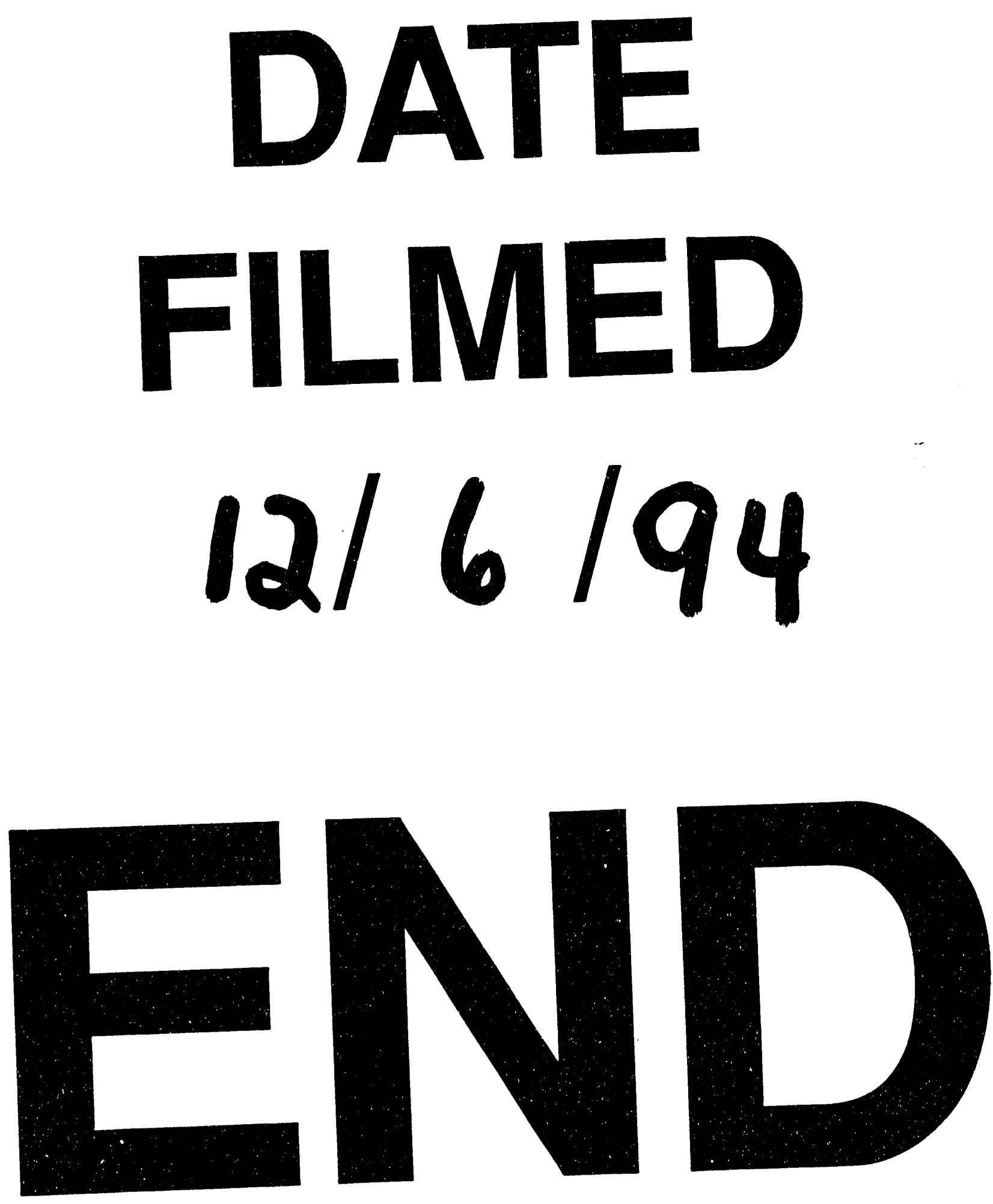